Florida International University FIU Digital Commons

$11-13-2013$

\title{
The Investigation of Photocatalysts and Iron Based Materials in the Oxidation and the Adsorption of Toxic Organic and Chromium Materials
}

Wenjun Jiang

Florida International University, wjian001@fiu.edu

DOI: $10.25148 /$ etd.FI13120608

Follow this and additional works at: https:// digitalcommons.fiu.edu/etd

Part of the Chemistry Commons

\section{Recommended Citation}

Jiang, Wenjun, "The Investigation of Photocatalysts and Iron Based Materials in the Oxidation and the Adsorption of Toxic Organic and Chromium Materials" (2013). FIU Electronic Theses and Dissertations. 1023.

https://digitalcommons.fiu.edu/etd/1023 


\title{
FLORIDA INTERNATIONAL UNIVERSITY
}

Miami, Florida

\section{THE INVESTIGATION OF PHOTOCATALYSTS AND IRON BASED MATERIALS IN THE OXIDATION AND ADSORPTION OF TOXIC ORGANIC AND CHROMIUM MATERIALS}

\author{
A dissertation submitted in partial fulfillment of \\ the requirements for the degree of \\ DOCTOR OF PHILOSOPHY \\ in \\ CHEMISTRY \\ by
}

Wenjun Jiang 
To: Dean Kenneth G. Furton

College of Arts and Sciences

This dissertation, written by Wenjun Jiang, and entitled The Investigation of Photocatalysts and Iron Based Materials in the Oxidation and the Adsorption of Toxic Organic and Chromium Materials, having been approved in respect to style and intellectual content, is referred to you for judgment.

We have read this dissertation and recommend that it be approved.

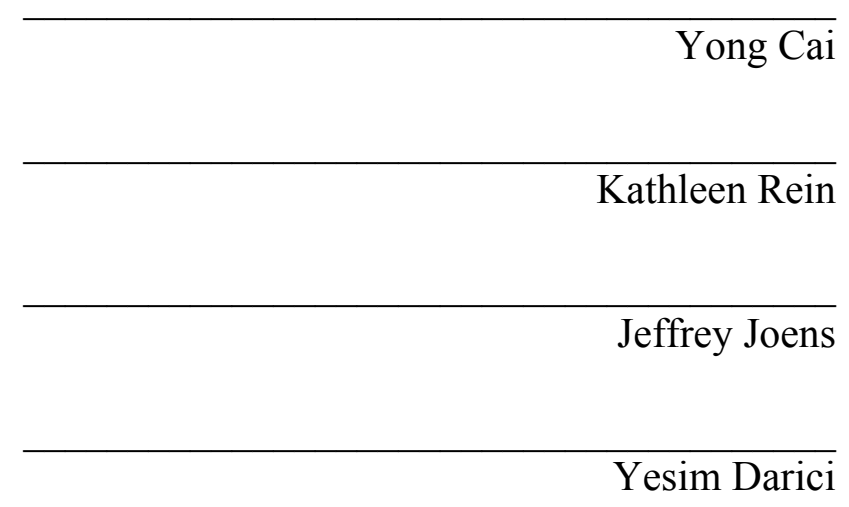

Kevin E. O'Shea, Major Professor

Date of Defense: November 13, 2013

The dissertation of Wenjun Jiang is approved.

Dean Kenneth G. Furton

College of Arts and Sciences

Dean Lakshmi N. Reddi

University Graduate School

Florida International University, 2013 
C Copyright 2013 by Wenjun Jiang

All rights reserved. 


\section{DEDICATION}

I dedicate this dissertation to all my beloved mentors, my parents, Ms. Dianzhi Lv and Mr. Zuoyu Jiang, my wife Min Cai, and my son Alex Jiang. Without their unconditional support and love, this dissertation could not be completed. 


\section{ACKNOWLEDGMENTS}

First, I wish to express my special thanks to my major professor, Dr. Kevin E. O'Shea, for his insightful advice, encouragement and support. In addition, I would like to thank my committee members, Dr. Yong Cai, Dr. Kathleen Rein, Dr. Jeff Joens and Dr. Yesim Darici, for their helpful suggestions and comments on my research and dissertion.

Appreciations are extended to my research collaborators. I would like to thank Dr. Dionysios D. Dionysiou and Dr. Miguel Pelaez at University of Cincinnati for providing doped $\mathrm{TiO}_{2}$ materials and valuable discussions, Dr. Jianming Bai for his assistance with X-ray diffraction and Dr. Syed Khalid for X-ray absorption spectra analysis at National Synchrotron Light Source, Brookhaven National Lab, Dr. Quan Cai and Dr. Wei Bai at Institute of High Energy Physics, Chinese Academy of Sciences for the data analysis of X-ray absorption near edge structure spectroscopy and extended Xray absorption fine structure spectroscopy, Dr. Mohammad H. Entezari for the synthesis of maghemite particles. I also thank all the group members in Dr. O'Shea lab for their cooperation.

Finally, I thank Department of Chemistry \& Biochemistry and Florida International University for financial supports, and the copyright permissions from Chemical Engineering Journal, Journal of Photochemistry and Photobiology A: Chemistry, and American Chemical Society Publications. 


\title{
ABSTRACT OF THE DISSERTATION \\ THE INVESTIGATION OF PHOTOCATALYSTS AND IRON BASED MATERIALS \\ IN THE OXIDATION AND ADSORPTION OF TOXIC ORGANIC AND \\ CHROMIUM MATERIALS
}

\author{
by \\ Wenjun Jiang \\ Florida International University, 2013 \\ Miami, Florida \\ Professor Kevin E. O’Shea, Major Professor
}

The presences of heavy metals, organic contaminants and natural toxins in natural water bodies pose a serious threat to the environment and the health of living organisms. Therefore, there is a critical need to identify sustainable and environmentally friendly water treatment processes. In this dissertation, I focus on the fundamental studies of advanced oxidation processes and magnetic nano-materials as promising new technologies for water treatments.

Advanced oxidation processes employ reactive oxygen species (ROS) which can lead to the mineralization of a number of pollutants and toxins. The rates of formation, steady-state concentrations, and kinetic parameters of hydroxyl radical and singlet oxygen produced by various $\mathrm{TiO}_{2}$ photocatalysts under UV or visible irradiations were measured using selective chemical probes. Hydroxyl radical is the dominant ROS, and its generation is dependent on experimental conditions. The optimal condition for generation of hydroxyl radical by of $\mathrm{TiO}_{2}$ coated glass microspheres is studied by response surface methodology, and the optimal conditions are applied for the degradation 
of dimethyl phthalate. Singlet oxygen $\left({ }^{1} \mathrm{O}_{2}\right)$ also plays an important role for advanced processes, so the degradation of microcystin-LR by rose bengal, an ${ }^{1} \mathrm{O}_{2}$ sensitizer was studied. The measured bimolecular reaction rate constant between MC-LR and ${ }^{1} \mathrm{O}_{2}$ is $10^{6} \mathrm{M}^{-1} \mathrm{~s}^{-1}$ based on competition kinetics with furfuryl alcohol.

The typical adsorbent needs separation after the treatment, while magnetic iron oxides can be easily removed by a magnetic field. Maghemite and humic acid coated magnetite $\left(\mathrm{HA}-\mathrm{Fe}_{3} \mathrm{O}_{4}\right)$ were synthesized, characterized and applied for chromium(VI) removal. The adsorption of chromium(VI) by maghemite and $\mathrm{HA}-\mathrm{Fe}_{3} \mathrm{O}_{4}$ follow a pseudosecond-order kinetic process. The adsorption of chromium(VI) by maghemite is accurately modeled using adsorption isotherms, and solution $\mathrm{pH}$ and presence of humic acid influence adsorption. Humic acid coated magnetite can adsorb and reduce chromium(VI) to non-toxic chromium (III), and the reaction is not highly dependent on solution $\mathrm{pH}$. The functional groups associated with humic acid act as ligands lead to the Cr(III) complex via a coupled reduction-complexation mechanism. Extended X-ray absorption fine structure spectroscopy demonstrates the $\mathrm{Cr}(\mathrm{III})$ in the Cr-loaded HA$\mathrm{Fe}_{3} \mathrm{O}_{4}$ materials has six neighboring oxygen atoms in an octahedral geometry with average bond lengths of $1.98 \AA$. 


\section{TABLE OF CONTENTS}

\section{CHAPTER}

PAGE

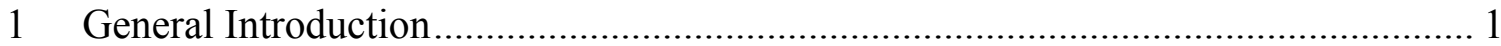

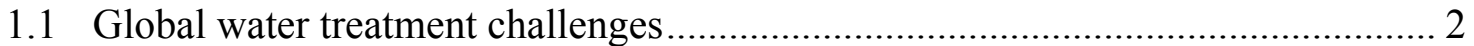

1.1.1 Chromium contamination ............................................................. 2

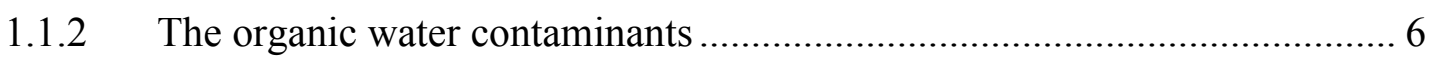

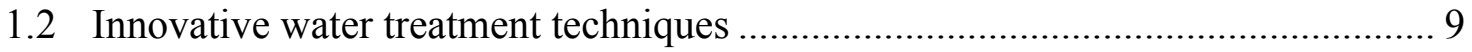

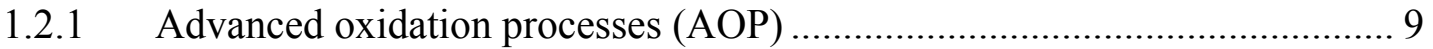

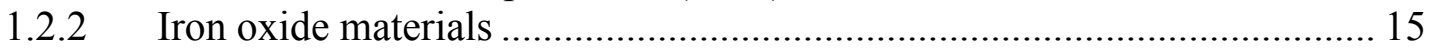

1.3 General objective of dissertation projects................................................... 17

2 Quantification of Hydroxyl Radical and Singlet Oxygen Formation by Various $\mathrm{TiO}_{2}$

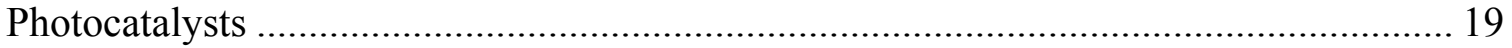

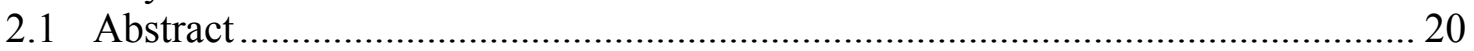

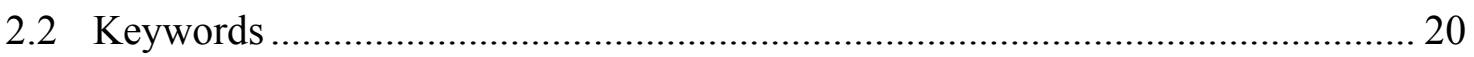

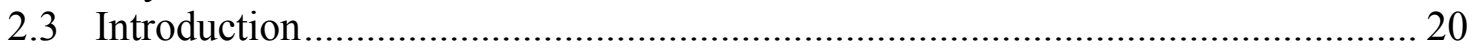

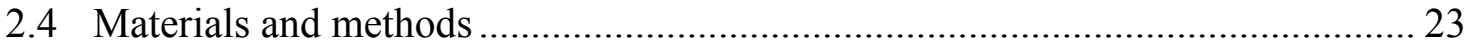

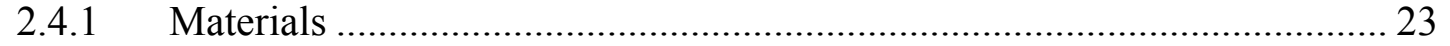

2.4.2 Determination of hydroxyl radical and singlet oxygen.......................... 23

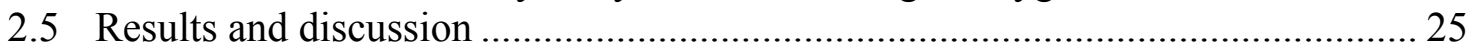

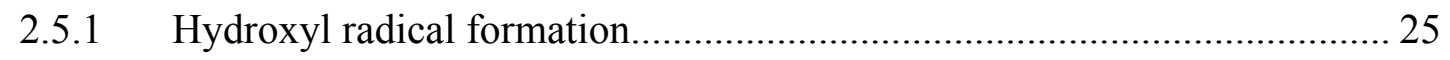

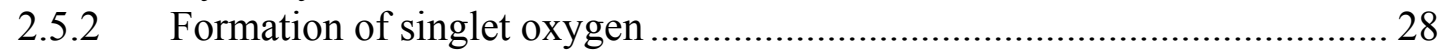

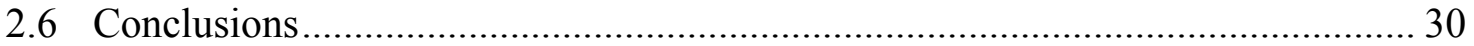

3 Optimization of Photocatalytic Performance of $\mathrm{TiO}_{2}$ Coated Glass Microspheres Using Response Surface Methodology and the Application for Degradation of Dimethyl Phthalate. 31

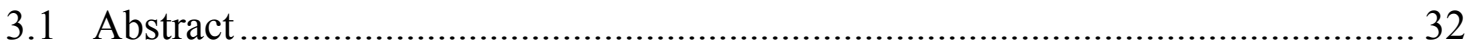

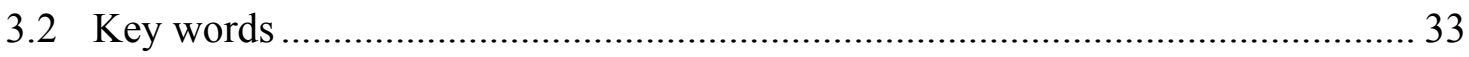

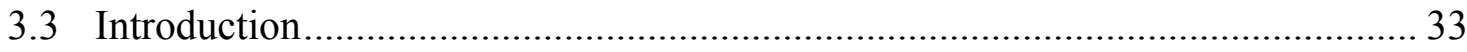

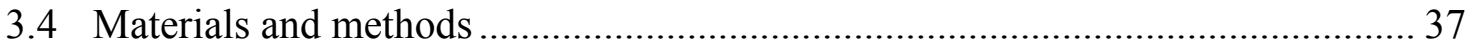

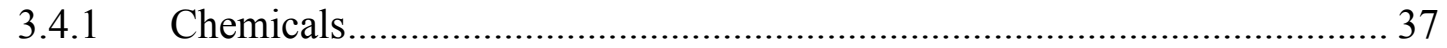

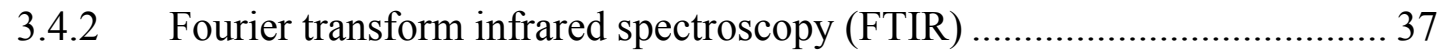

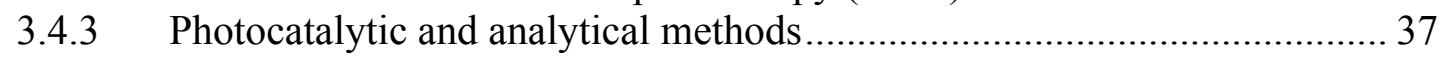

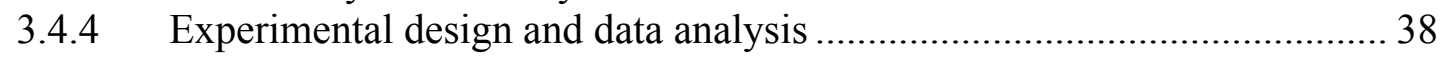

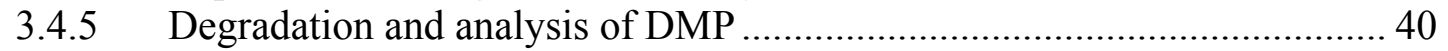

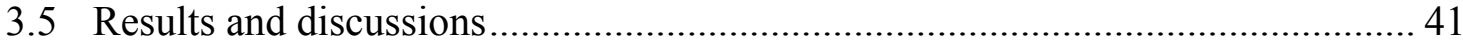

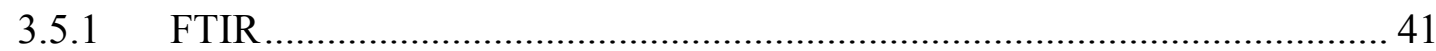

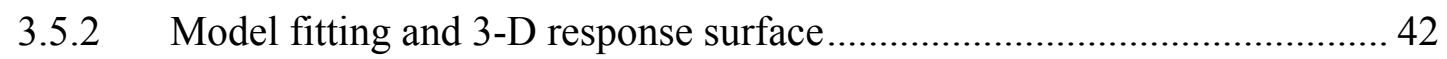

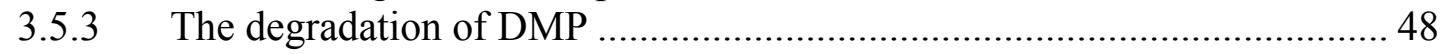

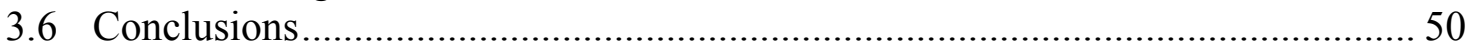

4 Photocatalytic Degradation of Microcystin-LR by Rose Bengal: the Role of Singlet

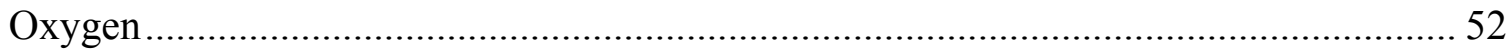




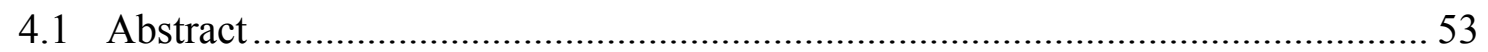

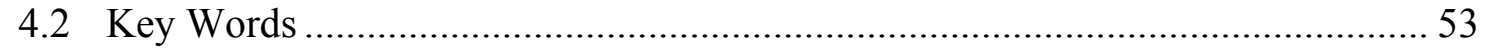

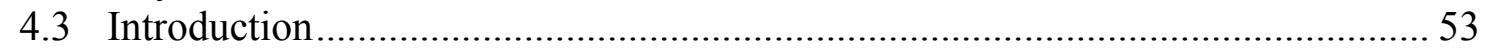

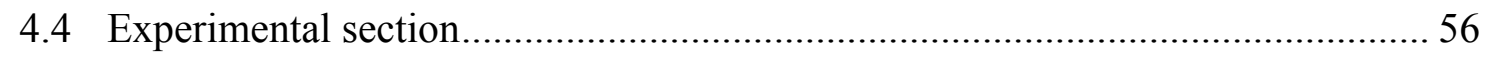

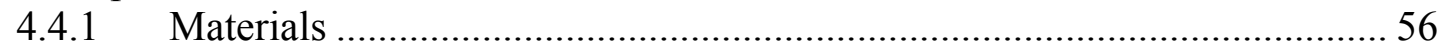

4.4.2 Experimental .................................................................................... 56

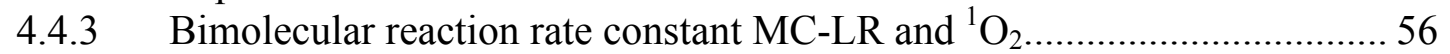

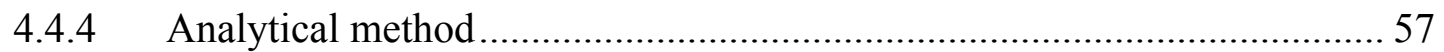

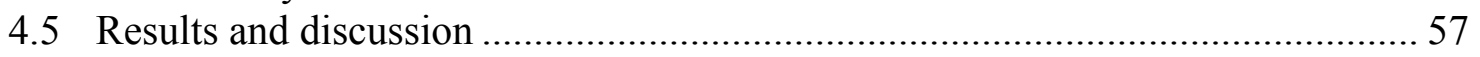

4.5.1 Degradation of MC-LR by rose bengal ………….................................. 57

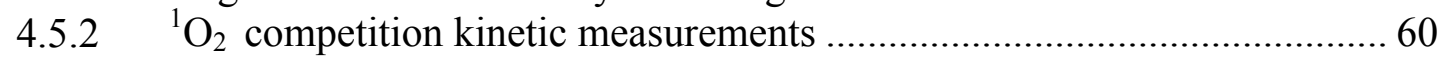

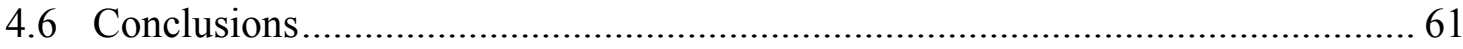

5 Chromium(VI) Removal by Maghemite Nanoparticles ……………………............ 62

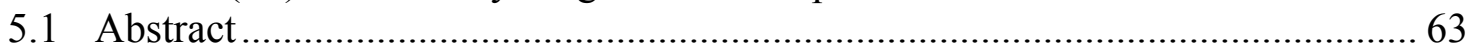

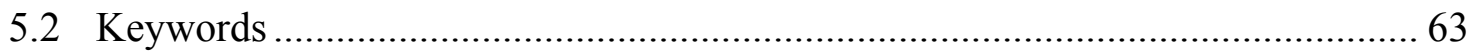

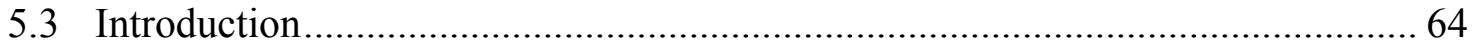

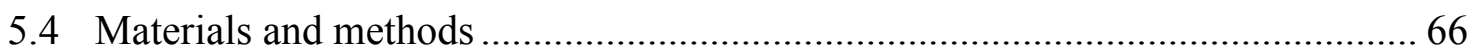

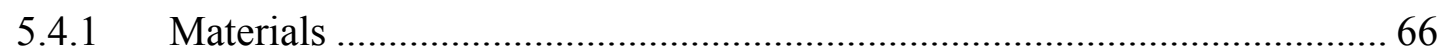

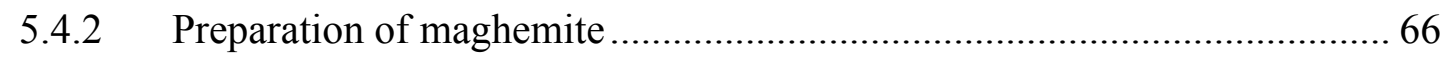

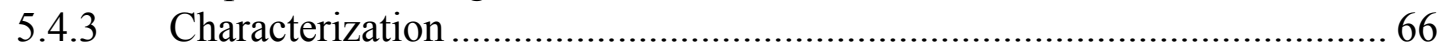

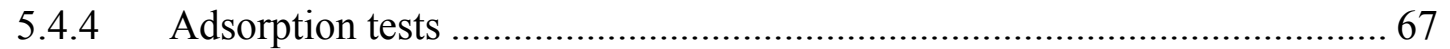

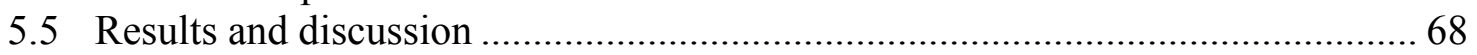

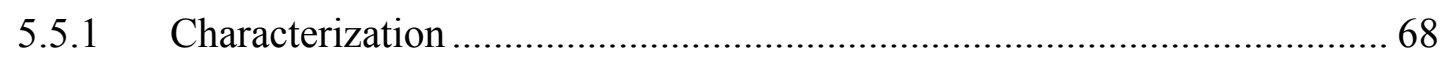

5.5.2 Effect of the concentration of maghemite on $\mathrm{Cr}(\mathrm{VI})$ adsorption................. 71

5.5.3 Effect of the initial $\mathrm{Cr}(\mathrm{VI})$ concentration and contact time on $\operatorname{Cr}(\mathrm{VI})$

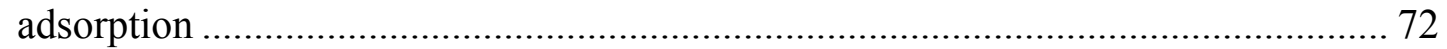

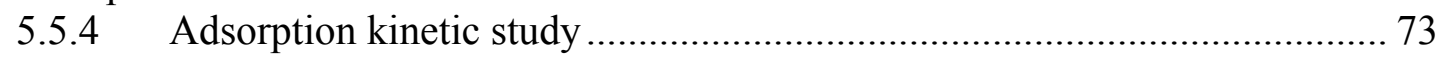

5.5.5 Adsorption isotherms ............................................................................ 76

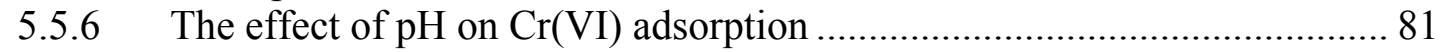

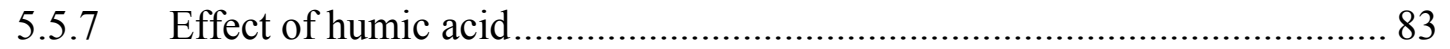

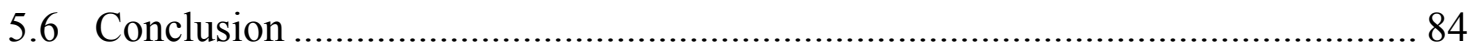

$6 \mathrm{Cr}(\mathrm{VI})$ Adsorption and Reduction by Humic Acid Coated Magnetite ....................... 86

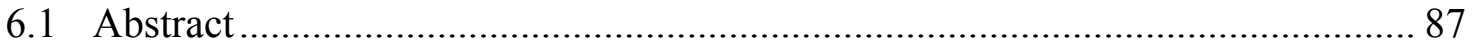

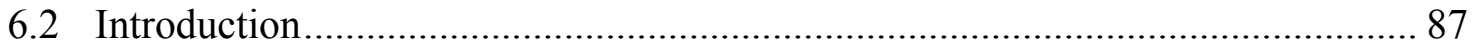

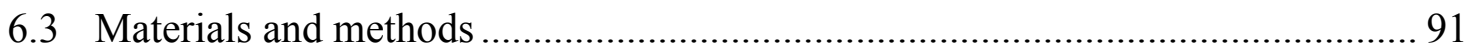

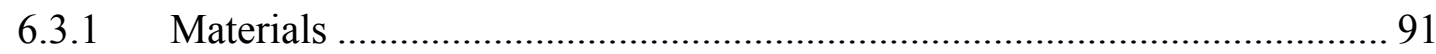

6.3.2 Preparation of bare $\mathrm{Fe}_{3} \mathrm{O}_{4}, \mathrm{HA}-\mathrm{Fe}_{3} \mathrm{O}_{4}$ and $\mathrm{Cr}$-loaded $\mathrm{HA}-\mathrm{Fe}_{3} \mathrm{O}_{4} \ldots \ldots \ldots \ldots \ldots . . . . .91$

6.3.3 Characterizations.......................................................................... 92

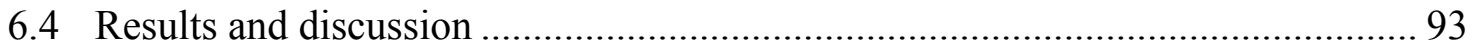

6.4.1 The $\mathrm{pH}$ effect on adsorption and reduction of $\mathrm{Cr}(\mathrm{VI})$............................... 93

6.4.2 The local coordination environment ..................................................... 99

6.4.3 Crystal transformation ....................................................................... 102

6.4.4 Adsorption kinetics and adsorption isotherm .......................................... 104

6.5 Implications for $\mathrm{Cr}(\mathrm{VI})$ detoxification in natural aquatic systems. .................... 106 


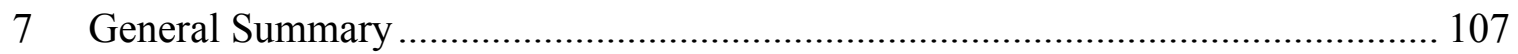

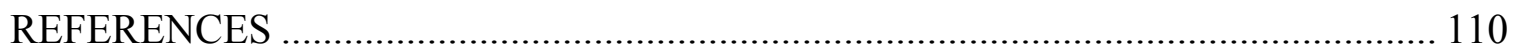

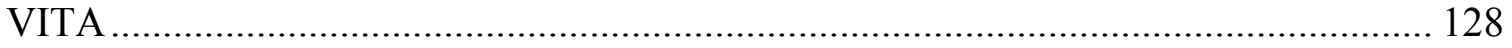




\section{LIST OF FIGURES}

FIGURE

PAGE

Figure 1.1 The structures of $\mathrm{Cr}(\mathrm{VI})$ species: (a) chromic acid, (b) bichormate, (c) chromate, $(\mathrm{d})$ dichromate and $(\mathrm{e})$ hydrogen dichromate................................... 5

Figure 1.2 The structure of microcystin................................................................ 8

Figure 1.3 VB and $\mathrm{CB}$ positions, band gaps for a number of common semiconductor materials at $\mathrm{pH} 0$. The energy scale is referenced by normal hydrogen electrode (NHE). 11

Figure 1.4 Representation of ROS generation during $\mathrm{UV} \mathrm{TiO}{ }_{2}$ photocatalysis ............. 12

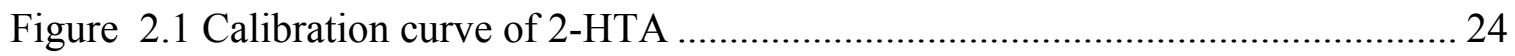

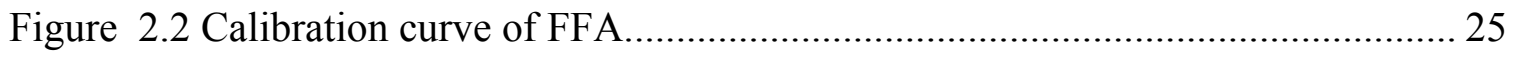

Figure 2.3 Hydroxyl radical yields by various $\mathrm{TiO}_{2}$ under $350 \mathrm{~nm}$ illumination ............ 27

Figure 2.4 Hydroxyl radical yield by various $\mathrm{TiO}_{2}$ under $419 \mathrm{~nm}$ illumination.............. 27

Figure 3.1 FTIR spectra of $\mathrm{HGM}^{-\mathrm{TiO}_{2}}$, TA- and DMP- loaded onto HGM-TiO $\mathrm{Ti}_{2} \ldots \ldots . . .42$

Figure 3.2 Response surface showing of any two independent variables on the $\bullet \mathrm{OH}$ yield

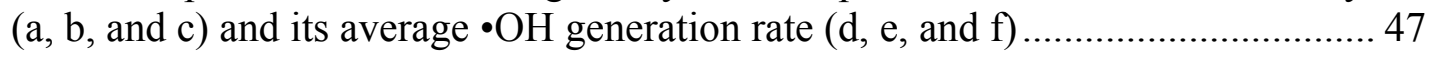

Figure 3.3 The rate constants of pseudo-first order kinetic model for degradation of DMP as a function of HGM-TiO2 loading. The data at 10,12 and $15 \mathrm{~g} / \mathrm{L}$ were not used for the trend-line since the rate did not increase above $8.0 \mathrm{~g} / \mathrm{L}$. Error bars represent standard deviation of triplicate experiments. The insert is the molecular structure of DMP.

Figure 4.1 Molecular structures of rose bengal (top) and MC-LR (bottom) .................. 54

Figure $4.2 \mathrm{UV}$-vis absorbance spectrum of $20 \mu \mathrm{M}$ RB in water ...............................5

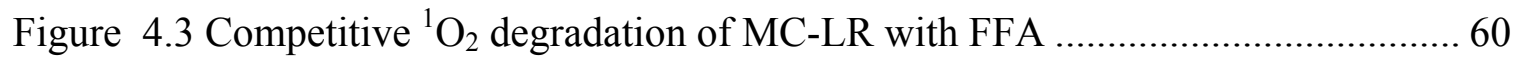

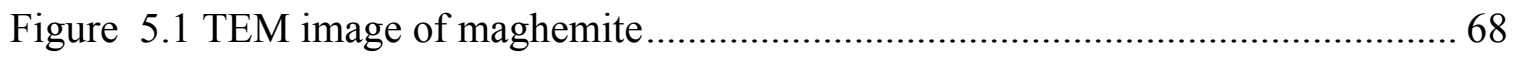

Figure 5.2 Nitrogen adsorption and desorption isotherms. The insert is pore size distribution of maghemite particles 70 
Figure 5.3 XPS of maghemite particles and high resolution XPS of Fe2p core level (the insert) 70

Figure 5.4 Effect of the concentration of maghemite particles on $\mathrm{Cr}$ (VI) adsorption .... 72

Figure 5.5 Effect of the initial concentration of $\mathrm{Cr}(\mathrm{VI})$ and contact time on $\mathrm{Cr}(\mathrm{VI})$ removal 73

Figure 5.6 Intraparticle diffusion plots for removal of $\mathrm{Cr}(\mathrm{VI})$ by maghemite particles .. 76

Figure 5.7 Freundlich isotherm illustrating the linear dependence of $\log Q_{e}$ on $\log C_{e} \ldots 77$

Figure 5.8 Langmuir isotherm illustrating the linear dependence of $C_{e} / Q_{e}$ on $C_{e} \ldots \ldots \ldots . . .78$

Figure 5.9 L-F isotherm illustrating the linear dependence of $1 / Q_{e}$ on $1 / C_{e}{ }^{\mathrm{m}} \ldots \ldots \ldots \ldots \ldots . . . . . . .80$

Figure 5.10 Temkin isotherm illustrating the linear dependence of $Q_{e}$ on $\ln C_{e} \ldots \ldots \ldots \ldots . . .81$

Figure 5.11 Effect of $\mathrm{pH}$ on $\mathrm{Cr}(\mathrm{VI})$ adsorption. $[\mathrm{Cr}(\mathrm{VI})]_{0}=500 \mathrm{ppb},[$ maghemite $]=0.3$ $\mathrm{g} / \mathrm{L}$ 82

Figure 5.12 Effect of humic acid on $\mathrm{Cr}(\mathrm{VI})$ adsorption. $[\mathrm{Cr}(\mathrm{VI})]_{0}=500 \mathrm{ppb}$,

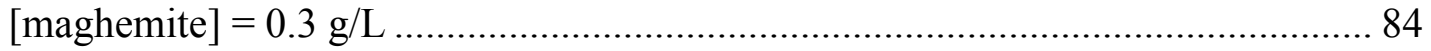

Figure 6.1 Nitrogen adsorption and desorption isotherms of humic acid coated magnetite 94

Figure 6.2 Effect of $\mathrm{pH}$ on removal efficiency of chromium by $\mathrm{HA}-\mathrm{Fe}_{3} \mathrm{O}_{4} \cdot[\mathrm{Cr}(\mathrm{VI})]_{0}=1$

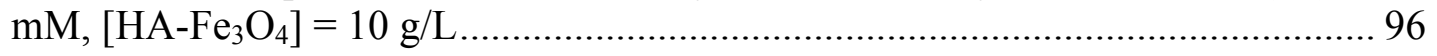

Figure 6.3 Zeta potential of bare $\mathrm{HA}-\mathrm{Fe}_{3} \mathrm{O}_{4}, \mathrm{HA}-\mathrm{Fe}_{3} \mathrm{O}_{4}$, and $\mathrm{Cr}$-loaded $\mathrm{HA}-\mathrm{Fe}_{3} \mathrm{O}_{4}$ at

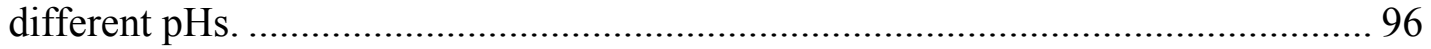

Figure 6.4 $\mathrm{Cr} K$-edge XANES spectra of chromium reference compounds and Cr-loaded $\mathrm{HA}-\mathrm{Fe}_{3} \mathrm{O}_{4}$ at different $\mathrm{pH}$ conditions. 98

Figure $6.5 \mathrm{Fe} K$-edge XANES spectra of iron reference compounds and Cr-loaded HA$\mathrm{Fe}_{3} \mathrm{O}_{4}$ at different $\mathrm{pH}$ conditions...... 99

Figure $6.6 \mathrm{k}^{3}$-weighted $\mathrm{Cr}(\mathrm{A})$ and $\mathrm{Fe}(\mathrm{B}) \mathrm{K}$-edge EXAFS spectra ............................ 100

Figure 6.7 Fourier-transform spectral of $\mathrm{Cr}(\mathrm{A})$ and $\mathrm{Fe}(\mathrm{B})$ resulting in a radial structure function 101

Figure 6.8 The proposed surface structure of adsorbed $\mathrm{Cr}$ on $\mathrm{HA}-\mathrm{Fe}_{3} \mathrm{O}_{4}$ 101 
Figure 6.9 FTIR of $\mathrm{HA}-\mathrm{Fe}_{3} \mathrm{O}_{4}$ and $\mathrm{Cr}$-loaded $\mathrm{HA}-\mathrm{Fe}_{3} \mathrm{O}_{4}$ particles: (a) $\mathrm{HA}-\mathrm{Fe}_{3} \mathrm{O}_{4}$, (b) $\mathrm{Cr}$ loaded HA-Fe ${ }_{3} \mathrm{O}_{4}\left(\mathrm{pH}\right.$ 4), (c) Cr-loaded HA-Fe $\mathrm{O}_{4}$ (pH 7), and (d) Cr-loaded HA$\mathrm{Fe}_{3} \mathrm{O}_{4}(\mathrm{pH} 10)$ 102

Figure 6.10 XRD patterns of $\mathrm{HA}-\mathrm{Fe}_{3} \mathrm{O}_{4}$ and $\mathrm{Cr}$-loaded $\mathrm{HA}-\mathrm{Fe}_{3} \mathrm{O}_{4}$ particles: (a) $\mathrm{HA}$ $\mathrm{Fe}_{3} \mathrm{O}_{4}$, (b) Cr-loaded HA-Fe $\mathrm{O}_{4}$ (pH 4), (c) Cr-loaded $\mathrm{HA}-\mathrm{Fe}_{3} \mathrm{O}_{4}(\mathrm{pH}$ 7), and (d) Crloaded $\mathrm{HA}-\mathrm{Fe}_{3} \mathrm{O}_{4}(\mathrm{pH} 10)$...... 103

Figure 6.11 Intraparticle diffusion plots . 105 


\section{LIST OF TABLES}

TABLE

PAGE

Table 1.1 The chromium oxides ............................................................................ 5

Table 1.2 The common microcystins variants ....................................................... 9

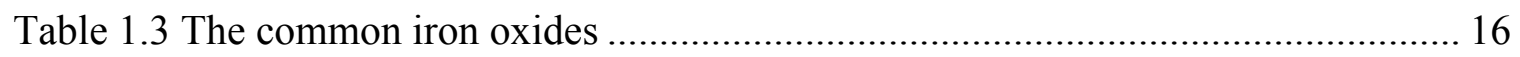

Table 2.1 Band gap energy of $\mathrm{TiO}_{2}$ materials....................................................... 26

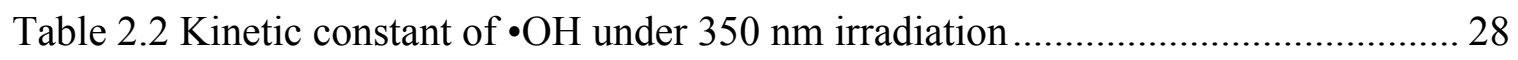

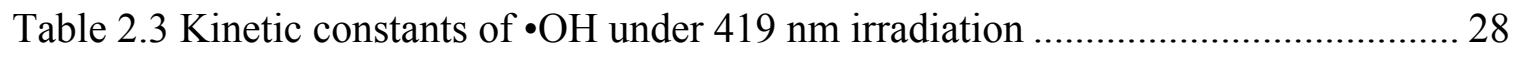

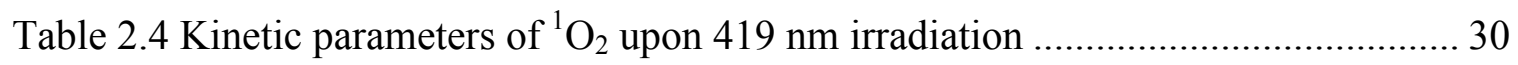

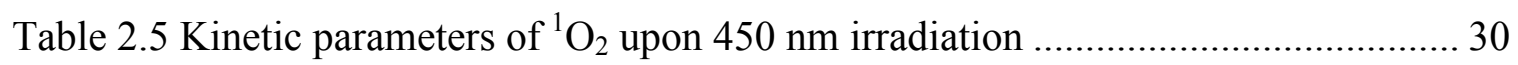

Table 3.1 Central composite design for RSM ....................................................... 39

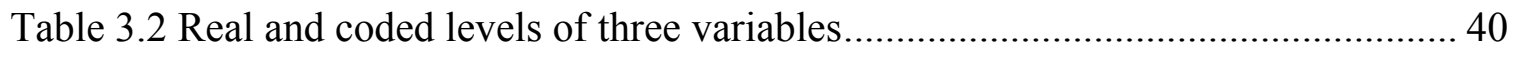

Table 3.3 RSM central composite design and experimental and expected responses ...... 43

Table 3.4 Estimated regression coefficients for $\bullet \mathrm{OH}$ yield and the average $\bullet \mathrm{OH}$

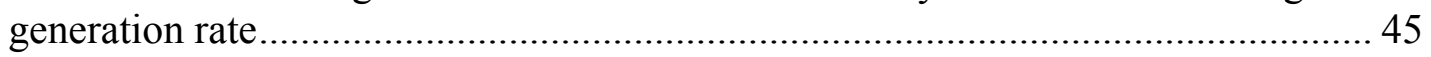

Table 3.5 ANOVA for the second-order models of $\bullet \mathrm{OH}$ yield and average $\bullet \mathrm{OH}$

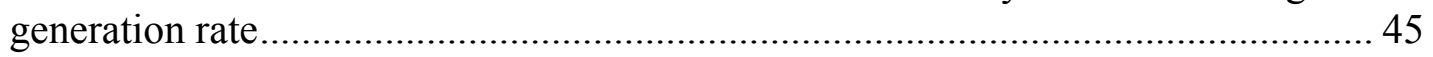

Table 4.1 Kinetics parameters of MC-LR degradation in presence of $500 \mu \mathrm{M}$ RB ........ 59

Table 5.1 Kinetic parameters of pseudo-second-order model for adsorption of $\mathrm{Cr}(\mathrm{VI})$ as a

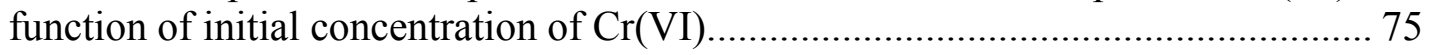

Table 6.1 Chromium K-edge EXAFS fitting parameters ...................................... 101

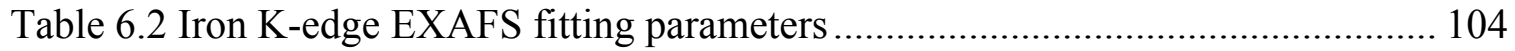


1 General Introduction 


\subsection{Global water treatment challenges}

Access to clean water is a serious global problem. An estimated $22 \%$ of the world's populations do not have the access to clean drinking water (Nordstrom, 2002). Waterborne diseases, especially in the developing countries, are widely spread through contaminated drinking water (Montgomery et al., 2007), and more than 1.5 million children die from diarrheal disease and lack of access to clean drinking water annually (Fenwick, 2006). Two-thirds of the global population will have severe water shortages in the next 10-15 years (Malmqvist et al., 2002), because the increasing level of heavy metals, organic contaminants and natural toxins introduced into natural water bodies through population growth, industrialization and anthropogenic activities (Bove et al., 2002; Olness, 1995). The consumption of contaminated water can result in both chronic and acute effects on human beings and wildlife (Berg et al., 2001; Bove et al., 1995; Chorus et al., 1999). With the demand for clean water increasing and the availability decreasing, water management is a critical challenge for sustainable drinking water supplies in the $21^{\text {st }}$ century (Gatrell et al., 2009; Levine et al., 2004; Viessman et al., 2009). The identification and development of effective economic technologies for water purification is a global challenge.

\subsubsection{Chromium contamination}

The most problematic heavy metal contaminants include aluminum (Al), arsenic (As), chromium $(\mathrm{Cr})$, copper $(\mathrm{Cu})$, lead $(\mathrm{Pb})$, mercury $(\mathrm{Hg})$, and silver $(\mathrm{Ag})$ (Nordberg et al., 2007). Heavy metals can lead to adverse biological consequences at trace levels. The cleanup of heavy metals from natural water bodies is particularly challenging because they are generally persistent under typical environmental conditions and can accumulate 
in the biological systems. In addition, the toxicities of heavy metals are often highly dependent on their chemical forms and oxidation state.

Chromium, which can enter the environment through natural and industrial processes, is one of the common heavy metals and receives significant attention. The annual chromium production was approximately 13 million tons in 1999 , and 140 thousand ton of $\mathrm{Cr}(\mathrm{VI})$ was produced in 1985 (Anger et al., 2000). Metal chromium(0) is primarily used in steel and other alloy industries. Chromium compounds are widely used in refractory and chemical industries, wood preservatives (Hingston et al., 2001), leathertanning (Agrawal et al., 2006), manufacture of dyes and pigments (Wang et al., 1991), and chrome plating of metals (Barnhart, 1997b). Thus, chromium is discharged into the environment via a variety of industrial processes, and an estimated 2 million tons chromium are introduced into hydrosphere from natural sources annually (Chernousov et al., 2003).

Chromium, the first element in group 6 of the periodic table of the elements, is the $21^{\text {st }}$ most abundance element in the earth's crust, and the average concentration of chromium in USA's soils is $\sim 40$ ppm (Barnhart, 1997a). Chromium can exist in several different oxidation states $(0,+2,+3,+4,+6)$. A number of chromium oxides exist and they are summarized in Table 1.1 (Bell et al., 1975; Firouzabadi et al., 1986; Jaleel et al., 1983; Richard et al., 1991; Stomberg, 1962). The metal form of chromium(0) is not found in nature, and the $\mathrm{Cr}$ (II) (chromous) ion is unstable in water and readily oxidized to $\mathrm{Cr}(\mathrm{III})$ in nature (Ardon et al., 1959). $\mathrm{Cr}(\mathrm{III})$ and $\mathrm{Cr}(\mathrm{VI})$ are the predominantly oxidation states observed in aqueous media. The mobility, toxicity, environmental fate and behavior of chromium are highly dependent on the oxidation state. Chromium(III) has 
lower water solubility than $\mathrm{Cr}(\mathrm{VI})$ and more readily adsorbed onto solid substrates (Saliba et al., 2000; Wehrli et al., 1990; Wu et al., 2008). Chromium(III) is an essential nutrient for humans (Anderson, 1997). Chromium(III) plays an important role in glucose and protein metabolism (Morris et al., 1992) and can enhance the action of insulin (Mertz, 1993). The recommended dietary intakes of chromium is 50-200 micrograms per day for adults ("US Food Nutrition Board. Recommended Dietary Allowances", 1989). However, $\operatorname{Cr}(\mathrm{III})$ may be toxic at higher concentration (Stearns et al., 1995). Chromium(VI) is $\sim 500-1000$ times more toxic than $\mathrm{Cr}(\mathrm{III})$ and is a serious threat to the environment and human health. In addition, $\mathrm{Cr}(\mathrm{VI})$ is more soluble, and the more stable chemical form in oxygenated aqueous solution (Bartlett et al., 1976). The $\mathrm{pK}_{\mathrm{a} 1}$ and $\mathrm{pK}_{\mathrm{a} 2}$ of chromic acid $\left(\mathrm{H}_{2} \mathrm{CrO}_{4}\right)$ are 0.74 and 6.50 , respectively. Chromic acid, chromate, bichormate, hydrogen dichromate $\left(\mathrm{pK}_{\mathrm{a}}=1.8\right)$ and dichromate (as shown in Figure 1.1) in aqueous solution are in equilibrium. The chemical equilibrium is described by Eqs. 1.11.5 (Brito et al., 1997; Hoffmann et al., 2001; Swinehart et al., 1964). The chromate and dichromate compounds are strong oxidizing agents (Bokare et al., 2010; Reitsema et al., 1962).

$$
\begin{aligned}
& \mathrm{H}_{2} \mathrm{CrO}_{4} \rightleftarrows \mathrm{H}^{+}+\mathrm{HCrO}_{4}^{-} \\
& \mathrm{HCrO}_{4}{ }^{-} \rightleftarrows \mathrm{H}^{+}+\mathrm{CrO}_{4}{ }^{2-} \\
& 2 \mathrm{HCrO}_{4}{ }^{-} \rightleftarrows \mathrm{Cr}_{2} \mathrm{O}_{7}{ }^{2-}+\mathrm{H}_{2} \mathrm{O} \\
& 2 \mathrm{CrO}_{4}{ }^{2-}+2 \mathrm{H}^{+} \rightleftarrows \mathrm{Cr}_{2} \mathrm{O}_{7}{ }^{2-}+\mathrm{H}_{2} \mathrm{O} \\
& \mathrm{HCr}_{2} \mathrm{O}_{7}{ }^{-} \rightleftarrows \mathrm{H}^{+}+\mathrm{Cr}_{2} \mathrm{O}_{7}{ }^{2-}
\end{aligned}
$$


Table 1.1 The chromium oxides

\begin{tabular}{ccc}
\hline Name & Chemical formula \\
\hline chromium(II) oxide & $\mathrm{CrO}$ & Structure \\
chromium(III) oxide & $\mathrm{Cr}_{2} \mathrm{O}_{3}$ & $\mathrm{CrO}_{2}$ \\
chromium(VI) oxide & $\mathrm{CrO}_{3}$ & $\mathrm{CrO}_{5}$ \\
chromium(VI) oxide & &
\end{tabular}

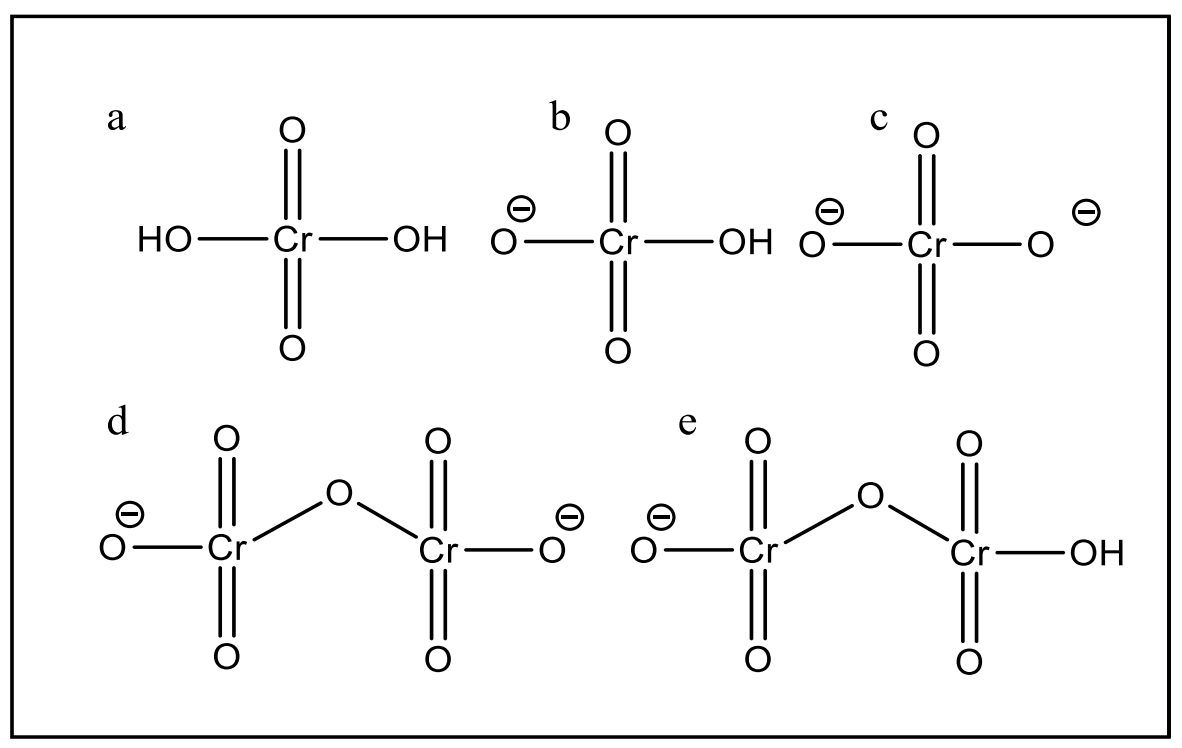

Figure 1.1 The structures of $\mathrm{Cr}(\mathrm{VI})$ species: (a) chromic acid, (b) bichormate, (c) chromate, (d) dichromate and (e) hydrogen dichromate. 
The reduction of $\mathrm{Cr}(\mathrm{VI})$ to $\mathrm{Cr}(\mathrm{III})$ is critial to reduce the health risk associated with chromium contaminated water. The exposure to $\mathrm{Cr}(\mathrm{VI})$ is the main source of the acute and chronic biological effects of Cr (Gochfeld, 1991). The exposure to Cr(VI) compounds can result in carcinomas of the respiratory organs (Léonard et al., 1980; Satoh et al., 1994), mutations (Hepburn et al., 2003), and DNA damage (Peterson-Roth et al., 2005). The World Health Organization recommended maximum allowable limit for total chromium in drinking water at 50 ppb (Fowler et al., 2011).

\subsubsection{The organic water contaminants}

Great varieties of organic contaminants are introduced into water bodies via paper-making, pharmacy, printing and textile industries. Persistent organic pollutants (POPs), phthalate acid esters (PAEs), chlorinated hydrocarbon, pharmaceuticals and personal care products are common pollutants in drinking water sources. Estimated $4 \times$ $10^{8} \mathrm{~kg}$ of organic pesticides are used in USA annually, and $\sim 9 \times 10^{8} \mathrm{~kg}$ of industrial organic contaminants were discharged into atmosphere in 1989 in the USA (Simonich et al., 1995). Even in the treated water, 72 microconstituents were detected in USA (Wang et al., 2013). Organic compounds encompass diverse structural features, and some of them can pose hazardous biological activities on living organisms (Aksu, 2005).

The presence of highly toxic POPs in natural water bodies are especially problematic because they are resistant to natural degradation and can have serious biological impacts. The common sources of POPs are pesticides and pharmaceuticals compounds. Persistent organic pollutants can bioaccumulate in food chain, thus they may pose adverse effects on human health and wildlife (Jones et al., 1999). Pharmaceuticals are emerging contaminants because of their increasing use in human and 
veterinary medicine. The most common pharmaceutical contaminants in environment are antibiotics, anti-inflammatory drugs, lipid regulators, steroids and related hormones, betablockers, cancer therapeutics, diuretics and antiepileptics (Nikolaou et al., 2007). Phthalate acid esters represent another widespread pollutant. Phthalate acid esters are used in most plastics as plasticizers and often leach into environment (Bauer et al., 1997; Stales et al., 1997). The uptake of phthalate acid esters by mice has significant effects on body weight and liver weight (Lamb Iv et al., 1987).

While POPs, pharmaceuticals and PAEs are synthetic organic compounds, there are a group of natural toxins produced by algae which also possess a serious threat to drinking water sources. The incidences of cyanobacterial blooms in freshwater bodies have increased as a result of the euthrophication and global warming (Heisler et al., 2008). The cyanobacteria are detected in various habitats, and cyanobacterial blooms become an international problem as a consequence of water euthrophication (Pelaez et al., 2010). Exposure to cyanobacterial toxins can have lethal effects on human being and wildlife. For the purpose of this dissertation, we focus on the specific family of microcystins cyanotoxin.

Microcystins are produced by cyanobacteria and pose serious chronic and acute toxic effects on human beings and animals. Microcystins are cyclic heptapeptides which have seven amino acids connected by peptide bond: $\gamma$-linked D-glutamic acid, D-alanine, $\beta$-linked D-erythro- $\beta$-methylaspartic acid, $N$-methyldehydroalanine and a unique $C_{20} \beta$ amino acid, (2S, 3S, 8S, 9S), 3-amino-9-methoxy-2, 6, 8- trimethyl-10-phenyldeca-4 (E), 6(E)-dienoic acid (Adda) and two variable L-amino acids $\left(\mathrm{R}_{1}\right.$ and $\mathrm{R}_{2}$ as shown in Figure. 1. 2). Adda is not toxic alone, but it is critical to the toxicity of microcystins. While 
approximately 80 different variants of microcystins have been identified, microcystin-LR (MC-LR) is one of the most toxic and problematic variants. The two variable L-amino acids of MC-LR are leucine (L) and arginine (R). The lethal dose for $50 \%$ mice of MCLR is $\sim 50 \mu \mathrm{g} / \mathrm{kg}$ and World Health Organization guideline of $1 \mu \mathrm{g} / \mathrm{L}$ MC-LR has been adopted as the drink water standard in 1998 (WHO, 1998). The concentration of MC-LR may exceed the drinking water guideline of $1 \mu \mathrm{g} / \mathrm{L}$, especially during the lysis of cyanobacteria leading to the closure of specific water bodies. Although there are a number of natural processes that can contribute to the reduction of MC-LR levels in water: dilution, adsorption, thermal degradation, photolysis and biodegradation (Chen et al., 2010), specific effective water treatments are needed for the removal MC-LR.

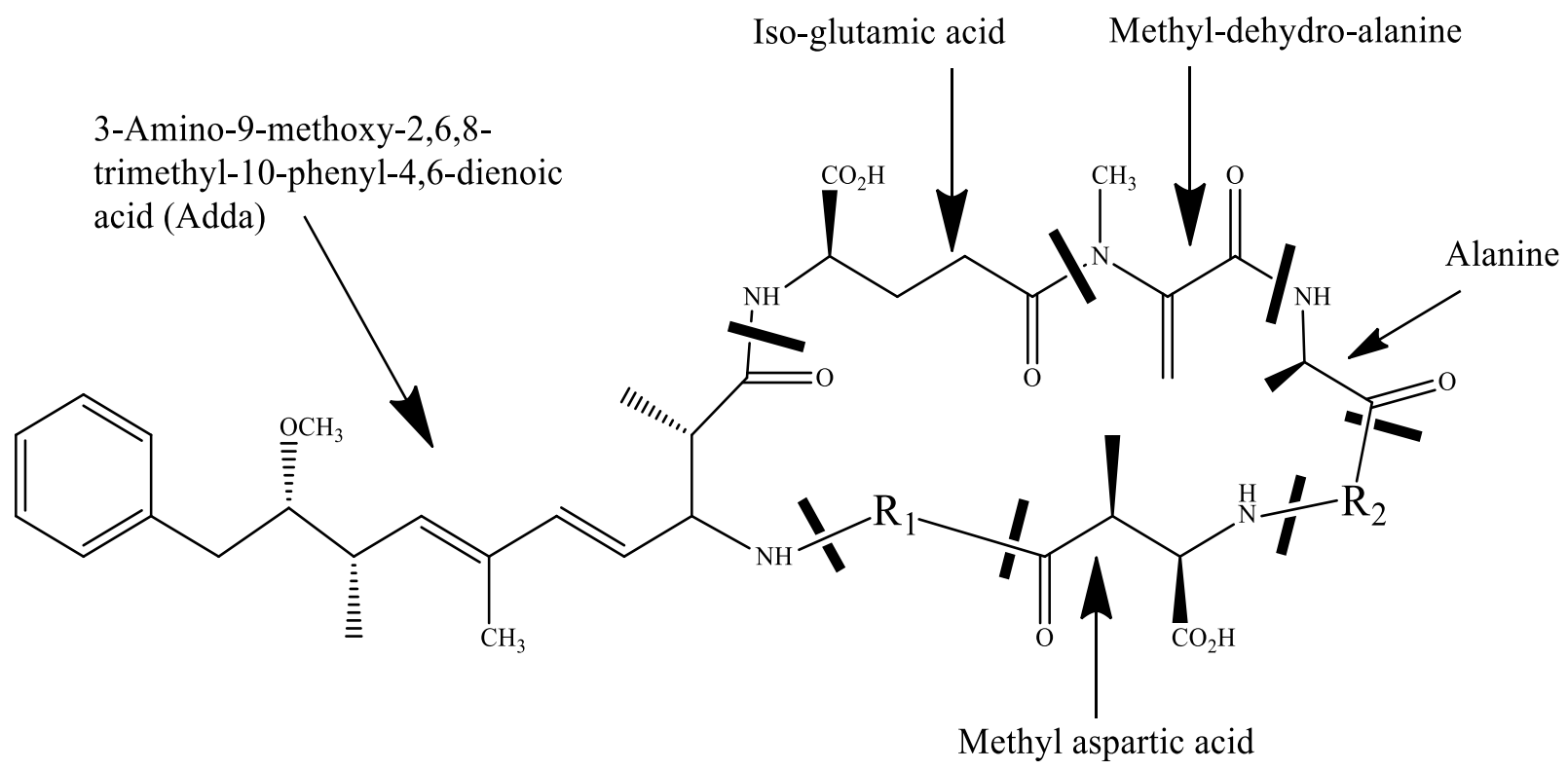

Figure 1.2 The structure of microcystin 
Table 1.2 The common microcystins variants

\begin{tabular}{ccc}
\hline Name & $\mathbf{R}_{\mathbf{1}}$ & $\mathbf{R}_{\mathbf{2}}$ \\
\hline MC-LR & Arginine & Leucine \\
MC-LA & Alanine & Leucine \\
MC-RR & Arginine & Arginine \\
MC-YR & Arginine & Tyrosine \\
\hline
\end{tabular}

Conventional methods are often not effective for the removal of microcystins. The degradation of MC-LR by various advanced oxidation process has been extensively studied, including $\mathrm{TiO}_{2}$ photocatalysis (Lawton et al., 1999), ultrasound (Song et al., 2005), sulfate radical (Antoniou et al., 2010), Fenton and photo-Fenton process (Bandala et al., 2004), hydrogen peroxide enhanced process (Cornish et al., 2000) and ozone (Shawwa et al., 2001).

\subsection{Innovative water treatment techniques}

Because of the diversity of contaminants in water, the conventional water treatment techniques are not effective for emerging contaminants. Multistep drinking water purification systems may be effective but typically have costly high-energy requirements and/or heavy doses of chemical additives. Advanced oxidation process and iron oxide materials have distinct advantages and exhibit excellent potential for the drinking water treatment.

\subsubsection{Advanced oxidation processes (AOP)}

Semiconductor photocatalysis has shown tremendous promise for the environmental remediation of an extensive number of pollutants and toxins in water and air streams (Serpone et al., 2012). Titanium dioxide is a typical semiconductor 
photocatalyst, since it is low-cost, readily available, and chemical stable. Photoexcitation of a semiconductor material can promote an electron from the valence band (VB) to the conduction band $(\mathrm{CB})$ resulting in an electron-hole pair. In competition with recombination the electron can act as a reducing entity and the hole as an oxidizing entity. The VB and $\mathrm{CB}$ positions are critical to the effectiveness and economic feasibility of semiconductor photocatalytic materials for water purification. The energy difference between the $\mathrm{VB}$ and $\mathrm{CB}$ dictates the wavelength of irradiation required for photoexcitation. Large band gaps require higher energy UV irradiation, while semiconductor materials with smaller band gaps can be photoexcited with lower energy visible light irradiation (Hoffmann et al., 1995). Photoexcitation with visible light has a significant economic advantage because of the high cost associated with generating the UV light required for activating materials with large band gaps. Doping of $\mathrm{TiO}_{2}$ materials can extend the absorbance into the visible light range, but the semiconductor photocatalytic reaction pathways initiated by UV and visible light involve significantly different processes (Choi et al., 2007). Another critical factor is the oxidation and reduction potential of the hole and electron (band position). The VB and CB positions as well as band gaps energy of a number of common semiconductor catalysts are summarized in Figure 1.3 (Choi, 2006). 


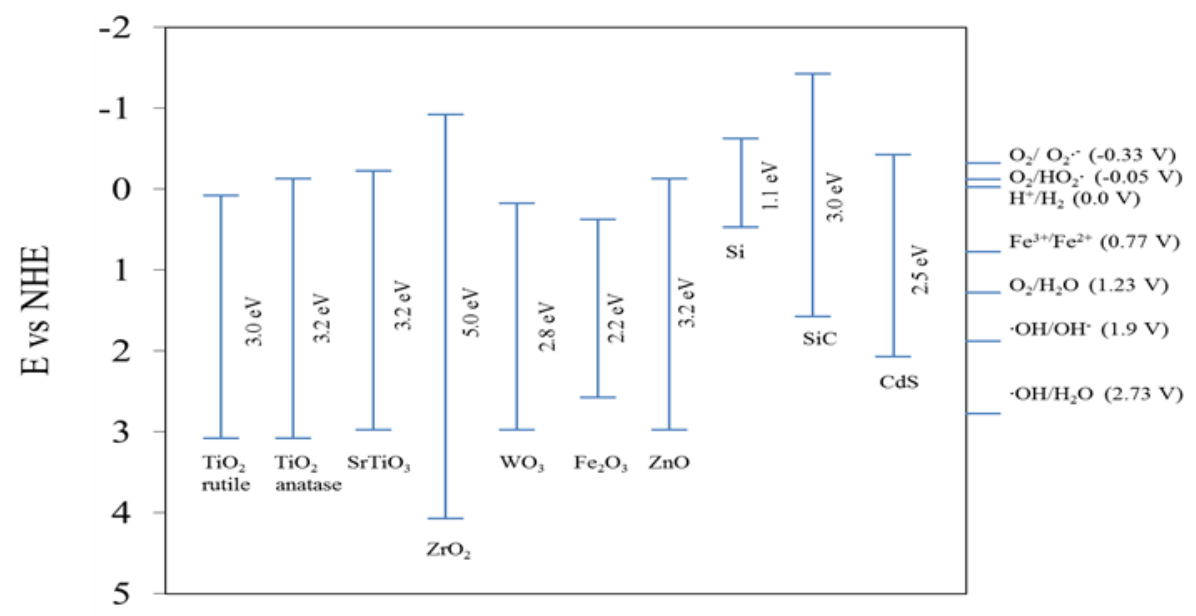

Figure 1.3 VB and $\mathrm{CB}$ positions, band gaps for a number of common semiconductor materials at $\mathrm{pH} 0$. The energy scale is referenced by normal hydrogen electrode (NHE)

A variety of reactive oxygen species (ROS) can be produced during semiconductor photocatalysis. ROS are central to the semiconductor photocatalytic and advanced oxidative water treatment technologies (Serpone et al., 2012). Hydroxyl radical $(\bullet \mathrm{OH})$, superoxide anion radical $\left(\mathrm{O}_{2} \bullet^{-}\right)$, singlet oxygen $\left({ }^{1} \mathrm{O}_{2}\right)$ and hydrogen peroxide $\left(\mathrm{H}_{2} \mathrm{O}_{2}\right)$, can be produced (as shown in Figure. 1. 4) during semiconductor photocatalysis but the production and role of the different ROS are dependent on the photocatalyst, reaction conditions and target compound. Ultraviolet (UV) $\mathrm{TiO}_{2}$ photocatalysis has been extensively studied and hydroxyl radical is generally believed to be responsible for the primary degradation of target pollutants (Buxton et al., 1988). Visible light initiated (VLA) photocatalysis typically does not possess the oxidation potential required for the direct formation of hydroxyl radical and thus superoxide anion radical and singlet oxygen appear to play important roles in the degradation processes associated with VLA photocatalysis (Hoffmann et al., 1995). Ultimately, the VB and CB positions are critical to the effective production of ROS and the economic feasibility of 
semiconductor photocatalytic materials for water purification (Linsebigler et al., 1995).

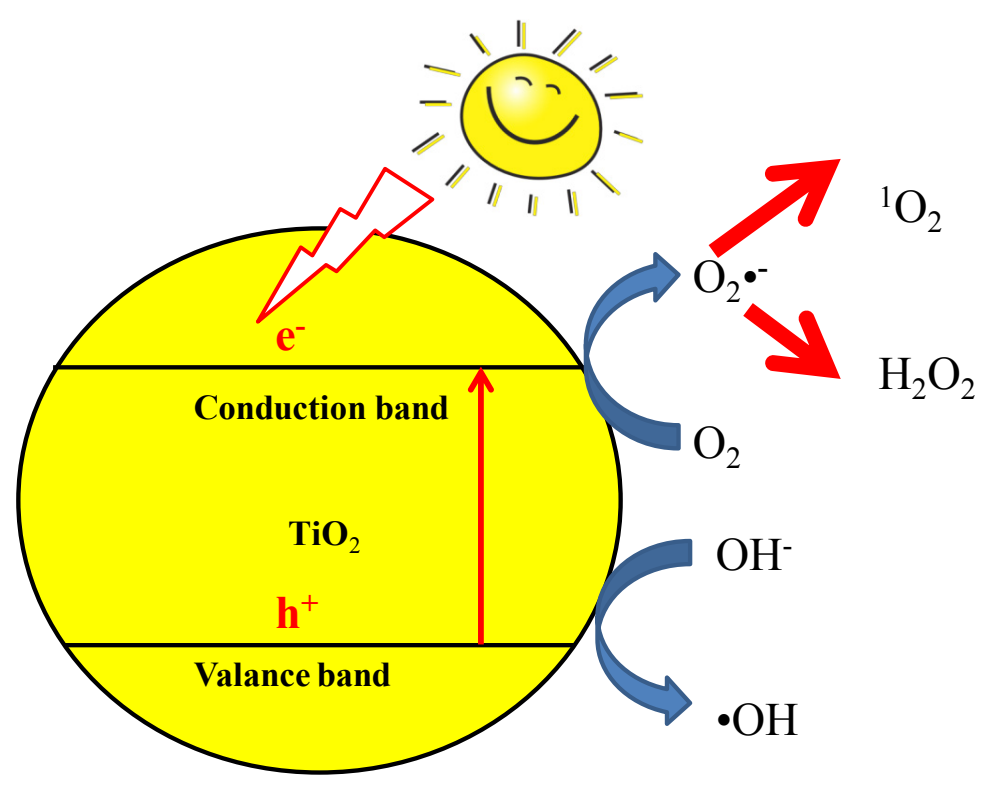

Figure 1.4 Representation of $\mathrm{ROS}$ generation during $\mathrm{UV} \mathrm{TiO}_{2}$ photocatalysis

Among the ROS, $\bullet \mathrm{OH}$ is the most powerful oxidant and primarily responsible for the degradation processes during UV photocatalysis in aqueous solution (Sun et al., 2008) and advance oxidation technologies (O'Shea et al., 2012). Hydroxyl radical reacts by addition, hydrogen and electron transfer processes with most organic compounds and many inorganic substrates often at nearly diffusion-controlled rates (Buxton et al., 1988). Singlet oxygen, superoxide anion radical, and hydrogen peroxide have lower oxidation potentials than hydroxyl radical, however these species can still lead to the remediation of a variety of pollutants and toxins. The lower oxidation of these species can lead to better selectivity, which can be advantageous for treatment of solutions containing innocuous substrates such as dissolved organic matter, which can compete for and quench hydroxyl radical. Hydrogen peroxide and singlet oxygen are generally formed as secondary oxidants but their specific impact in the UV and VLA semiconductor photocatalysis are still not clear. Singlet oxygen can be produced through a photosensitized process and 
from the reduction of superoxide anion radical, while hydrogen peroxide can be generated from disproportionation of superoxide anion radical and combination of two hydroxyl radicals. Hydrogen peroxide is commonly employed for remediation through $\mathrm{UV} / \mathrm{H}_{2} \mathrm{O}_{2}$ disinfection processes, Fenton-type reactions and Haber-Weiss reactions. $\mathrm{O}_{2} \bullet^{-}$ can act as a oxidizing or reducing agent depending on the reactivity of the target substrate. The role of $\mathrm{O}_{2} \bullet^{-}$especially in VLA photocatalysis is not well understood ( $\mathrm{Li}$ et al., 2012).

Accurate determination of ROS can be challenging because of their high reactivities, short lifetimes and the requirement for specialized equipment. Direct measurement of $\bullet \mathrm{OH}$ is not feasible given the short wavelength absorbance and short lifetime. Common methods for detection and measurement of hydroxyl radical include monitoring of initial reaction products, use of trapping agents and competition kinetics (Song et al., 2009). The formation of hydroxyl radical products with absorbance from $\sim 260-700 \mathrm{~nm}$ can be directly monitored by transient absorption spectroscopy and absolute rate constants can be extracted by varying the concentration of substrate. Trapping experiments and competition kinetics employ probe compounds with known hydroxyl radical selectivity and reactivities. Formic acid and t-butanol have been added as hydroxyl radical inhibitors during photocatalysis to access the role of hydroxyl radical in the observed degradation of a target compound. A decrease in the degradation upon addition of a hydroxyl radical inhibitor implies hydroxyl radical plays an important role in the degradation process. While inhibitors are effective for a qualitative assessment, trapping of hydroxyl radical can provide an accurate determination of the concentration and production rate of hydroxyl radical. Hydroxyl radical spin traps produce a spin 
adducts which can be measured by electron spin resonance (ESR) spectroscopy (Fu et al., 2006; Schwarz et al., 1997). Terephthalic acid and coumarin react with hydroxyl radical to yield adducts with characteristic fluorescence (Ishibashi et al., 2000b; Louit et al., 2005). These fluorescence probes are easy to use and excellent for quantification of hydroxyl radical in a variety of systems.

Singlet oxygen is an excited state unlike the other ROS mentioned earlier. While it requires specialized equipment it is possible to measure the presence of singlet oxygen directly on the basis of phosphorescence at $1270 \mathrm{~nm}$ of the ${ }^{1} \Delta_{\mathrm{g}}$ state (Nosaka et al., 2004). Another challenge in measuring singlet oxygen during photocatalysis is its short lifetime in aqueous media. Azide, 1,4-diazabicyclo[2.2.2]octane (DABCO), and furfuryl alcohol are used to probe singlet oxygen reactions. Addition of these probes to the reaction solution will quench singlet oxygen and inhibit reactions with target substrates. The generation rate and steady-state concentration of ${ }^{1} \mathrm{O}_{2}$ can be measured by using furfuryl alcohol as a probe (Haag et al., 1986). Thus, simple addition of a singlet oxygen quencher can provide qualitative evidence for the involvement of singlet oxygen. The role of ${ }^{1} \mathrm{O}_{2}$ during photocatalysis can be probed by conducting experiments in water and in heavy water $\left(\mathrm{D}_{2} \mathrm{O}\right)$. The lifetime of singlet oxygen in $\mathrm{D}_{2} \mathrm{O}$ is $\sim 20$ times longer than in $\mathrm{H}_{2} \mathrm{O}$, thus singlet oxygen mediated processes are dramatically enhanced in $\mathrm{D}_{2} \mathrm{O}$ compared to $\mathrm{H}_{2} \mathrm{O}$.

The production of $\mathrm{H}_{2} \mathrm{O}_{2}$ can be achieved using simple reliable colorimetric methods based on peroxidic-type reactions, i.e., the $\mathrm{I}_{3}{ }^{-}$method is based on the spectrophotometric determination of formed $\mathrm{I}_{3}^{-}$, when $\mathrm{H}_{2} \mathrm{O}_{2}$ is mixed with a concentrated I' solution. The dimerization of p-hydroxyphenyl acetic acid and enzymatic-colorimetric 
method are also employed for $\mathrm{H}_{2} \mathrm{O}_{2}$ measurement (Miller et al., 1988). Catalyse has also been used to assess the involvement of hydrogen peroxide in oxidative and biological systems. The involvement of superoxide anion radical can be assessed using competition kinetics employing benzoquinone and superoxide dismutase. Electron spin resonance spectroscopy using a spin trap (Diaz-Uribe et al., 2010), a luminal chemiluminescent probe compound (Hirakawa et al., 1999), the combination of reduction of 2,3-bis (2methoxy-4-nitro-5-sulfophenyl)-2H-tetrazolium-5-carboxanilide and superoxide dismutase method have been used to monitor the production of superoxide anion radical (Auffan et al., 2010). While there are an extensive number of techniques for measuring and assessing the production of ROS, semiconductor photocatalysis involves heterogeneous systems, which can complicate measurements and limit the use of spectroscopic methods. Accurately determining the production and understanding the interplay among ROS generated under specific semiconductor photocatalytic condition is critical for practical water treatment applications.

\subsubsection{Iron oxide materials}

Use of the common adsorbents, including activated carbon, agricultural products, industrial by-products and biosorbents, can involve a time-consuming and sometimes costly separation process following a treatment (Babel et al., 2003; Owlad et al., 2009). The advantage of magnetic materials is the easy separation by an external magnetic field (Ambashta et al., 2010). The common iron oxides are summarized in Table 1.3 (Cornell et al., 2003). These iron oxide materials are low-cost and readily available. The bare magnetic iron oxide and functionalized magnetic iron oxides materials can be employed for water treatments. 
Table 1.3 The common iron oxides

\begin{tabular}{cccc}
\hline Iron oxide & Chemical formula & Structural type & Crystal system \\
\hline Hematite & $\alpha-\mathrm{Fe}_{2} \mathrm{O}_{3}$ & Corundum & Hexagonal \\
Magnetite & $\mathrm{Fe}_{3} \mathrm{O}_{4}$ & Inverse spinel & Cubic \\
Maghemite & $\gamma-\mathrm{Fe}_{2} \mathrm{O}_{3}$ & Defect spinel & Cubic or Tetragonal \\
Wüstite & $\mathrm{Fe}_{(1-\mathrm{x})} \mathrm{O}$ & & Cubic \\
\hline
\end{tabular}

Iron oxides materials have widely used for toxic heavy metals removal. Magnetite particles has been employed for the chromium(VI) removal from water, and the X-ray absorption near edge structure spectroscopy indicates that chromium(VI) was adsorbed and reduced to nontoxic species chromium(III) (Polizzotto et al., 2005). Amorphous iron oxide, maghemite, and magnetite, exhibit excellent adsorption capacity of arsenic species in aqueous solution (Dixit et al., 2003; Tuutijärvi et al., 2009). Mercury(II), lead(II), cadmium(II) and copper(II) are also can be removed from the aqueous solution by magnetic iron oxide materials (J.-f. Liu et al., 2008).

Another attractive feature of iron oxides is the ability to initiate oxidation processes through the decomposition of hydrogen peroxide generating $\bullet \mathrm{OH}$ in presence of $\mathrm{Fe}(\mathrm{II})$ or $\mathrm{Fe}(\mathrm{III})$ (Kwan et al., 2003). The Fe(II) containing materials, it can act via the well-known Fenton reaction:

$$
\mathrm{Fe}(\mathrm{II})+\mathrm{H}_{2} \mathrm{O}_{2}=\mathrm{Fe}(\mathrm{III})+\cdot \mathrm{OH}+\mathrm{OH}^{-}
$$

$\mathrm{Fe}(\mathrm{II})$ can be formed slowly from $\mathrm{Fe}(\mathrm{III})$ in the presence of hydrogen peroxide :

$$
\begin{aligned}
& \mathrm{Fe}(\mathrm{III})+\mathrm{H}_{2} \mathrm{O}_{2}=\mathrm{Fe}\left(\mathrm{HO}_{2}\right)^{2+}+\mathrm{H}^{+} \\
& \mathrm{Fe}\left(\mathrm{HO}_{2}\right)^{2+}=\mathrm{Fe}(\mathrm{II})+\mathrm{HO}_{2}
\end{aligned}
$$


The deprotonation of $\mathrm{HO}_{2}\left(\mathrm{pK}_{\mathrm{a}}=4.8\right)$ yields $\mathrm{O}_{2}{ }^{-}$, which initiates reduction of $\mathrm{Fe}(\mathrm{III})$ :

$$
\mathrm{O}_{2}^{-}+\mathrm{Fe}(\mathrm{III})=\mathrm{Fe}(\mathrm{II})+\mathrm{O}_{2}
$$

The generated Fe(II) initiates Eq. 1.6. Thus, the iron oxide can initiate the generation of - $\mathrm{OH}$ and degrade the contaminants in presence of hydrogen peroxide. The technique may combine the advantage of magnetic iron oxide and hydroxyl radical mediated degradation, resulting in an improvement of performance for the contaminant treatment (Valentine et al., 1998).

In order to improve its efficient purification technology, a number of magnetic iron-containing materials were synthesized and employed for water treatment. The silicacoated magnetite core material exhibits a good performance for removal of MC-LR due to the magnetic properties and unique microstructure (Deng et al., 2008). The other synthetic strategy is magnetic composite material. For example, magnetic $\mathrm{MnO}_{2}-\mathrm{Fe}_{2} \mathrm{O}_{3}$ composite shows an excellent adsorption of azo-dye from water (Wu et al., 2005). The clay-maghemite composite has a high adsorption capacity for the heavy metals (Oliveira et al., 2003). The activated carbon-magnetite composite was employed for adsorption of volatile organic compounds from water and the experimental results demonstrates that magnetic iron oxide core does not change the adsorption behavior of activated carbon (Oliveira et al., 2002).

\subsection{General objective of dissertation projects}

The generation of reactive oxygen species by various $\mathrm{TiO}_{2}$ catalysts was monitored. Since the hydroxyl radical is the dominant reactive oxygen species, the optimization conditions for hydroxyl radical generation by $\mathrm{TiO}_{2}$ coated glass 
photospheres were evaluated, and the optimal conditions were applied for the degradation of dimethyl phthalate. Conventional water treatment methods are often not effective or not practical for the removal of MC-LR. In the present study, we employed rose bengal, a singlet oxygen sensitizer, to study the photo-oxidative destruction of MC-LR. Two magnetic iron oxide nanoparticles, maghemite and humic acid coated magnetite, were synthesized and characterized for the removal of chromium(VI) from water. 
2 Quantification of Hydroxyl Radical and Singlet Oxygen Formation by Various $\mathrm{TiO}_{2}$ Photocatalysts 


\subsection{Abstract}

The formation rate, steady-state concentration, and other kinetics parameters of hydroxyl radical and singlet oxygen by various $\mathrm{TiO}_{2}$ photocatalysts under UV or visible irradiations were measured using selective chemical probes in our study. The generation of hydroxyl radical is highly dependent on the irradiation wavelength, and the steadystate concentration of hydroxyl radical is lower by 3-4 orders of magnitude than singlet

oxygen. The lower steady-state concentration of hydroxyl radical is mainly because hydroxyl radical reacts with most organic compounds at nearly diffusion-controlled rates. There is modest effect of type of $\mathrm{TiO}_{2}$ material and irradiation wavelength on the singlet oxygen formation kinetic parameters. It may be the results of generation mechanisms of hydroxyl radical and singlet oxygen: the hydroxyl radical is generated by an electron transfer mechanism and singlet oxygen is generated by an energy transfer followed by an inter-system crossing.

\subsection{Keywords}

Reactive oxygen species, $\mathrm{TiO}_{2}$, Photocatalysis, Hydroxyl radical, Singlet oxygen

\subsection{Introduction}

Advanced oxidation processes involve the generation of reactive oxygen species (ROS). Since ROS are capable of initiating a wide range of reactions, the technique has been applied to degrade and/or mineralize a variety of contaminants (Hoffmann et al., 1995; Linsebigler et al., 1995).

Among the ROS, hydroxyl radical $(\cdot \mathrm{OH})$ is the most powerful oxidant in aqueous solution. In general, $\bullet \mathrm{OH}$ is considered to be the dominant ROS produced during UV $\mathrm{TiO}_{2}$ photocatalysis. Hydroxyl radical reacts with most organic compounds at or near the 
diffusion-controlled rate. The predominant reaction pathways of $\bullet \mathrm{OH}$ with organic compounds include the addition to double bonds, triple bonds, and aromatic rings, hydrogen-atom abstraction, and electron transfer processes (Buxton et al., 1988). Since - $\mathrm{OH}$ is critical for effective degradation of organic contaminants by $\mathrm{TiO}_{2}$ photocatalysis, we used terephthalate acid (TA) as a $\cdot \mathrm{OH}$ trap to determine the rates of generation, steady-state concentrations and rate constants of $\bullet \mathrm{OH}$ employing different $\mathrm{TiO}_{2}$ materials. TA selectively reacts with $\bullet \mathrm{OH}$ to produce 2-hydroxy terephthalic acid (35\% yield) which can be readily and accurately measured using fluorescence (Fang et al., 1996). The mechanism is described in Scheme 2.1.

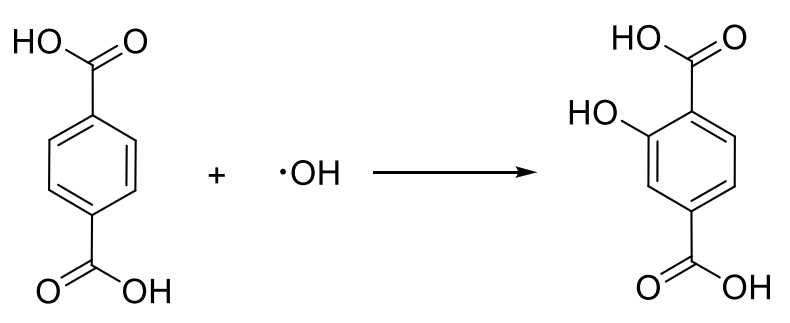

Scheme 2.1 Reaction of TA with $\bullet \mathrm{OH}$

Although $\bullet \mathrm{OH}$ is considered predominant for the treatment of pollutants/toxins by UV $\mathrm{TiO}_{2}$ photocatalysis, visible light activated (VLA) $\mathrm{TiO}_{2}$ photocatalysis appears to involve different ROS and the formation of singlet oxygen $\left({ }^{1} \mathrm{O}_{2}\right)$ has been reported (Rengifo-Herrera et al., 2009; Stylidi et al., 2004). Singlet oxygen is an excited state of molecular oxygen, which reacts with alkenes, conjugated and aromatic systems by enetype, [2+2] cycloaddition, and Diels-Alder reaction pathways (Kearns, 1971).

To access the formation and reaction of ${ }^{1} \mathrm{O}_{2}$ under $\mathrm{VLA} \mathrm{TiO}_{2}$ photocatalysis, furfuryl alcohol (FFA) is employed as a ${ }^{1} \mathrm{O}_{2}$ trap (Haag et al., 1984). Furfuryl alcohol reacts with ${ }^{1} \mathrm{O}_{2}$ with the bimolecular rate constant of $\mathrm{k}=1.2 \times 10^{8} \mathrm{M}^{-1} \mathrm{~s}^{-1}$ (Haag et al., 
1986). The generation of ${ }^{1} \mathrm{O}_{2}$ is monitored by the loss of FFA, and the mechanism is described in Scheme 2.2.
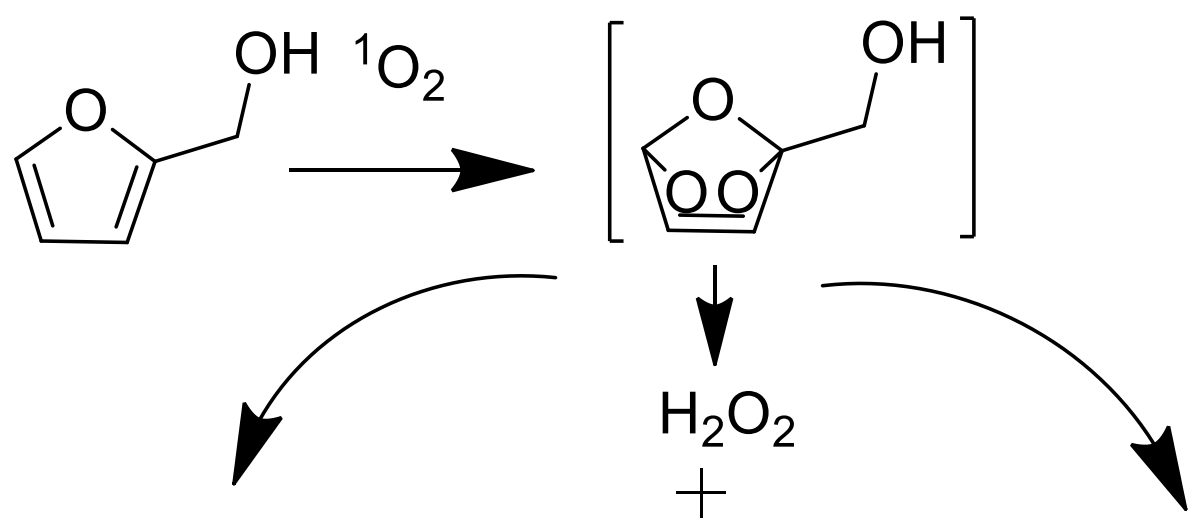

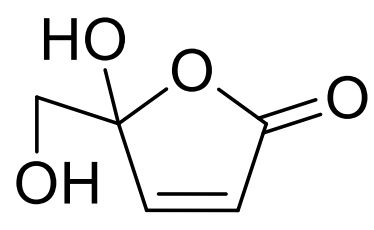

$\leq 10 \%$

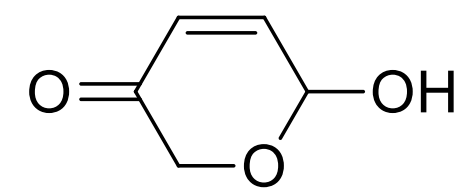

$85 \%$

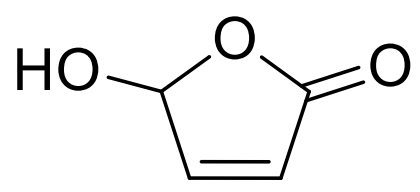

$\leq 10$

Scheme 2.2 Mechanism of reaction of FFA with ${ }^{1} \mathrm{O}_{2}$

Considering the band gap of $\mathrm{TiO}_{2}$ is $3.2 \mathrm{eV}$ (anatase $\mathrm{TiO}_{2}$ ), $\mathrm{UV}$ light is required to activate the photocatalysis process. Visible light reaching the earth's surface represents $45 \%$ of the solar spectrum, whereas only $\sim 5 \%$ is in the UV region. The use of an external UV light source is expensive. Fortunately, doped $\mathrm{TiO}_{2}$ materials have been developed to lower band gap, thus, visible light can be utilized for the activation of $\mathrm{TiO}_{2}$ photocatalysis (Pelaez et al., 2009). $\mathrm{TiO}_{2}$ photocatalysis involves the generation of ROS as a primary step followed by subsequent reactions with contaminants. The majority of publications focus on the degradations efficiency and removal effectiveness. The present study investigates the generation of ROS by various $\mathrm{TiO}_{2}$ materials. 
The objective of this study is to quantify the formations of $\bullet \mathrm{OH}$ and ${ }^{1} \mathrm{O}_{2}$ by various $\mathrm{TiO}_{2}$ materials under visible and $\mathrm{UV}$ irradiation. The productions of $\bullet \mathrm{OH}$ and ${ }^{1} \mathrm{O}_{2}$ by different $\mathrm{TiO}_{2}$ materials can be compared and used to access the potential applications for the degradation of a wide varieties of pollutants and toxins.

\subsection{Materials and methods}

\subsubsection{Materials}

Furfuryl alcohol (98\%), and HPLC-grade methanol were purchased from Acros Organics. Terephthalate acid (disodium salt) was purchased from Sigma-Aldrich. Hollow glass microspheres coated with photocatalytic $\mathrm{TiO}_{2}\left(\mathrm{HGM}-\mathrm{TiO}_{2}\right)$ was obtained from Microsphere Technology Limited (Limerick, Ireland). 2-hydroxy terephthalic acid (2-HTA) was synthesized for calibration by using a published method (Mason et al., 1994). All the compounds were used as received without any further purification. Millipore filtered water $(18 \mathrm{M} \Omega \cdot \mathrm{cm})$ was used for the preparation of all solutions.

\subsubsection{Determination of hydroxyl radical and singlet oxygen}

Terephthalate acid is used to scavenge $\bullet \mathrm{OH}$ and to produce 2- $\mathrm{HTA}$. $\mathrm{TiO}_{2}$ was prepared as a suspension $(0.10 \mathrm{~g} / \mathrm{L})$ in $100 \mathrm{~mL}$ TA solution. The suspension was magnetically stirred and purged with oxygen for $15 \mathrm{~min}$ (unless otherwise stated) prior to and during irradiation, in order to establish the adsorption/desorption equilibrium. The illumination of $\mathrm{TiO}_{2}$ suspension was conducted in a Rayonet photochemical reactor (Southern New England Ultra Violet Company, www.rayonet.org, model RPR-100) equipped with a cooling fan and four lamps. Samples $(3.0 \mathrm{~mL})$ were taken from the suspension at the given time intervals and immediately filtered through a $0.45 \mu \mathrm{m}$ filter. 2-hydroxy terephthalic acid was excited at $315 \mathrm{~nm}$ and fluorescence measured at $425 \mathrm{~nm}$ 
(Ishibashi et al., 2000b), using a Horiba FluoroMax 3 spectrofluorometer. The instrument was calibrated using standard solutions of 2-HTA from $0.01-15 \mu \mathrm{M}$ (Figure 2.1).

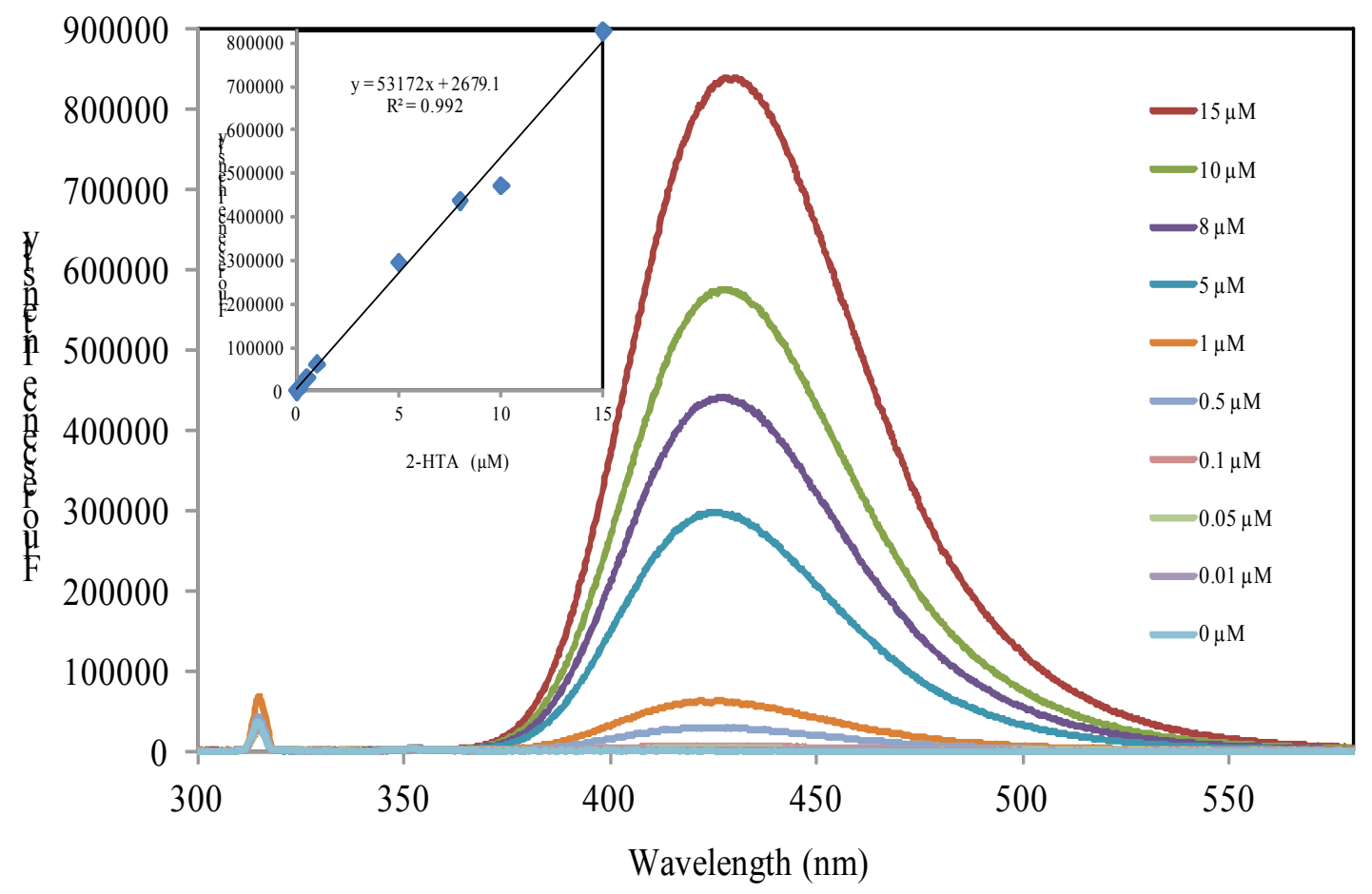

Figure 2.1 Calibration curve of 2-HTA

Furfuryl alcohol was employed to determine the generation of singlet oxygen. Twenty $\mathrm{mL} \mathrm{TiO}_{2}$ suspension $(0.25 \mathrm{~g} / \mathrm{L})$ with FFA $(20 \mu \mathrm{M})$ was magnetically stirred and purged with oxygen for 15 min prior to and during the irradiation in a Rayonet photochemical reactor (12 lamps). A $1.0 \mathrm{~mL}$ sample was taken from the suspension at the given time intervals and immediately filtered through a $0.45 \mu \mathrm{m}$ filter.

The concentration of FFA residual was measured using a Varian ProStar HPLC system equipped with a ProStar 410 autosampler and a ProStar 335 photodiode array detector. FFA was analyzed as the following HPLC conditions: C18 column of $250 \times 4.6$ mm Luna $5 \mu \mathrm{m}$, mobile phase of $20 \%$ methanol and $80 \%$ water, $50 \mu \mathrm{L}$ injection volume 
and detection wavelength at $219 \mathrm{~nm}$. The flow rate was $1 \mathrm{~mL} \cdot \mathrm{min}^{-1}$ at room temperature. Figure 2.2 was the calibration curve of measurement of singlet oxygen with FFA.

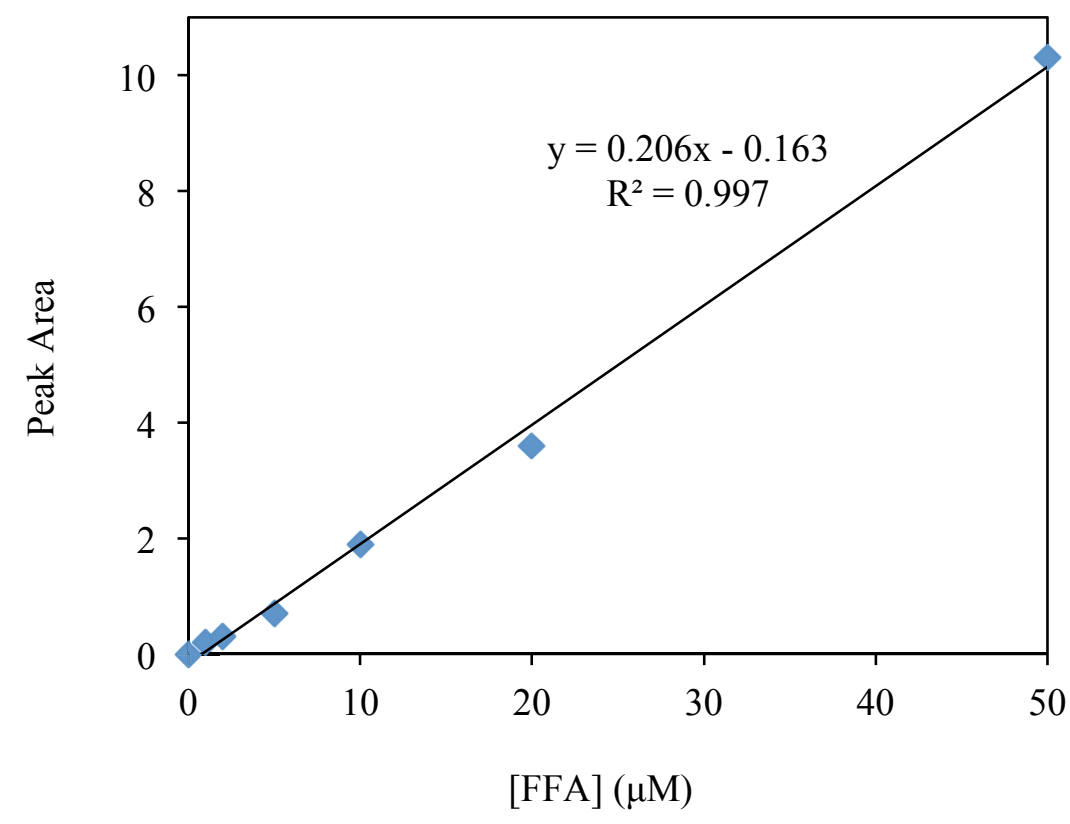

Figure 2.2 Calibration curve of FFA

\subsection{Results and discussion}

\subsubsection{Hydroxyl radical formation}

The preparation of doped $\mathrm{TiO}_{2}$ materials was described in the previous publications (Choi et al., 2007; Han et al., 2011; Pelaez et al., 2009) and the band gap energies of different $\mathrm{TiO}_{2}$ materials are summarized in Table 2.1. Doped $\mathrm{TiO}_{2}$ materials are attractive, because solar energy is available for photocatalysis without the need of external radiation resource. Figure. 2.3 and 2.4 show the yield of hydroxyl radical as a function of time by various $\mathrm{TiO}_{2}$ materials under 350 and $419 \mathrm{~nm}$ irradiations. The yield increases in an approximately linear relationship with time. Wavelength of irradiation is a major factor affecting the yield of hydroxyl radical. It is shown that hydroxyl radical 
yield increases with the increase of irradiation energy. The effect of irradiation wavelength was not the same for different $\mathrm{TiO}_{2}$ materials.

The generation of $\bullet \mathrm{OH}$ fits pseudo-zero order kinetics model with $\mathrm{k}_{0}$ as a pseudozero order rate constant. The coefficients of determination $\left(R^{2}\right) \geq 0.939$ indicate they follow pseudo-zero order kinetics well. It occurs because the photocatalyst was not consumed during irradiation, and there was excessive TA $(1000 \mu \mathrm{M})$ present in $\mathrm{TiO}_{2}$ suspension and the loss of TA is negligible during photocatalysis. Therefore, zero-order kinetics was applied to describe the generation of hydroxyl radical well. The $\cdot \mathrm{OH}$ formation rate $\left(\mathrm{r}_{\cdot \mathrm{OH}}\right)$ is equal to the rate constant $\left(\mathrm{k}_{0}\right)$ for zero-order kinetics model.

$$
\begin{aligned}
& \mathrm{d}[\cdot \mathrm{OH}] / \mathrm{dt}=\mathrm{k}_{0} \\
& \mathrm{~d}[\cdot \mathrm{OH}] / \mathrm{dt}=\mathrm{k} \cdot \mathrm{OH}+\mathrm{TA} \times[\mathrm{TA}] \times[\cdot \mathrm{OH}]
\end{aligned}
$$

where $\mathrm{k} \cdot \mathrm{OH}+\mathrm{TA}=1.98 \times 10^{11} \mathrm{M}^{-1} \min ^{-1}$ (Fang et al., 1996)

Since hydroxyl radical reacts with most organic compounds at or near the diffusion limit rate, the steady-state concentration of hydroxyl radical is extremely low (Buxton et al., 1988). The $\cdot \mathrm{OH}$ formation rate is in the $10^{-1} \mu \mathrm{M} / \mathrm{min}$ range, while the steady state concentration of $\bullet \mathrm{OH}$ is $\sim 0.7-2$ femtomole/L $\left(10^{-15} \mathrm{M}\right.$, fM) level upon 350 $\mathrm{nm}$ irradiation (Table 2.2). For $419 \mathrm{~nm}$ (Table 2.3), the $\bullet \mathrm{OH}$ formation rate is $10^{-2}$ $\mu \mathrm{M} / \mathrm{min}$ level, and the steady state concentration is $\sim 10^{-1}-10^{-2} \mathrm{fM}$. The wavelength of irradiation source plays a critical role in $\bullet \mathrm{OH}$ formation.

\begin{tabular}{|c|c|c|c|c|c|}
\hline & ${\mathrm{HGM}-\mathrm{TiO}_{2}}_{2}$ & $\mathrm{~S} \mathrm{TiO}_{2}$ & $\mathrm{NF} \mathrm{TiO}_{2}$ & Brookite $\mathrm{TiO}_{2}$ & $\mathrm{PF} \mathrm{TiO}_{2}$ \\
\hline Band gap & & 2.94 & 2.75 & 3.4 & 2.68 \\
\hline Energy $(\mathrm{eV})$ & & (Han et al., 2011) & & (Hu et al., 2009) & \\
\hline
\end{tabular}

Table 2.1 Band gap energy of $\mathrm{TiO}_{2}$ materials 


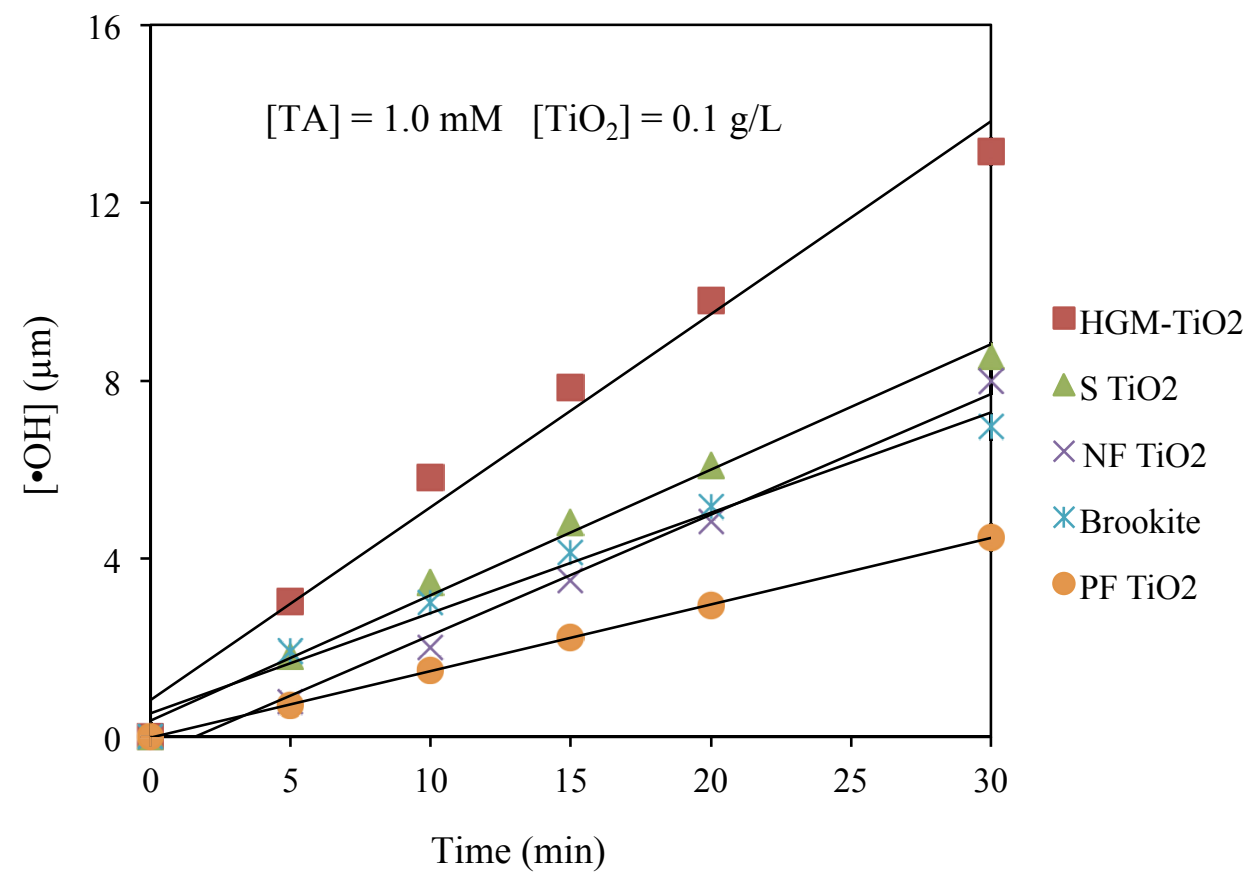

Figure 2.3 Hydroxyl radical yields by various $\mathrm{TiO}_{2}$ under $350 \mathrm{~nm}$ illumination

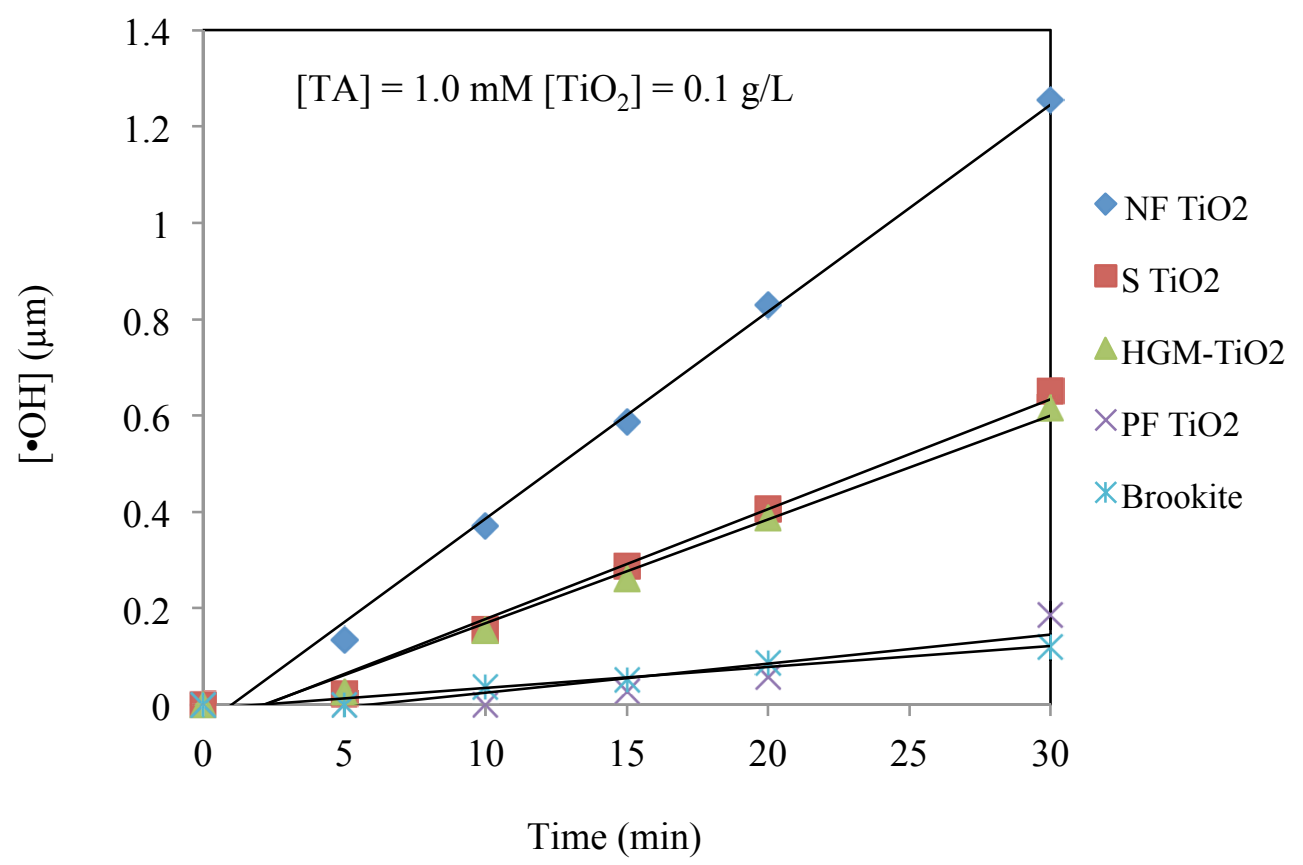

Figure 2.4 Hydroxyl radical yield by various $\mathrm{TiO}_{2}$ under $419 \mathrm{~nm}$ illumination 
Table 2.2 Kinetic constant of $\bullet \mathrm{OH}$ under $350 \mathrm{~nm}$ irradiation

\begin{tabular}{cccc}
\hline Catalyst & $\mathrm{k}_{0}(\mu \mathrm{M} / \mathrm{min})$ & $\mathrm{R}^{2}$ & {$[\cdot \mathrm{OH}]_{\mathrm{ss}}(\mathrm{fM})$} \\
\hline $\mathrm{NF} \mathrm{TiO}_{2}$ & 0.27 & 0.991 & 1.4 \\
${\mathrm{HGM}-\mathrm{TiO}_{2}}$ & 0.43 & 0.982 & 2.2 \\
$\mathrm{~S} \mathrm{TiO}_{2}$ & 0.28 & 0.992 & 1.4 \\
$\mathrm{Brookite}$ & 0.22 & 0.981 & 1.1 \\
$\mathrm{PF} \mathrm{TiO}_{2}$ & 0.15 & 0.999 & 0.76 \\
\hline
\end{tabular}

Table 2.3 Kinetic constants of $\bullet \mathrm{OH}$ under $419 \mathrm{~nm}$ irradiation

\begin{tabular}{cccc}
\hline Catalyst & $\mathrm{k}_{0}(\mu \mathrm{M} / \mathrm{min})$ & $\mathrm{R}^{2}$ & {$[\cdot \mathrm{OH}]_{\mathrm{ss}}(\mathrm{fM})$} \\
\hline $\mathrm{NF} \mathrm{TiO}_{2}$ & 0.043 & 0.996 & 0.22 \\
$\mathrm{~S} \mathrm{TiO}_{2}$ & 0.023 & 0.984 & 0.12 \\
$\mathrm{HGM}^{\mathrm{TiOO}}{ }_{2}$ & 0.022 & 0.985 & 0.11 \\
$\mathrm{PF} \mathrm{TiO}_{2}$ & 0.006 & 0.939 & 0.03 \\
${\mathrm{Brookite} \mathrm{TiO}_{2}}$ & 0.004 & 0.969 & 0.02 \\
\hline
\end{tabular}

\subsubsection{Formation of singlet oxygen}

In order to assess the efficiency of ${ }^{1} \mathrm{O}_{2}$ generation upon visible light irradiation, ${ }^{1} \mathrm{O}_{2}$ was identified and quantified using FFA as a scavenger compound since the generation of ${ }^{1} \mathrm{O}_{2}$ was correlated to the loss of FFA. The disappearance of FFA was measured as a function of time. The loss of FFA follows the pseudo-first order kinetic model. The pseudo-first order kinetic model can be expressed as: 


$$
-\frac{d[\mathrm{C}]}{d t}=\mathrm{k}_{1}[\mathrm{c}]
$$

After integration, the equation becomes

$$
\ln \frac{\mathrm{C}}{\mathrm{Co}}=-\mathrm{k}_{1} \mathrm{t}
$$

where $\mathrm{k}_{1}$ is the rate constant of pseudo-first order model $\left(\mathrm{s}^{-1}\right)$, and $\mathrm{t}$ is the time (s). Rate constants can be derived from the linear plots of $\ln C / C_{0}$ against time. The measurement of ${ }^{1} \mathrm{O}_{2}$ is performed upon visible light irradiation, so the reaction of FFA with hydroxyl radical is negligible. The steady state concentration of ${ }^{1} \mathrm{O}_{2}$ is derived from $\mathrm{k}_{1} / \mathrm{k}_{\mathrm{FFA}}$, where $\mathrm{k}_{\mathrm{FFA}}$ is the rate constant of FFA and ${ }^{1} \mathrm{O}_{2}\left(1.2 \times 10^{8} \mathrm{M}^{-1} \mathrm{~s}^{-1}\right)$ (Coelho et al., 2011). Singlet oxygen may be deactivated to return to its ground state by collision with water $\left(2.5 \times 10^{5} \mathrm{~s}^{-}\right.$ ${ }^{1}$ ), so the formation rate of ${ }^{1} \mathrm{O}_{2}\left(\mathrm{r}_{\mathrm{so}}\right)$ is $2.5 \times 10^{5} \times\left[{ }^{1} \mathrm{O}_{2}\right]_{\mathrm{ss}}$ (Vione et al., 2010). The kinetic parameters of ${ }^{1} \mathrm{O}_{2}$ generation of various $\mathrm{TiO}_{2}$ materials upon 419 and $450 \mathrm{~nm}$ irradiations are given in Table 2.4 and 2.5. The $\mathrm{R}^{2}$ indicates that the formation of ${ }^{1} \mathrm{O}_{2}$ fits the pseudofirst order model well under 419 and $450 \mathrm{~nm}$ irradiations. These kinetic parameters vary among catalysts. The steady state concentration of ${ }^{1} \mathrm{O}_{2}$ is $\sim$ picomole/L $\left(10^{-12} \mathrm{M}, \mathrm{pM}\right)$ level and the formation rate of ${ }^{1} \mathrm{O}_{2}$ is $\sim 10^{-7} \mathrm{M} \mathrm{s}^{-1}$. Therefore, they have the same order of magnitude, implying that photocatalysts have the similar photoactivity of ${ }^{1} \mathrm{O}_{2}$ generation and ${ }^{1} \mathrm{O}_{2}$ may exhibit a similar contribution to $\mathrm{TiO}_{2}$ photocatalysis. ${ }^{1} \mathrm{O}_{2}$ is generated by an energy transfer followed by an inter-system crossing, so the mechanism is different from $\cdot \mathrm{OH}$ generation. The steady state concentration of ${ }^{1} \mathrm{O}_{2}$ is higher by 3-4 orders of magnitude than $\cdot \mathrm{OH}$, which is analogous to the generation of ${ }^{1} \mathrm{O}_{2}$ and $\bullet \mathrm{OH}$ by dissolved organic matter upon UV irradiation (Vione et al., 2010). The higher ${ }^{1} \mathrm{O}_{2}$ steady state concentration is likely due to higher ${ }^{1} \mathrm{O}_{2}$ formation rate. 
Table 2.4 Kinetic parameters of ${ }^{1} \mathrm{O}_{2}$ upon $419 \mathrm{~nm}$ irradiation

\begin{tabular}{ccccc}
\hline Catalyst & $\mathrm{k}_{1}\left(\mathrm{~s}^{-1}\right)$ & $\mathrm{R}^{2}$ & $\left.{ }^{1} \mathrm{O}_{2}\right]_{\mathrm{ss}}(\mathrm{pM})$ & $\mathrm{r}_{\mathrm{so}}\left(\mu \mathrm{M} \mathrm{s}^{-1}\right)$ \\
\hline $\mathrm{S}^{-\mathrm{TiO}_{2}}$ & $1.36 \times 10^{-4}$ & 0.993 & 1.13 & 0.28 \\
${\mathrm{PF}-\mathrm{TiO}_{2}}$ & $9.88 \times 10^{-5}$ & 0.989 & 0.82 & 0.20 \\
$\mathrm{NF}^{-\mathrm{TiO}_{2}}$ & $2.30 \times 10^{-4}$ & 0.977 & 1.92 & 0.48 \\
$\mathrm{HGM}^{\mathrm{TiO}}{ }_{2}$ & $1.81 \times 10^{-4}$ & 0.990 & 1.51 & 0.38 \\
${\text { Brookite } \mathrm{TiO}_{2}}^{2.89 \times 10^{-4}}$ & 0.950 & 2.41 & 0.60 \\
\hline
\end{tabular}

Table 2.5 Kinetic parameters of ${ }^{1} \mathrm{O}_{2}$ upon $450 \mathrm{~nm}$ irradiation

\begin{tabular}{ccccc}
\hline Catalyst & $\mathrm{k}_{1}\left(\mathrm{~s}^{-1}\right)$ & $\mathrm{R}^{2}$ & {$\left[{ }^{1} \mathrm{O}_{2}\right]_{\mathrm{ss}}(\mathrm{pM})$} & $\mathrm{r}_{\mathrm{so}}\left(\mu \mathrm{M} \mathrm{s}^{-1}\right)$ \\
\hline $\mathrm{S}^{-\mathrm{TiO}_{2}}$ & $1.03 \times 10^{-4}$ & 0.985 & 0.86 & 0.22 \\
${\mathrm{PF}-\mathrm{TiO}_{2}}$ & $1.61 \times 10^{-4}$ & 0.972 & 1.34 & 0.34 \\
$\mathrm{NF}^{-\mathrm{TiO}_{2}}$ & $1.80 \times 10^{-4}$ & 0.999 & 1.50 & 0.38 \\
${\mathrm{HGM}-\mathrm{TiO}_{2}}$ & $2.06 \times 10^{-4}$ & 0.996 & 1.72 & 0.43 \\
${\text { Brookite } \mathrm{TiO}_{2}}$ & $3.15 \times 10^{-4}$ & 0.961 & 2.62 & 0.66 \\
\hline
\end{tabular}

\subsection{Conclusions}

The formation of $\bullet \mathrm{OH}$ and ${ }^{1} \mathrm{O}_{2}$ by various $\mathrm{TiO}_{2}$ materials were measured using probes methods the transformation of TA into 2-HTA and degradation of FFA, respectively. The generation of $\bullet \mathrm{OH}$ upon is relative more efficient upon UV irradiation. The difference is mainly related to their formation mechanisms. The $\bullet \mathrm{OH}$ generation follows pseudo-zero order kinetics, and it is pseudo-first order kinetics for ${ }^{1} \mathrm{O}_{2}$ formation. Because of the extremely high reaction rate of $\bullet \mathrm{OH}$, its steady-state concentration is lower by 3-4 orders of magnitude than singlet oxygen. 
3 Optimization of Photocatalytic Performance of $\mathrm{TiO}_{2}$ Coated Glass Microspheres Using Response Surface Methodology and the Application for Degradation of Dimethyl Phthalate 


\subsection{Abstract}

Hollow glass microspheres coated with photocatalytic $\mathrm{TiO}_{2}\left(\mathrm{HGM}-\mathrm{TiO}_{2}\right)$, recently became commercially available and have the distinct advantages of easy separation and recovery after treatment. With this in mind, we determined the optimum conditions for hydroxyl radical generation from $\mathrm{HGM}-\mathrm{TiO}_{2}$ photocatalysis using response surface methodology (RSM). The hydroxyl radical yield and its average generation rate are critical parameters for practical applications of $\mathrm{TiO}_{2}$ photocatalysis. In this study, terephthalic acid was used as a hydroxyl radical trap because of the selective formation of the readily detectable hydroxyl radical adduct, 2-hydroxy terephthalic acid. Three independent variables, including loading of $\mathrm{HGM}-\mathrm{TiO}_{2}$, concentration of terephthalic acid and irradiation time, were investigated. The 3D response surface graphs of hydroxyl radical yield and average hydroxyl radical generation rate indicated that optimum conditions of loading of $\mathrm{HGM}^{-\mathrm{TiO}_{2}}$, concentration of terephthalate acid and irradiation time were $8.0 \mathrm{~g} / \mathrm{L}, 4.0 \mathrm{mM}$, and $20 \mathrm{~min}$, respectively. Under these optimized conditions, we measured the photocatalysis employing $\mathrm{HGM}-\mathrm{TiO}_{2}$ for the remediation of dimethyl phthalate (DMP), as a representative compound for problematic phthalate acid esters. $\mathrm{HGM}-\mathrm{TiO}_{2}$ photocatalysis leads to the rapid destruction of DMP and there is a linear correlation between the DMP destruction and hydroxyl radical production. The results of our study demonstrate RSM can be used to readily determine the optimal conditions for hydroxyl radical production and the subsequent treatment of target compounds may be correlated to the hydroxyl radical production during $\mathrm{HGM}-\mathrm{TiO}_{2}$ photocatalysis. 


\subsection{Key words}

Advanced oxidation; Photocatalysis; FTIR; Response surface methodology; Dimethyl phthalate remediation

\subsection{Introduction}

Access to clean water is a global problem and one of the primary causes of human health problems worldwide (O'Shea et al., 2012). $\mathrm{TiO}_{2}$ photocatalysis is an attractive method for the purification of water, due to its abilities to effectively degrade a tremendous variety of toxins and pollutants (Hoffmann et al., 1995). The degradation processes are initiated at the surface of $\mathrm{TiO}_{2}$ (Fox et al., 1993). When $\mathrm{TiO}_{2}$ is photoexcited by photons with energy equal to or greater than the band gap, an electron is promoted from the valence band to the empty conduction band, resulting in an electronhole pair. Electron-hole pairs can recombine or migrate to the surface and react with the adsorbed species on $\mathrm{TiO}_{2}$ surface. The process can generate a variety of reactive oxygen species (ROS), including hydroxyl radical, hydrogen peroxide, singlet oxygen, and superoxide anion radical. Among the ROS, hydroxyl radical is generally responsible for the degradation during $\mathrm{UV} \mathrm{TiO}_{2}$ photocatalysis in aqueous solution (Linsebigler et al., 1995) The processes initiated during $\mathrm{TiO}_{2}$ photocatalysis are represented in Eqs. 3.1-3.8. Hydroxyl radical is capable of reacting with most organic compounds and many inorganic compounds often at nearly diffusion controlled rates. Hydroxyl radical is a powerful electrophile and reacts with organic substances mainly by the addition to double and triple bonds, and aromatic rings, hydrogen-atom abstraction from $\mathrm{C}_{(\mathrm{sp} 3)}-\mathrm{H}$ bonds, and electron transfer pathways (Buxton et al., 1988). Since the performance of $\mathrm{TiO}_{2}$ photocatalysis for water treatment processes is highly dependent on hydroxyl radical, it is 
critical to evaluate and optimize experimental conditions for maximizing hydroxyl radical generation during $\mathrm{TiO}_{2}$ photocatalysis.

$$
\begin{aligned}
& \mathrm{TiO}_{2}+h v \rightarrow \mathrm{h}^{+}{ }_{\mathrm{VB}}+\mathrm{e}_{\mathrm{CB}}^{-} \\
& \mathrm{e}_{\mathrm{CB}}^{-}+\mathrm{O}_{2} \rightarrow \mathrm{O}_{2} \bullet^{-} \\
& 2 \mathrm{O}_{2} \bullet^{-}+2 \mathrm{H}_{2} \mathrm{O} \rightarrow \mathrm{H}_{2} \mathrm{O}_{2}+2 \mathrm{OH}^{-}+\mathrm{O}_{2} \\
& \mathrm{H}_{2} \mathrm{O}+\mathrm{h}^{+}{ }_{\mathrm{VB}} \rightarrow \cdot \mathrm{OH}+\mathrm{H}^{+} \\
& \mathrm{OH}^{-}+\mathrm{h}^{+}{ }_{\mathrm{VB}} \rightarrow \cdot \mathrm{OH} \\
& \mathrm{H}_{2} \mathrm{O}_{2}+\mathrm{e}_{\mathrm{CB}}^{-} \rightarrow \mathrm{OH}^{-}+\cdot \mathrm{OH} \\
& \mathrm{TiO}_{2}+h v+{ }^{3} \mathrm{O}_{2} \rightarrow \mathrm{TiO}_{2}+{ }^{1} \mathrm{O}_{2} \\
& \bullet \mathrm{OH}+\text { toxin } \rightarrow \text { oxidation product }
\end{aligned}
$$

In an attempt to improve the performance of $\mathrm{UV} \mathrm{TiO}_{2}$ photocatalysis, a variety of $\mathrm{TiO}_{2}$ materials have been developed, including surface modification (Kado et al., 2011), $\mathrm{TiO}_{2}$ films (Yogi et al., 2008), doped $\mathrm{TiO}_{2}$ (Graham et al., 2010), $\mathrm{TiO}_{2}$ nanotubes (Z. Liu et al., 2008), porous $\mathrm{TiO}_{2}$ microspheres (Wang et al., 2009) and microspheric cores covered with $\mathrm{TiO}_{2}$ shell/film ( $\mathrm{Li}$ et al., 2008). Among these means, microspheric cores covered with nano- or micro- sized shells are novel fabricated composite materials and have received significant attention (Jackson et al., 1991). As an important composite material, $\mathrm{HGM}-\mathrm{TiO}_{2}$, recently became commercially available and has the major advantages of easy separation and recovery. Thus, $\mathrm{HGM}-\mathrm{TiO}_{2}$ is promising for use in industrial wastewater treatment plants and gaseous pollutants reduction, due to unique properties, such as low density $\left(0.22 \mathrm{~g} / \mathrm{cm}^{3}\right)$, buoyancy, and transparency to visible light. 
However, detailed studies on the photocatalytic performance and applications of HGM$\mathrm{TiO}_{2}$ have received limited attention.

An excellent study on the optimization of the experimental conditions to produce the highest $\bullet \mathrm{OH}$ yield during photocatalysis using suspensions of Degussa $\mathrm{P} 25 \mathrm{TiO}_{2}$ has been reported (Eremia et al., 2008), but to the best of our knowledge there are no reports on optimized conditions for $\mathrm{HGM}-\mathrm{TiO}_{2}$ photocatalysis. The $\bullet \mathrm{OH}$ generation rate is also an important parameter, since a high generation rate results in rapid degradation and short reaction times to achieve specific treatment objectives. The specific experimental conditions are critical to generation rate and yield of $\bullet \mathrm{OH}$ during $\mathrm{HGM}-\mathrm{TiO}_{2}$ photocatalysis. For example, as the concentration of catalyst increases, the photodegradation efficiency can increase to a maximum at a specific catalyst loading above which light scattering and screening may reduce the $\mathrm{TiO}_{2}$ photocatalytic efficiency. Terephthalic acid (TA) was employed to trap $\bullet \mathrm{OH}$ effectively and selectively. Although quenching and inter filter effects may occur at high TA concentrations, these issues are not significant under dilute concentrations (Ishibashi et al., 2000a). Another important factor is irradiation time. Since there are significant costs associated with generation of UV light, it is important to evaluate the treatment time required to achieve desired levels of degradation. From our study, $\cdot \mathrm{OH}$ yield increases, whereas $\cdot \mathrm{OH}$ generation rate decreases under extended irradiation time. Photocatalytic deactivation can occur when the intermediate products compete for radical species $(\bullet \mathrm{OH})$ leading to inhibition of the photocatalytic performance (Cao et al., 2000). Therefore, it is critical to determine the optimal yield and rate of $\bullet \mathrm{OH}$ generation, as a function of loading of $\mathrm{HGM}-\mathrm{TiO}_{2}$, concentration of TA and irradiation time. 
The classical one-variable-at-a-time methodology does not enable the study of combined effects of two or more variables on a measured response. Probing each variable independently is also labor intensive and time consuming. Thus, RSM was originally developed by Box and Wilson (Box et al., 1951), to access the interactions of various variables simultaneously and provide an empirical description of effects of variables and their interactions on a measured response. The RSM has successfully applied to determine the optimal conditions for a variety of processes (Arslan-Alaton et al., 2009). Herein, RSM is used to optimize yield and average generation rate of $\bullet \mathrm{OH}$ by $\mathrm{HGM}-\mathrm{TiO}_{2}$ photocatalysis. A central composite design was used to investigate the effects of three independent variables, namely loading of $\mathrm{HGM}-\mathrm{TiO}_{2}$, concentration of TA, and reaction time coded at five levels.

The RSM results were used to guide the application of $\mathrm{HGM}^{-\mathrm{TiO}_{2}}$ photocatalysis in the photocatalytic degradation of DMP, as a model for problematic phthalate acid esters which have wide spread use and an annual production of approximately 4 million tons (Lin et al., 2003). The US Environmental Protection Agency and European Union have classified these compounds as priority pollutants (Hansen et al., 1999) because of the significant threat they pose on reproductive and behavioral health of humans and wildlife at low concentrations (Matsumoto et al., 2008). $\mathrm{HGM}-\mathrm{TiO}_{2}$ photocatalysis leads to the rapid destruction of DMP and there is a linear correlation between the DMP destruction and hydroxyl radical production. The results of our study demonstrate RSM can be used to readily determine the optimal conditions for hydroxyl radical production and the subsequent treatment of target compounds can be correlated to the hydroxyl radical production during $\mathrm{HGM}-\mathrm{TiO}_{2}$ photocatalysis. 


\subsection{Materials and methods}

\subsubsection{Chemicals}

$\mathrm{HGM}-\mathrm{TiO}_{2}$ material was obtained from Microsphere Technology Limited (Limerick, Ireland). The characterization information of this material (including median

diameter, particle size) is available from the company website http://www.microspheretechnology.com/photospheres.php. TA (disodium salt) and DMP were purchased from Aldrich. HPLC grade methanol was obtained from Fisher. 2hydroxy terephthalic acid (2-HTA) was synthesized for calibration by using a published method (Mason et al., 1994). All the chemicals were used without further purification and all solutions were made with Millipore filtered water $(18 \mathrm{M} \Omega \cdot \mathrm{cm})$.

\subsubsection{Fourier transform infrared spectroscopy (FTIR)}

The TA and DMP loaded $\mathrm{HGM}-\mathrm{TiO}_{2}$ were prepared by adding $1.0{\mathrm{~g} \mathrm{HGM}-\mathrm{TiO}_{2}}$ into $100 \mathrm{~mL}$ solution with $1.0 \mathrm{~g}$ TA or DMP. The suspension was put on an orbit shaker at 300 RPM for half an hour. Solid samples for FTIR were separated, and dried in a vacuum oven at room temperature. FTIR was collected using Perkin Elmer Spectrum 100 FTIR spectrometer.

\subsubsection{Photocatalytic and analytical methods}

HGM-TiO 2 suspension was prepared by suspending $\mathrm{HGM}^{-\mathrm{TiO}_{2}}$ into $100 \mathrm{~mL}$ TA aqueous solution in a Pyrex cylindrical reactor $(12 \times 1$ inch, $\sim 150 \mathrm{~mL}$ capacity, with a vented Teflon screw top). The suspension was magnetically stirred and purged with oxygen gently for 15 min prior to radiation and during the reaction, in order to maintain the adsorption/desorption equilibrium. The suspensions were irradiated in a Rayonet photochemical reactor (Southern New England Ultra Violet Company, www.rayonet.org, 
model RPR-100), equipped with a cooling fan on the bottom and four phosphor-coated low-pressure mercury lamps (RPR $350 \mathrm{~nm}, 8.34 \times 10^{-9}$ Einstein $\left.\mathrm{mL}^{-1} \mathrm{~s}^{-1}\right)$. Samples (3 $\mathrm{mL}$ ) were taken from the suspension at given time intervals and immediately filtered through a $0.45 \mu \mathrm{m}$ PTFE filter to remove suspended particles prior to analysis.

TA is used to selectively trap $\cdot \mathrm{OH}$ and to produce 2 -HTA with a percent yield of $35 \%$ (Fang et al., 1996) (Scheme 3.1). The yield of $\bullet \mathrm{OH}$ is quantified by fluorescent measurement of the generated 2-HTA. 2-HTA was excited at $315 \mathrm{~nm}$ to emit fluorescence at $425 \mathrm{~nm}$ (Ishibashi et al., 2000b), which was measured on a Horiba FluoroMax 3 spectrofluorometer.

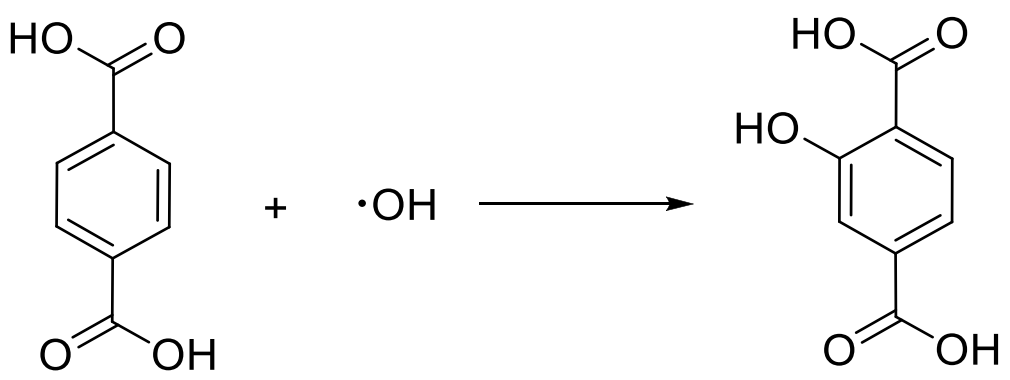

Scheme 3.1. Reaction of TA with $\cdot \mathrm{OH}$

\subsubsection{Experimental design and data analysis}

To identify best combination of experimental parameters for optimal $\cdot \mathrm{OH}$ generation, RSM was applied. Central composite design was employed for the optimal conditions. A full factorial 5-level experimental design with 3 variables needs to run $5^{3}=$ 125 experiments. However, as shown in Table 3.1, application of the central composite design reduces the number of required experiments to 20 ( 8 factor points, 6 axial points and 6 replications at the center points) (Parilti et al., 2011). Alpha $(\alpha)$ is the coded level of axial point from the center. The coded level is $\left(\mathrm{x}_{\mathrm{i}}\right)$ defined by the following equation:

$$
\mathrm{X}_{\mathrm{i}}=\left(\mathrm{X}_{\mathrm{i}}-\mathrm{X}_{0}\right) / \Delta \mathrm{X}_{\mathrm{i}}
$$


where, $\mathrm{X}_{0}$ is the real value of the independent variable at the center point, $\mathrm{X}_{\mathrm{i}}$ is the real value of the independent variable, and $\Delta \mathrm{X}_{\mathrm{i}}$ is the step changing value.

Table 3.1 Central composite design for RSM

\begin{tabular}{|c|c|c|c|}
\hline \multirow{2}{*}{ Experiment entry } & \multicolumn{3}{|c|}{ Variable in coded levels } \\
\hline & $x_{1}$ & $x_{2}$ & $x_{3}$ \\
\hline 1 & -1 & -1 & -1 \\
\hline 2 & -1 & -1 & 1 \\
\hline 3 & -1 & 1 & -1 \\
\hline 4 & -1 & 1 & 1 \\
\hline 5 & 1 & 1 & 1 \\
\hline 6 & 1 & 1 & -1 \\
\hline 7 & 1 & -1 & 1 \\
\hline 8 & 1 & -1 & -1 \\
\hline 9 & 0 & 0 & $\alpha$ \\
\hline 10 & 0 & 0 & $-\alpha$ \\
\hline 11 & 0 & $\alpha$ & 0 \\
\hline 12 & 0 & $-\alpha$ & 0 \\
\hline 13 & $\alpha$ & 0 & 0 \\
\hline 14 & $-\alpha$ & 0 & 0 \\
\hline 15 & 0 & 0 & 0 \\
\hline 16 & 0 & 0 & 0 \\
\hline 17 & 0 & 0 & 0 \\
\hline 18 & 0 & 0 & 0 \\
\hline 19 & 0 & 0 & 0 \\
\hline 20 & 0 & 0 & 0 \\
\hline
\end{tabular}


In this study, the loading of $\mathrm{HGM}-\mathrm{TiO}_{2}\left(\mathrm{X}_{1}\right)$, TA concentration $\left(\mathrm{X}_{2}\right)$ and irradiation time $\left(\mathrm{X}_{3}\right)$ were varied. The real levels and coded levels are showed in Table 3.2. The equation can quantitatively describe the predicted response as a function of three variables and the optima of three variables are obtained by surface response. Herein, $\mathrm{Y}$ is the yield of $\bullet \mathrm{OH}$ or its average generation rate, which is defined by the following equation:

$$
Y=b_{0}+b_{1} X_{1}+b_{2} X_{2}+b_{3} X_{3}+b_{12} X_{1} X_{2}+b_{13} X_{1} X_{3}+b_{23} X_{2} X_{3}+b_{11} X_{1}^{2}+b_{22} X_{2}^{2}+b_{33} X_{3}^{2}
$$

where $\mathrm{Y}$ is the predicted response, $\mathrm{b}_{0}$ is the intercept, $\mathrm{b}_{1}, \mathrm{~b}_{2}$ and $\mathrm{b}_{3}$ are linear coefficients, $b_{12}, b_{13}$ and $b_{23}$ are squared coefficients, $b_{11}, b_{22}$ and $b_{33}$ are quadratic coefficients.

Table 3.2 Real and coded levels of three variables

\begin{tabular}{|c|c|c|c|c|c|c|}
\hline \multirow{2}{*}{ Variable } & \multirow{2}{*}{ Symbol coded } & \multicolumn{5}{|c|}{ Coded level } \\
\hline & & $-\alpha(-2)$ & -1 & 0 & 1 & $\alpha(2)$ \\
\hline$\left[\mathrm{HGM}-\mathrm{TiO}_{2}\right](\mathrm{g} / \mathrm{L})$ & $\mathrm{X}_{1}$ & 2 & 4 & 6 & 8 & 10 \\
\hline$[\mathrm{TA}](\mathrm{mM})$ & $\mathrm{X}_{2}$ & 1 & 2 & 3 & 4 & 5 \\
\hline Irradiation time (min) & $\mathrm{X}_{3}$ & 5 & 10 & 15 & 20 & 25 \\
\hline
\end{tabular}

\subsubsection{Degradation and analysis of DMP}

The optimal conditions for the generation of $\bullet \mathrm{OH}$ were employed for degradation of DMP. The concentration of DMP residual was analyzed using a Varian ProStar HPLC system equipped with a ProStar 410 autosampler and a ProStar 335 photodiode array detector with the stationary phase being a Luna RP C18 column of $250 \times 4.6 \mathrm{~mm}$ I.D. (5 $\mu \mathrm{m}$ particle size). The mobile phase consisted of a mixture of water (50\%) and methanol (50\%), and detection wavelength was $230 \mathrm{~nm}$. The flow rate was $1 \mathrm{~mL} \mathrm{~min}^{-1}$ and the 
injection volume is $30 \mu \mathrm{L}$ at room temperature (Chen et al., 2009). The retention time of DMP is $\sim 12.2$ min under these HPLC conditions.

\subsection{Results and discussions}

\subsubsection{FTIR}

The FTIR spectra of were recorded in the range $600-4000 \mathrm{~cm}^{-1}$ to identify the functional groups of $\mathrm{HGM}-\mathrm{TiO}_{2}$ and access the adsorption of TA and DMP onto HGM$\mathrm{TiO}_{2}$ (Figure 3.1). For the neat $\mathrm{HGM}-\mathrm{TiO}_{2}$ sample, the infrared band at $3374 \mathrm{~cm}^{-1}$ shows the presence of OH stretching vibration (Burgos et al., 1999), while the IR band at $1631 \mathrm{~cm}^{-1}$ is ascribed to $\mathrm{Si}-\mathrm{H}_{2} \mathrm{O}$ adsorption (Ding et al., 2003; Wang et al., 2007). The peak at $1404 \mathrm{~cm}^{-1}$ corresponds to O-H bending mode (B. P. Singh et al., 2012), the band at $1019 \mathrm{~cm}^{-1}$ corresponds to Si-OH and Si-O-Ti vibration modes (Zhai et al., 1999) while a Ti-O-Ti band appears at $787 \mathrm{~cm}^{-1}$. These assignments clearly demonstrate the HGM$\mathrm{TiO}_{2}$ contains characteristic bands associated with $\mathrm{TiO}_{2}$ and glass (Minella et al., 2009). The DMP loaded $\mathrm{HGM}-\mathrm{TiO}_{2}$ materials exhibit a band at $2954 \mathrm{~cm}^{-1}$ corresponding to Csp ${ }^{3}-\mathrm{H}$ stretching (Ibarra et al., 1996), a band at $1727 \mathrm{~cm}^{-1}$ is assigned to $\mathrm{C}=\mathrm{O}$ stretching (Khare et al., 2002), a C-O stretching band at $1289 \mathrm{~cm}^{-1}$, a band at $743 \mathrm{~cm}^{-1}$ indicative of ortho-disubstituted benzene ring (Liu et al., 2006) and a band at $1434 \mathrm{~cm}^{-1}$ is assigned to $\mathrm{C}-\mathrm{H}$ group (Matuana et al., 2001). For TA loaded $\mathrm{HGM}^{-\mathrm{TiO}_{2}}$, the band at $1555 \mathrm{~cm}^{-1}$

corresponds to antisymmetric $-\mathrm{CO}_{2}$ stretching (Liao et al., 2002), the band at $823 \mathrm{~cm}^{-1}$ is ascribed to $=\mathrm{C}-\mathrm{H}$ bending of an aromatic ring (Pavia et al., 2009). The remaining bands are ascribed to $\mathrm{HGM}-\mathrm{TiO}_{2}$. The results demonstrate adsorption of DMP and TA onto the $\mathrm{HGM}-\mathrm{TiO}_{2}$ materials. 


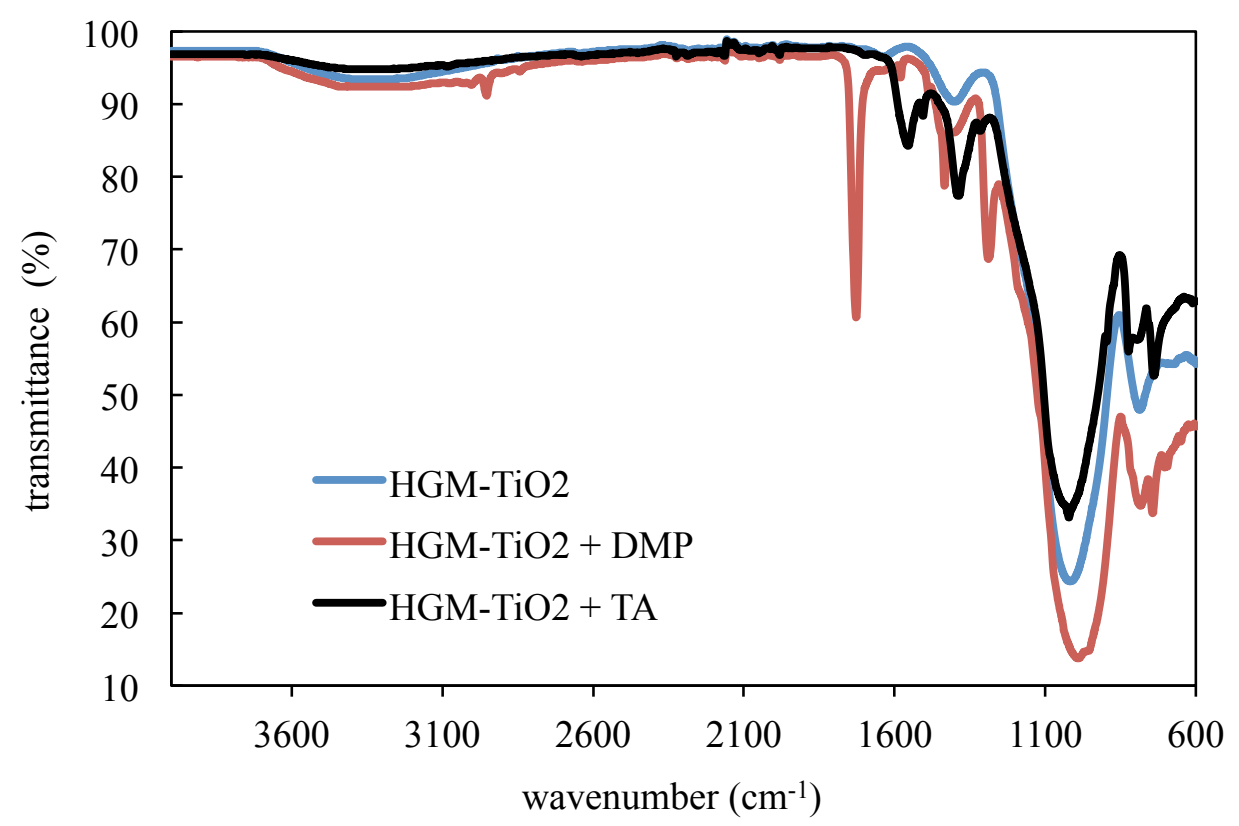

Figure 3.1 FTIR spectra of $\mathrm{HGM}-\mathrm{TiO}_{2}$, TA- and DMP- loaded onto $\mathrm{HGM}-\mathrm{TiO}_{2}$

\subsubsection{Model fitting and 3-D response surface}

The data of $\bullet \mathrm{OH}$ yield and average rate of $\bullet \mathrm{OH}$ generation are shown in Table

3.3. The experimental data were fitted to empirical second-order polynomial models by a regression function in Microsoft Excel 2007. The results indicate that the experimental and expected responses match well, and the experimental responses fit the second-order polynomials well. The empirical second-order polynomials were obtained as the following two equations:

$$
\begin{aligned}
& \mathrm{Y}_{1}=-98.78+20.49 \mathrm{X}_{1}+41.91 \mathrm{X}_{2}+7.28 \mathrm{X}_{3}+1.48 \mathrm{X}_{1} \mathrm{X}_{2}+0.15 \mathrm{X}_{1} \mathrm{X}_{3}+0.91 \mathrm{X}_{2} \mathrm{X}_{3}- \\
& 1.45 \mathrm{X}_{1}^{2}-8.39 \mathrm{X}_{2}^{2}-0.16 \mathrm{X}_{3}^{2} \\
& \mathrm{Y}_{2}=6.71+2.02 \mathrm{X}_{1}+3.81 \mathrm{X}_{2}-0.93 \mathrm{X}_{3}+0.096 \mathrm{X}_{1} \mathrm{X}_{2}-0.027 \mathrm{X}_{1} \mathrm{X}_{3}+0.0015 \mathrm{X}_{2} \mathrm{X}_{3}-0.10 \mathrm{X}_{1}^{2}- \\
& 0.58 \mathrm{X}_{2}{ }^{2}+0.022 \mathrm{X}_{3}^{2}
\end{aligned}
$$


where $Y_{1}$ is the predicted response of yield of generated $\bullet \mathrm{OH}(\mu \mathrm{M}), \mathrm{Y}_{2}$ is the predicted average generation rate of $\bullet \mathrm{OH}(\mu \mathrm{M} / \mathrm{min})$, the variables of $\mathrm{X}_{1}, \mathrm{X}_{2}$ and $\mathrm{X}_{3}$ are the loading of $\mathrm{HGM}_{-\mathrm{TiO}}(\mathrm{g} / \mathrm{L})$, concentration of TA $(\mathrm{mM})$ and irradiation time (min), respectively.

Table 3.3 RSM central composite design and experimental and expected responses

\begin{tabular}{|c|c|c|c|c|c|c|}
\hline $\mathrm{X}_{1}$ & $\mathrm{X}_{2}$ & $\mathrm{X}_{3}$ & Experimental $\mathrm{Y}_{1}$ & Predicted $\mathrm{Y}_{1}$ & Experimental $\mathrm{Y}_{2}$ & Predicted $\mathrm{Y}_{2}$ \\
\hline 6 & 3 & 5 & 95.8 & 99.4 & 19.17 & 18.28 \\
\hline 6 & 3 & 15 & 176.7 & 176.5 & 11.78 & 11.80 \\
\hline 6 & 3 & 25 & 228.2 & 221.6 & 9.13 & 9.73 \\
\hline 2 & 3 & 15 & 108.0 & 114.1 & 7.20 & 7.39 \\
\hline 10 & 3 & 15 & 202.1 & 192.4 & 13.47 & 13.02 \\
\hline 6 & 1 & 15 & 115.0 & 114.7 & 7.67 & 7.63 \\
\hline 6 & 5 & 15 & 174.4 & 171.1 & 11.63 & 11.34 \\
\hline 4 & 2 & 10 & 107.0 & 103.1 & 10.70 & 11.11 \\
\hline 4 & 2 & 20 & 152.0 & 152.1 & 7.60 & 7.36 \\
\hline 8 & 2 & 10 & 131.5 & 133.3 & 13.15 & 14.08 \\
\hline 8 & 2 & 20 & 178.0 & 188.3 & 8.90 & 9.25 \\
\hline 4 & 4 & 10 & 120.9 & 116.3 & 12.09 & 12.57 \\
\hline 4 & 4 & 20 & 179.5 & 183.5 & 8.97 & 8.85 \\
\hline 8 & 4 & 10 & 152.6 & 158.3 & 15.26 & 16.30 \\
\hline 8 & 4 & 20 & 221.9 & 231.5 & 11.09 & 11.50 \\
\hline 6 & 3 & 15 & 175.9 & 176.5 & 11.72 & 11.80 \\
\hline 6 & 3 & 15 & 177.4 & 176.5 & 11.83 & 11.80 \\
\hline 6 & 3 & 15 & 176.9 & 176.5 & 11.79 & 11.80 \\
\hline 6 & 3 & 15 & 176.0 & 176.5 & 11.73 & 11.80 \\
\hline 6 & 3 & 15 & 177.5 & 176.5 & 11.83 & 11.80 \\
\hline
\end{tabular}


In order to check the adequacy of the second-order models, the significance test and analysis of variance (ANOVA) were employed for the second-order models for $\bullet \mathrm{OH}$ yield and the average $\bullet \mathrm{OH}$ generation rate. The significance tests of estimated regression coefficients for $\bullet \mathrm{OH}$ yield and average $\bullet \mathrm{OH}$ generation rate are shown in Table 3.4. The probability value $(\mathrm{P})$ of coefficients was greater than 0.05 , indicating the term did not have a significant effect on the predicted response. Otherwise, it was rejected and this term influenced the predicted response at a significant confidence level. For Eq. 3.11 and 3.12, $X_{1}, X_{2}, X_{3}, X_{1} X_{1}, X_{2} X_{2}$ and $X_{3} X_{3}$ were significant terms for the predicted response, and $X_{1} X_{2}, X_{1} X_{3}$ and $X_{2} X_{3}$ were insignificant terms. The determination coefficient $\left(R^{2}\right)$ for $\bullet \mathrm{OH}$ yield was calculated as 0.982 , which can explain the variability of response at a 0.982 confidence level. Moreover, the adjusted $\mathrm{R}^{2}$ value of 0.966 was also close to 1 . For $\mathrm{Y}_{2}, \mathrm{R}^{2}$ was 0.974 and adjusted $\mathrm{R}^{2}$ was 0.951 . Therefore, as well as the model for $\bullet \mathrm{OH}$ yield, the predicted values had a good agreement with experimental data.

The response surface models were further analyzed by ANOVA and the output results are summarized in Table 3.5. The $\mathrm{P}$ value of regression model was less than 0.05 , so the models were adequate to describe the variability of $Y_{1}$ and $Y_{2}$ as a function of $X_{1}$, $\mathrm{X}_{2}$ and $\mathrm{X}_{3}$. The linear and square effects were highly significant for the predicted responses, whereas the interaction effects were insignificant. In conclusion, both Eq. 3.11 and Eq. 3.12 are good approximations. 
Table 3.4 Estimated regression coefficients for $\bullet \mathrm{OH}$ yield and the average $\bullet \mathrm{OH}$ generation rate

\begin{tabular}{l|lll|lll}
\hline & \multicolumn{5}{|c|}{$\cdot$ OH yield } & \multicolumn{3}{|c}{ average $\bullet$ OH generation rate } \\
\hline Term & Coefficient & Std. Error & $\mathrm{P}$ & Coefficient & Std. Error & $\mathrm{P}$ \\
\hline $\mathrm{X}_{1}$ & 20.49 & 6.71 & 0.012 & 2.02 & 0.60 & 0.007 \\
$\mathrm{X}_{2}$ & 41.91 & 13.43 & 0.011 & 3.81 & 1.19 & 0.010 \\
$\mathrm{X}_{3}$ & 7.28 & 2.69 & 0.022 & -0.93 & 0.24 & 0.003 \\
$\mathrm{X}_{1} \mathrm{X}_{2}$ & 1.48 & 1.23 & 0.256 & 0.096 & 0.11 & 0.398 \\
$\mathrm{X}_{1} \mathrm{X}_{3}$ & 0.15 & 0.24 & 0.550 & -0.027 & 0.022 & 0.236 \\
$\mathrm{X}_{2} \mathrm{X}_{3}$ & 0.91 & 0.49 & 0.093 & 0.0015 & 0.044 & 0.973 \\
$\mathrm{X}_{1} \mathrm{X}_{1}$ & -1.45 & 0.35 & 0.002 & -0.10 & 0.031 & 0.008 \\
$\mathrm{X}_{2} \mathrm{X}_{2}$ & -8.39 & 1.38 & 0.000 & -0.58 & 0.12 & 0.001 \\
$\mathrm{X}_{3} \mathrm{X}_{3}$ & -0.16 & 0.055 & 0.015 & 0.022 & 0.0049 & 0.001 \\
\hline
\end{tabular}

Table 3.5 ANOVA for the second-order models of $\bullet \mathrm{OH}$ yield and average $\bullet \mathrm{OH}$ generation rate

\begin{tabular}{|c|c|c|c|c|c|c|c|c|}
\hline & \multicolumn{4}{|c|}{$\cdot \mathrm{OH}$ yield } & \multicolumn{4}{|c|}{ average $\cdot \mathrm{OH}$ generation rate } \\
\hline Source & $\mathrm{DF}^{\mathrm{a}}$ & $\begin{array}{l}\text { Sum of } \\
\text { squares }\end{array}$ & $\mathrm{F}$ & $\mathrm{P}$ & $\mathrm{DF}$ & $\begin{array}{l}\text { Sum of } \\
\text { squares }\end{array}$ & $\mathrm{F}$ & $\mathrm{P}$ \\
\hline Regression & 9 & 26446.4 & 60.99 & 0.000 & 9 & 144.03 & 42.08 & 0.000 \\
\hline Linear & 3 & 23932.0 & 5.02 & 0.022 & 3 & 118.47 & 19.02 & 0.000 \\
\hline Square & 3 & 2260.3 & 15.64 & 0.000 & 3 & 24.65 & 21.61 & 0.000 \\
\hline Interaction & 3 & 254.0 & 1.76 & 0.219 & 3 & 0.90 & 0.79 & 0.526 \\
\hline $\begin{array}{l}\text { Residual } \\
\text { error }\end{array}$ & 10 & 481.8 & & & 10 & 3.80 & & \\
\hline Total & 19 & 26928.2 & & & 19 & 147.83 & & \\
\hline
\end{tabular}

${ }^{\mathrm{a}} \mathrm{DF}$ is degree of freedom 
To obtain the optimal conditions for $\cdot \mathrm{OH}$ generation, the $3 \mathrm{D}$ response surface technique was employed to evaluate the effects of independent variables on $Y_{1}$ and $Y_{2}$. Figure 3.2 shows the effect of any two independent variables on the $\bullet \mathrm{OH}$ yield and its average $\bullet \mathrm{OH}$ generation rate, keeping the coded level of the third one at its central level (0). Figure 3.2 a, $\mathbf{c}, \mathbf{d}$ and $\mathbf{f}$ demonstrate the effect of concentration of TA on $Y_{1}$ and $Y_{2}$. $Y_{1}$ and $Y_{2}$ increase with increase in concentration of TA until $Y_{1}$ and $Y_{2}$ reach a highest value. The optimal value of concentration of TA for $Y_{1}$ and $Y_{2}$ is $4.0 \mathrm{mM}$. The effect of loading of $\mathrm{HGM}-\mathrm{TiO}_{2}$ on $\mathrm{Y}_{1}$ and $\mathrm{Y}_{2}$ is shown in Figure 3.2 b, c, e and f. The optimal value of concentration of $\mathrm{HGM}^{-\mathrm{TiO}_{2}}$ on $\mathrm{Y}_{1}$ and $\mathrm{Y}_{2}$ is $8.0 \mathrm{~g} / \mathrm{L}$. Figure $3.2 \mathrm{a}, \mathbf{b}, \mathbf{d}$ and $\mathbf{e}$ demonstrate the effect of irradiation time on $\mathrm{Y}_{1}$ and $\mathrm{Y}_{2} \cdot \cdot \mathrm{OH}$ yield increases whereas the average $\cdot \mathrm{OH}$ generation rate decreases with increase in irradiation time. The competition for hydroxyl radical between TA and the oxidation products and TA consumption are factors leading to the observed decrease in $\bullet \mathrm{OH}$ generation rate. Although the overall $\cdot \mathrm{OH}$ yields increase with irradiation time, the rate of $\bullet \mathrm{OH}$ yield slowed significantly after $20 \mathrm{~min}$. Thus, the optimal time for $Y_{1}$ and $Y_{2}$ is $20 \mathrm{~min}$. In summary, the optimal conditions for the yield of $\bullet \mathrm{OH}$ were $8.0 \mathrm{~g} / \mathrm{L} \mathrm{HGM}-\mathrm{TiO}_{2}, 4.0 \mathrm{mM}$ TA and $20 \mathrm{~min}$ for irradiation time. 

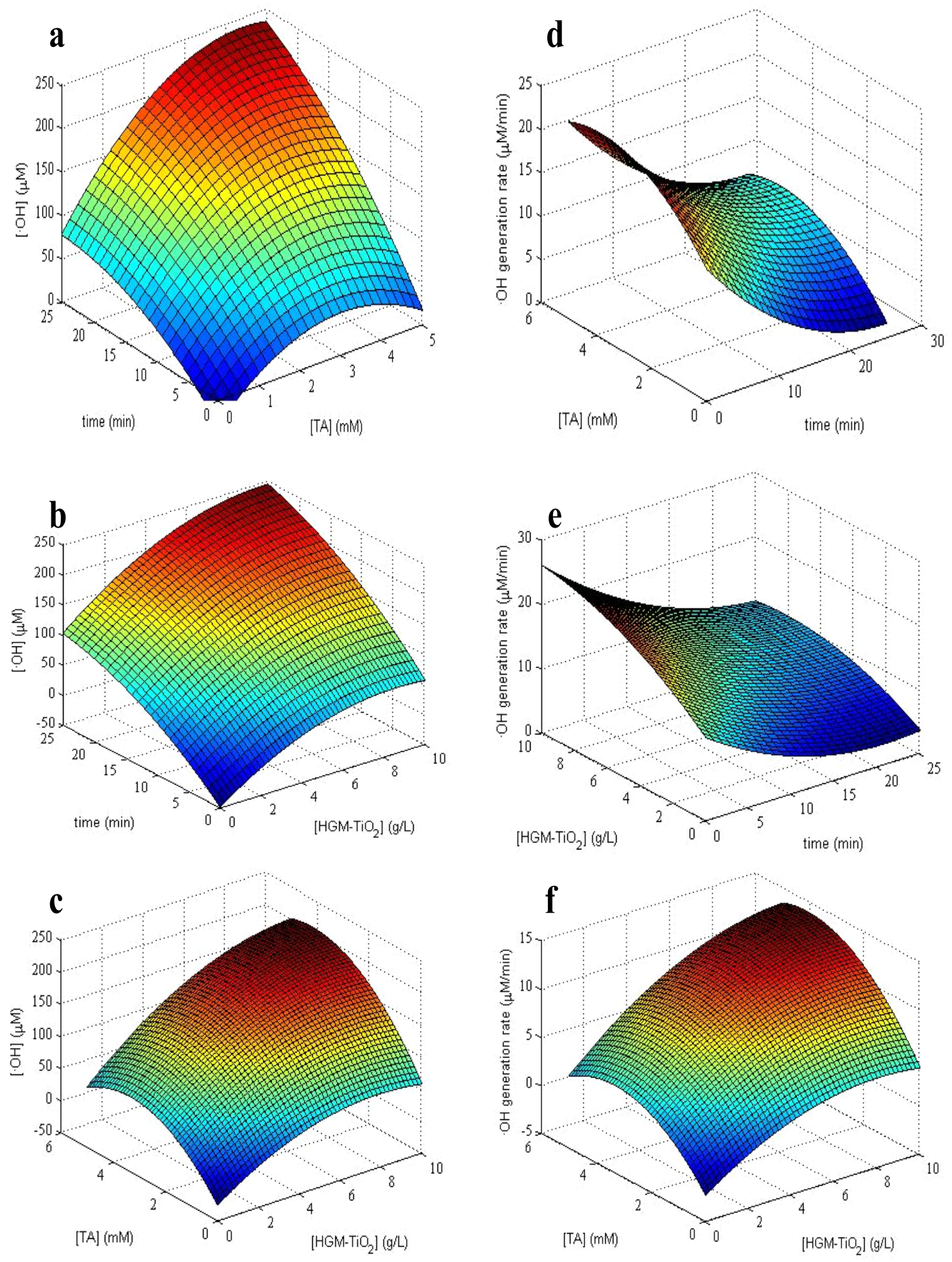

Figure 3.2 Response surface showing of any two independent variables on the $\bullet \mathrm{OH}$ yield $(\mathrm{a}, \mathrm{b}$, and $\mathrm{c})$ and its average $\bullet \mathrm{OH}$ generation rate $(\mathrm{d}, \mathrm{e}$, and $\mathrm{f})$ 


\subsubsection{The degradation of DMP}

The optimal conditions for the $\bullet \mathrm{OH}$ generation were applied for the degradation of DMP. The initial concentration of DMP is $50 \mu \mathrm{M}$. The loss of DMP follows the pseudo-first order kinetic model. The pseudo-first order kinetic model can be expressed as (Ye et al., 2009):

$$
d[\mathrm{C}] / d t=-\mathrm{k}[\mathrm{C}]
$$

After integration, the equation becomes

$$
\ln \left(\mathrm{C}_{0} / \mathrm{C}\right)=\mathrm{kt}
$$

where $\mathrm{k}$ is the rate constant of pseudo-first order model $\left(\mathrm{min}^{-1}\right)$, $\mathrm{t}$ is time (min), $\mathrm{C}_{0}$ is the initial concentration of DMP $(\mu \mathrm{M})$ and $\mathrm{C}$ is the concentration of DMP $(\mu \mathrm{M})$ at the specific time. Since $\mathrm{R}^{2}$ of plot of $\operatorname{lnC}_{0} / \mathrm{C}$ versus $\mathrm{t}$ is greater than 0.95 , the experimental data fit the pseudo-first-order model nicely.

As shown in Figure 3.3, the rate constants for degradation of DMP increased with increase in loading of $\mathrm{HGM}-\mathrm{TiO}_{2}$, and reached the highest at $8.0 \mathrm{~g} / \mathrm{L} \mathrm{HGM}-\mathrm{TiO}_{2}$. No significant increase is observed at loading levels above $8.0 \mathrm{~g} / \mathrm{L} \mathrm{HGM}-\mathrm{TiO}_{2}$. At high loadings of $\mathrm{HGM}^{-\mathrm{TiO}_{2}}(>8.0 \mathrm{~g} / \mathrm{L})$, the rate does not change but the standard deviation becomes larger due to the light scattering and screening effects. Therefore, the loading of HGM-TiO $2=8.0 \mathrm{~g} / \mathrm{L}$ was considered optimal. In order to assess the relationship between $\cdot \mathrm{OH}$ yield and degradation of DMP, the plot of degraded DMP against $\bullet \mathrm{OH}$ yield is demonstrated in Figure 3.4. The $\cdot \mathrm{OH}$ yield derived from Eq. 3.11 with the coded level of $\mathrm{X}_{2}$ at the central level (0) and $\mathrm{X}_{3}$ being 20 min, showing increased $\bullet \mathrm{OH}$ yield as the increasing of loading of $\mathrm{HGM}^{-\mathrm{TiO}_{2}}$ (2 to $10 \mathrm{~g} / \mathrm{L}$ ). After $20 \mathrm{~min}$, DMP was eliminated in presence of $\geq 8.0 \mathrm{~g} / \mathrm{L} H G M-\mathrm{TiO}_{2}$, in agreement with the optimal conditions of $\bullet \mathrm{OH}$ 
generation. The linear relationship between $\bullet \mathrm{OH}$ yield and DMP degradation indicates the $\cdot \mathrm{OH}$ is responsible for degradation of DMP. The bimolecular reaction rate constants for the reaction of $\bullet \mathrm{OH}$ with TA is $3.3 \times 10^{9} \mathrm{M}^{-1} \mathrm{~s}^{-1}$ (Song et al., 2012), while it is $4 \times 10^{9}$ $\mathrm{M}^{-1} \mathrm{~s}^{-1}$ for DMP (Haag et al., 1992). The rate constants are similar; however the trendline in Figure 3.4 demonstrates the destruction of DMP correlates to the $\cdot \mathrm{OH}$ yield, but not in a 1:1 ratio. The yield of $\bullet \mathrm{OH}$ and TA adduct versus destruction of DMP may be related to the different adsorption properties of DMP versus TA on $\mathrm{HGM}-\mathrm{TiO}_{2}$. Since $\bullet \mathrm{OH}$ is a relatively nonselective radical and is able to react with substance at nearly diffusion controlled rate, the oxidation products of DMP may be degraded further before they are released back to aqueous phase.

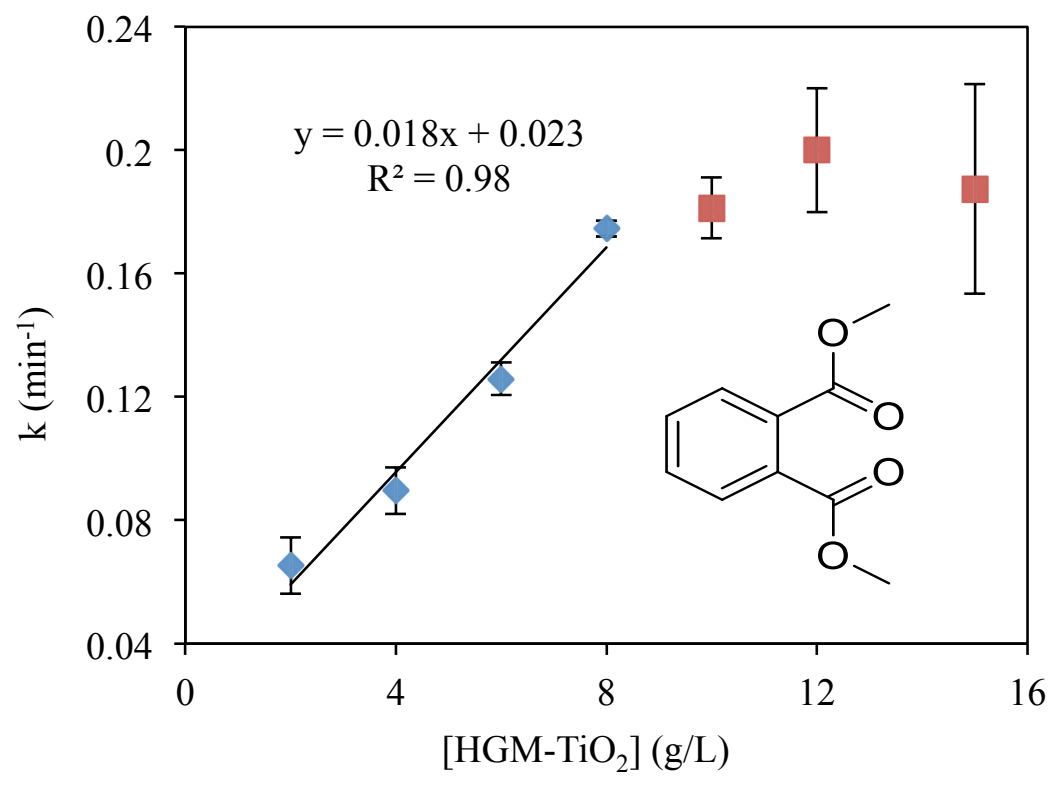

Figure 3.3 The rate constants of pseudo-first order kinetic model for degradation of DMP as a function of HGM-TiO2 loading. The data at 10,12 and $15 \mathrm{~g} / \mathrm{L}$ were not used for the trend-line since the rate did not increase above $8.0 \mathrm{~g} / \mathrm{L}$. Error bars represent standard deviation of triplicate experiments. The insert is the molecular structure of DMP. 


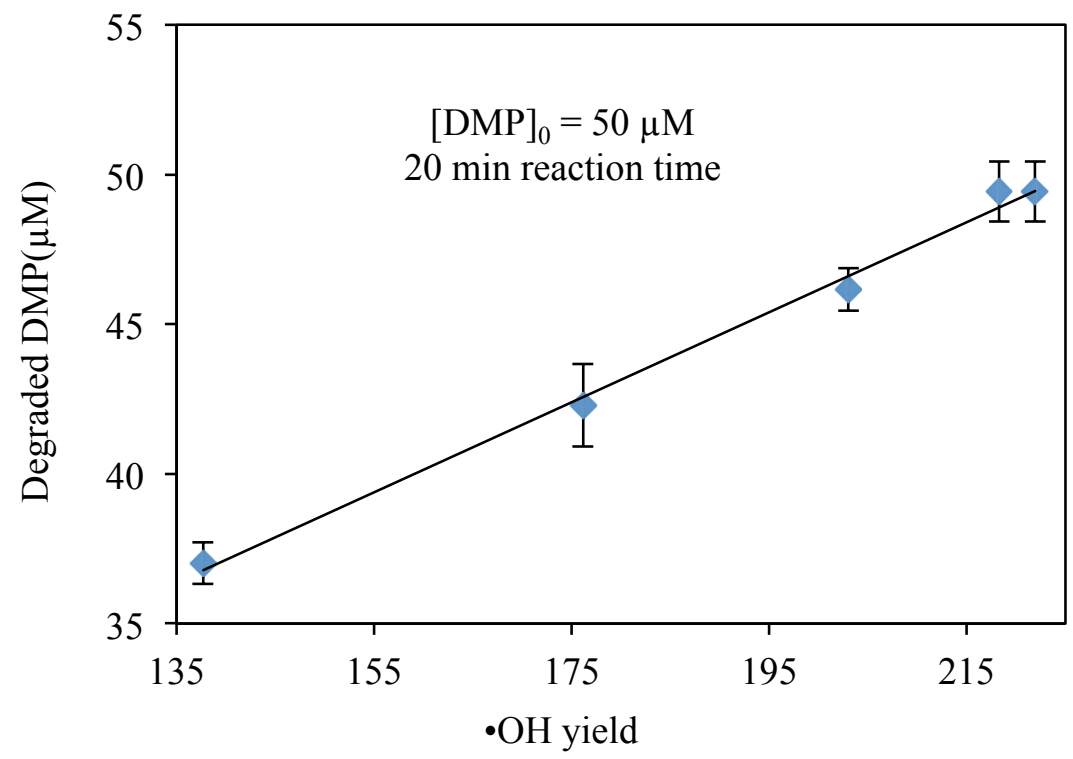

Figure 3.4. Plot of degraded DMP against $\bullet \mathrm{OH}$ yield. Error bars represent standard deviation of triplicate experiments.

\subsection{Conclusions}

The FTIR spectra show that the $\mathrm{HGM}-\mathrm{TiO}_{2}$ exhibits adsorption of $\mathrm{TA}(\cdot \mathrm{OH}$ trap) and DMP (target compound). The loading of $\mathrm{HGM}-\mathrm{TiO}_{2}$, the concentration of TA and

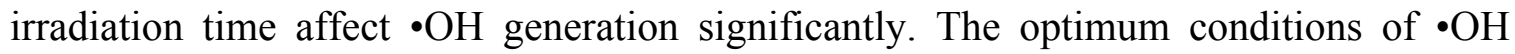
generation by $\mathrm{HGM}-\mathrm{TiO}_{2}$ were measured using RSM. Statistical analyses indicate the empirical second-order polynomials can accurately describe the $\bullet \mathrm{OH}$ yield and the average $\cdot \mathrm{OH}$ generation rate. The $3 \mathrm{D}$ response surface graphs showed that the optimum conditions of loading of $\mathrm{HGM}-\mathrm{TiO}_{2}$, concentration of TA and irradiation time were 8.0 $\mathrm{g} / \mathrm{L}, 4.0 \mathrm{mM}$, and $20 \mathrm{~min}$, respectively. The optimal condition for $\bullet \mathrm{OH}$ generation by HGM-TiO ${ }_{2}$ has applied to the degradation of DMP. The degradation of DMP follows the pseudo-first order kinetic model nicely, and rate constant increased linearly as increasing of loading of $\mathrm{HGM}-\mathrm{TiO}_{2}$ up to $8.0 \mathrm{~g} / \mathrm{L}$. We have demonstrated $\mathrm{RSM}$ can be used to determine the optimal conditions for $\bullet \mathrm{OH}$ generation. Employing the optimal conditions, 
the problematic pollutant, DMP, is readily degraded. The effective application of RSM for determining optimal conditions for hydroxyl radical production and rapid destruction of DMP show $\mathrm{HGM}-\mathrm{TiO}_{2}$ photocatalysis is a promising material for water treatment. 
4 Photocatalytic Degradation of Microcystin-LR by Rose Bengal: the Role of Singlet Oxygen 


\subsection{Abstract}

We used rose bengal (RB), a singlet oxygen $\left({ }^{1} \mathrm{O}_{2}\right)$ sensitizer, to study the photooxidative destruction of microcystin-LR (MC-LR). Under photolysis by visible or solar light no measureable degradation of MC-LR was observed in the absence of RB, however the concentration of MC-LR is significantly reduced under the same conditions in the presence of RB. The degradation of MC-LR in presence of $500 \mu \mathrm{M} R B$ follows the pseudo-first order kinetic model nicely. These results indicate RB can be used as a photosensitizer (catalyst) to effectively degrade MC-LR. Rate of degradation increase three fold under oxygen-saturated condition compared to argon-saturated condition, demonstrating that photo-oxidation is the predominant degradation process. Under argon saturation the degradation is likely because of the energy transfer between the RB* and MC-LR. Since the lifetime of ${ }^{1} \mathrm{O}_{2}$ in $\mathrm{D}_{2} \mathrm{O}$ is longer than in $\mathrm{H}_{2} \mathrm{O}$, the degradation of $\mathrm{MC}$ LR is enhanced in $\mathrm{D}_{2} \mathrm{O}$. The measured bimolecular reaction rate constant between $\mathrm{MC}$ LR and ${ }^{1} \mathrm{O}_{2}$ is $3.5 \times 10^{6} \mathrm{M}^{-1} \mathrm{~s}^{-1}$ using competition kinetics with furfuryl alcohol.

\subsection{Key Words}

Microcystin-LR, Rose bengal, Singlet oxygen, Photodegradation

\subsection{Introduction}

An emerging environmental issue is the increased occurrence of cyanobacteria (blue-green algae) in fresh water, and the bloom-forming cyanobacteria can produce and release cyanobacterial toxin in freshwater bodies, and microcystin (cyclic heptapeptides) is the most common toxin. The microcystins are reported to be potential tumor promoters. While approximately 80 variants of microcystins have been isolated and identified, microcystin-LR (MC-LR) is one of the most toxic and problematic variants 
(structure of MC-LR shown in Figure 4.1). Therefore, the World Health Organization recommended $1 \mu \mathrm{g} / \mathrm{L}$ as a guideline of MC-LR.<smiles>Cc1c2oc3c(C)c(O[N+](=O)[O-])c(I)cc3c(-c3c(Cl)c(Cl)c(Cl)c(Cl)c3C(=O)O)c-2cc(I)c1=O</smiles><smiles>C=C(C(=O)N[C@@H](C)C(=O)C[C@@H](CC(C)C)C(=O)N[C@H](C(=O)O)[C@@H](C)C(=O)N[C@@H](CCCNC(=N)N)C(=O)N[C@@H](/C=C/C(C)=C/[C@@H](C)[C@@H](Cc1ccccc1)OC)[C@@H](C)C(=O)S[C@@H](CCC(=O)N(C)C(=O)O)C(=O)O)[C@H](C)Cc1ccccc1</smiles>

Figure 4.1 Molecular structures of rose bengal (top) and MC-LR (bottom)

Conventional water treatment methods are often not effective or not practical for the removal of MC-LR. However, advanced oxidation processes (AOP) can be effective under specific conditions. Advanced oxidation processes involves the generation of 
reactive oxygen species (ROS), including hydroxyl radical, superoxide anion radical, singlet oxygen and hydrogen peroxide. Hydroxyl radical $(\cdot \mathrm{OH})$ is a strong oxidant and studied well for treatment of MC-LR (Song et al., 2009). Singlet oxygen $\left({ }^{1} \mathrm{O}_{2}\right)$ is another important ROS (Kearns, 1971), which can react with unsaturated organic compounds via ene-type reaction, [2+2] cycloaddition, and Diels-Alder reaction(Changseok et al., 2013). ${ }^{1} \mathrm{O}_{2}$ can be generated in the natural surface water in presence of dissolved organic matter (DOM) upon irradiation, since DOM is photoexcited to ${ }^{1} \mathrm{DOM}^{*}$, followed by intersystem crossing to ${ }^{3} \mathrm{DOM}^{*}$ and an energy transfer process between ${ }^{3} \mathrm{DOM}^{*}$ and triplet molecular oxygen $\left({ }^{3} \mathrm{O}_{2}\right)$. The biological activities of microcystins are associated with Adda (Carmichael et al., 1999). Robertson et al. proposed that the double bonds on the Adda moiety of MC-LR was susceptible to ${ }^{1} \mathrm{O}_{2}$ (Robertson et al., 1999), so ${ }^{1} \mathrm{O}_{2}$ can play an important role in the environmental fate and detoxification of MC-LR. However, the knowledge of role of singlet oxygen during MC-LR destruction is very limited. In this study, rose bengal (RB, shown in Fig. 1), ${ }^{1} \mathrm{O}_{2}$ sensitizer, is employed to study the photooxidative destruction of MC-LR.

$$
\begin{aligned}
& \mathrm{RB}+h v \rightarrow{ }^{1} \mathrm{RB} \rightarrow{ }^{3} \mathrm{RB} \\
& { }^{3} \mathrm{RB}+{ }^{3} \mathrm{O}_{2} \rightarrow \mathrm{RB}+{ }^{1} \mathrm{O}_{2}
\end{aligned}
$$

The main objective of current study was to conduct the kinetic study of the reaction of ${ }^{1} \mathrm{O}_{2}$ and MC-LR. The UV-vis absorbance spectrum of RB in water shows that it has a strong absorption of UV and visible light and the increased degradation of MC-LR in $\mathrm{D}_{2} \mathrm{O}$ indicates that ${ }^{1} \mathrm{O}_{2}$ plays a critical role in photodegradation of MC-LR. The results can also help understand the photochemical transformation of MC-LR by DOM in natural environments. 


\subsection{Experimental section}

\subsubsection{Materials}

Microcystin-LR was isolated and purified using a published method (Song et al., 2007). HPLC grade acetonitrile was purchased from Fisher. Furfuryl alcohol (FFA) and trifluoroacetic acid (TFA) were purchased from Acros Organics. All the solutions were prepared with Millipore filtered water $(18 \mathrm{M} \Omega \cdot \mathrm{cm})$.

\subsubsection{Experimental}

The UV-vis absorbance spectrum of rose Bengal in water was collected using a Cary 100-Bio UV/visible light spectrophotometer (Varian, Sugar Land, Tex). Rose bengal was employed as the sensitizer. Rose bengal concentration employed for our studies was $500 \mathrm{uM}$ and $[\mathrm{MC}-\mathrm{LR}]_{0}=5 \mathrm{ppm}$ unless otherwise stated. The solution was prepared in a Pyrex cylindrical reactor $(\sim 1 \times 4 \mathrm{inch}, \sim 20 \mathrm{~mL}$ capacities, with a vented Teflon screw top). The solution was purged with desired gas gently for 15 min prior to radiation and during the reaction, in order to saturate solution with desired gas. The solution was irradiated in a Rayonet photochemical reactor (Southern New England Ultra Violet Company, www.rayonet.org, model RPR-100), equipped with a cooling fan on the bottom and four phosphor-coated low-pressure mercury lamps (RPR $350 \mathrm{~nm}, 8.34 \times 10^{-9}$ Einstein $\left.\mathrm{mL}^{-1} \mathrm{~s}^{-1}\right)$. Aliquots were taken from the solution at given time intervals for analysis.

\subsubsection{Bimolecular reaction rate constant MC-LR and ${ }^{1} \mathrm{O}_{2}$}

The solution containing $50 \mathrm{uM}$ MC-LR, $50 \mathrm{uM}$ FFA and $500 \mathrm{uM} \mathrm{RB}$ was employed for determination of ${ }^{1} \mathrm{O}_{2}$ bimolecular reaction rate constant. Samples were measured at specific time intervals by HPLC. 


\subsubsection{Analytical method}

The concentration of MC-LR residual and FFA were analyzed using a Varian ProStar HPLC system equipped with a ProStar 410 autosampler and a ProStar 335 photodiode array detector with the stationary phase being a Luna RP C18 column of $250 \times 4.6 \mathrm{~mm}$ I.D. $(5 \mu \mathrm{m}$ particle size). The mobile phase consisted of a mixture of (A) $0.05 \%(\mathrm{v} / \mathrm{v})$ trifluoroacetic acid (TFA) in acetonitrile (40\%) and (B) $0.1 \%(\mathrm{v} / \mathrm{v})$ TFA aqueous solutions (60\%) (Antoniou et al., 2008). The flow rate was $1 \mathrm{~mL} \mathrm{~min}^{-1}$ and the injection volume is $30 \mu \mathrm{L}$ at room temperature. Detection wavelength was $238 \mathrm{~nm}$, and it is $219 \mathrm{~nm}$ for FFA. The retention time of MC-LR is $\sim 8.9 \mathrm{~min}$ and it is $\sim 4.1 \mathrm{~min}$ for $219 \mathrm{~nm}$ under these conditions.

\subsection{Results and discussion}

\subsubsection{Degradation of MC-LR by rose bengal}

When MC-LR solution is irradiated in absence of rose bengal (RB), no measureable degradation was observed in oxygen or argon saturation distilled water, implying that the direct photolysis had no effect on degradation of MC-LR. It is consistent with previous report the irradiation alone had no effect on the degradation of MC-LR(Robertson et al., 1999). Therefore, the sensitizer is necessary for this process.

In this study, we employed RB, a singlet oxygen $\left({ }^{1} \mathrm{O}_{2}\right)$ sensitizer, to study the photo-oxidative destruction of MC-LR. The UV-Vis absorption spectrum of RB (Figure 4.2) demonstrated a strong adsorption peak in the green region of the visible spectrum (495-565 nm), so ${ }^{1} \mathrm{O}_{2}$ can be generated via visible light irradiation of $\mathrm{RB}$. The photoexcited $\mathrm{RB}^{*}$ can interact with fundamental-state triplet oxygen, leading to the formation of ${ }^{1} \mathrm{O}_{2} .{ }^{1} \mathrm{O}_{2}$ is reactive oxygen species, which can react with unsaturated 
organic compounds via ene-type reaction, [2+2] cycloaddition, and Diels-Alder reaction. Thus, singlet oxygen mediated process may play an important role for degradation of MC-LR. Energy transfer is the other probable photocatalytic mechanism: degradation occurs by the interaction photoexcited RB* with MC-LR.

To study the role of energy transfer on degradation of MC-LR, the solution containing rose Bengal and MC-LR is purged with argon to eliminate the ${ }^{1} \mathrm{O}_{2}$ generation.

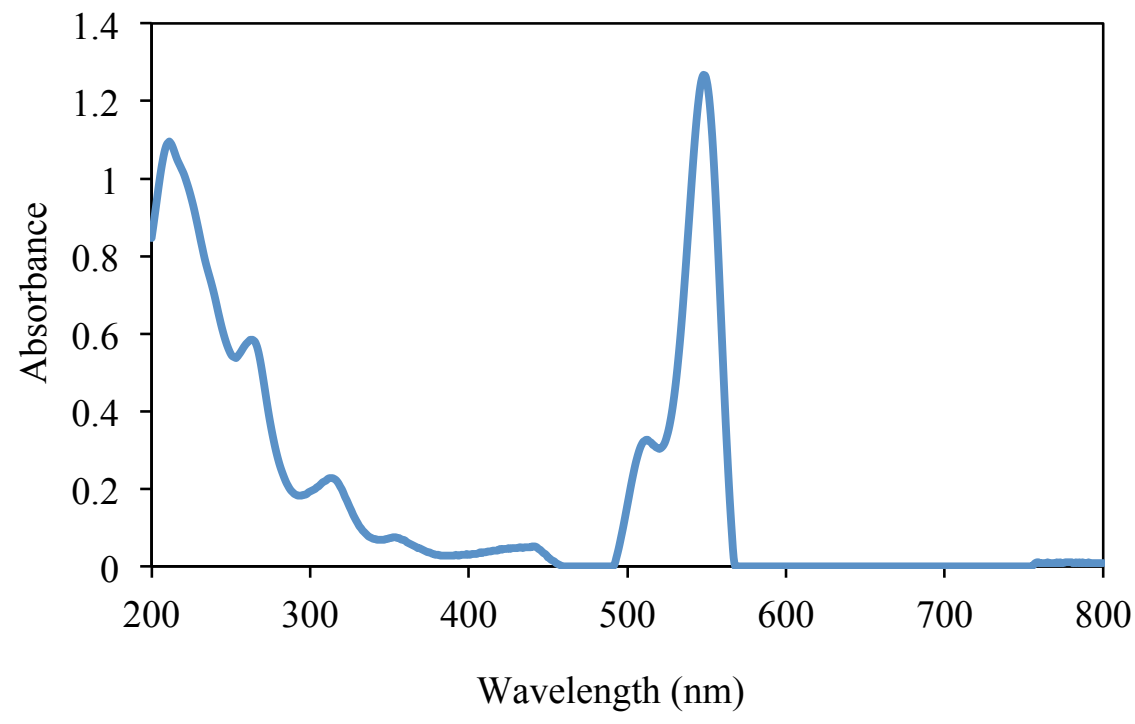

Figure 4.2 UV-vis absorbance spectrum of $20 \mu \mathrm{M} \mathrm{RB}$ in water

The degradation of MC-LR in presence of $500 \mu \mathrm{M}$ RB follows the pseudo-first order kinetic model. The pseudo-first order kinetic model can be expressed as:

$$
d[\mathrm{C}] / d t=-\mathrm{k}[\mathrm{C}]
$$

After integration, the equation becomes

$$
\ln \left(\mathrm{C}_{0} / \mathrm{C}\right)=\mathrm{kt}
$$

where $\mathrm{k}$ is the rate constant of pseudo-first order model $\left(\mathrm{min}^{-1}\right)$, $\mathrm{t}$ is time (min), $\mathrm{C}_{0}$ is the initial concentration of MC-LR (ppm) and C is the concentration of MC-LR (ppm) at the specific time. Coefficient of determination $\left(\mathrm{R}^{2}\right)$ of plot of $\ln \left(\mathrm{C} / \mathrm{C}_{0}\right)$ versus $t$ is close to 1 , 
indicating that the degradation fits the pseudo-first order kinetics nicely. These results indicate RB can be used as a photosensitizer (catalyst) to effectively degrade MC-LR. Rate of degradation increase three fold under oxygen saturated conditions compared to argon-saturated conditions (Table 4.1), demonstrating that photo-oxidation is the predominant degradation process. Under argon saturation the degradation is likely due to the energy transfer between the $\mathrm{RB}^{*}$ and MC-LR. These results are in general consistent with the interactions between ${ }^{1} \mathrm{O}_{2}$ and aquatic fulvic acids in presence of $\mathrm{RB}$. There are two pathways: ${ }^{1} \mathrm{O}_{2}$ process and non- ${ }^{1} \mathrm{O}_{2}$ process, and the ${ }^{1} \mathrm{O}_{2}$ process is predominant (Cory et al., 2008).

To investigate the role of singlet oxygen on degradation of MC-LR, reaction is conducted in $\mathrm{D}_{2} \mathrm{O}$. The quantum yield of $\mathrm{RB}$ in $\mathrm{D}_{2} \mathrm{O}$ is as same as in $\mathrm{H}_{2} \mathrm{O}$ (DeRosa et al., 2002), but the life time of ${ }^{1} \mathrm{O}_{2}$ in $\mathrm{D}_{2} \mathrm{O}$ is $\sim 20$ times longer in $\mathrm{H}_{2} \mathrm{O}$. Therefore, the ${ }^{1} \mathrm{O}_{2}$ mediated degradation is generally enhanced in $\mathrm{D}_{2} \mathrm{O}$. The degradation of MC-LR in $\mathrm{D}_{2} \mathrm{O}$ is evaluated. On the basis of the $\mathrm{R}^{2} \geq 97 \%$ of plot of $\ln \left([\mathrm{MC}-\mathrm{LR}] /[\mathrm{MC}-\mathrm{LR}]_{0}\right)$ against time, it follows pseudo-first order kinetic model nicely in oxygen-saturated $\mathrm{D}_{2} \mathrm{O}$. A significant increase of rate constant from0.036 \pm 0.007 to $0.073 \pm 0.017 \mathrm{~min}^{-1}$ is observed. The enhancement of photodegradation in $\mathrm{D}_{2} \mathrm{O}$ further supports the conclusion that ${ }^{1} \mathrm{O}_{2}$ plays a critical role in photodegradation of MC-LR.

Table 4.1 Kinetics parameters of MC-LR degradation in presence of $500 \mu \mathrm{M} R B$

\begin{tabular}{ccc}
\hline experimental condition & $\mathrm{k}\left(\mathrm{min}^{-1}\right)$ & $\mathrm{R}^{2}$ \\
\hline argon-saturated in $\mathrm{H}_{2} \mathrm{O}$ & $0.012 \pm 0.002$ & $\geq 96 \%$ \\
oxygen-saturated in $\mathrm{H}_{2} \mathrm{O}$ & $0.036 \pm 0.007$ & $\geq 98 \%$ \\
oxygen-saturated in $\mathrm{D}_{2} \mathrm{O}$ & $0.073 \pm 0.017$ & $\geq 97 \%$ \\
\hline
\end{tabular}




\subsection{2 ${ }^{1} \mathrm{O}_{2}$ competition kinetic measurements}

The singlet oxygen rate constant with MC-LR was determined using FFA as a competing probe based on the measurement of FFA concentration by HPLC monitoring absorption at $219 \mathrm{~nm}$. FFA reacts with ${ }^{1} \mathrm{O}_{2}$ with the bimolecular rate constant of $\mathrm{k}=$ $1.2 \times 10^{8} \mathrm{M}^{-1} \mathrm{~s}^{-1}$ in water (Haag et al., 1986). The bimolecular reaction rate constant between MC-LR and ${ }^{1} \mathrm{O}_{2}$ is $3.5 \times 10^{6} \mathrm{M}^{-1} \mathrm{~s}^{-1}$ by multiplying the slope of Fig.3 by $\mathrm{k}$ of FFA (Song et al., 2012). Since the MC-LR also can be degraded by RB* via energy transfer, the actual bimolecular rate constant is $\sim 10^{6} \mathrm{M}^{-1} \mathrm{~s}^{-1}$.

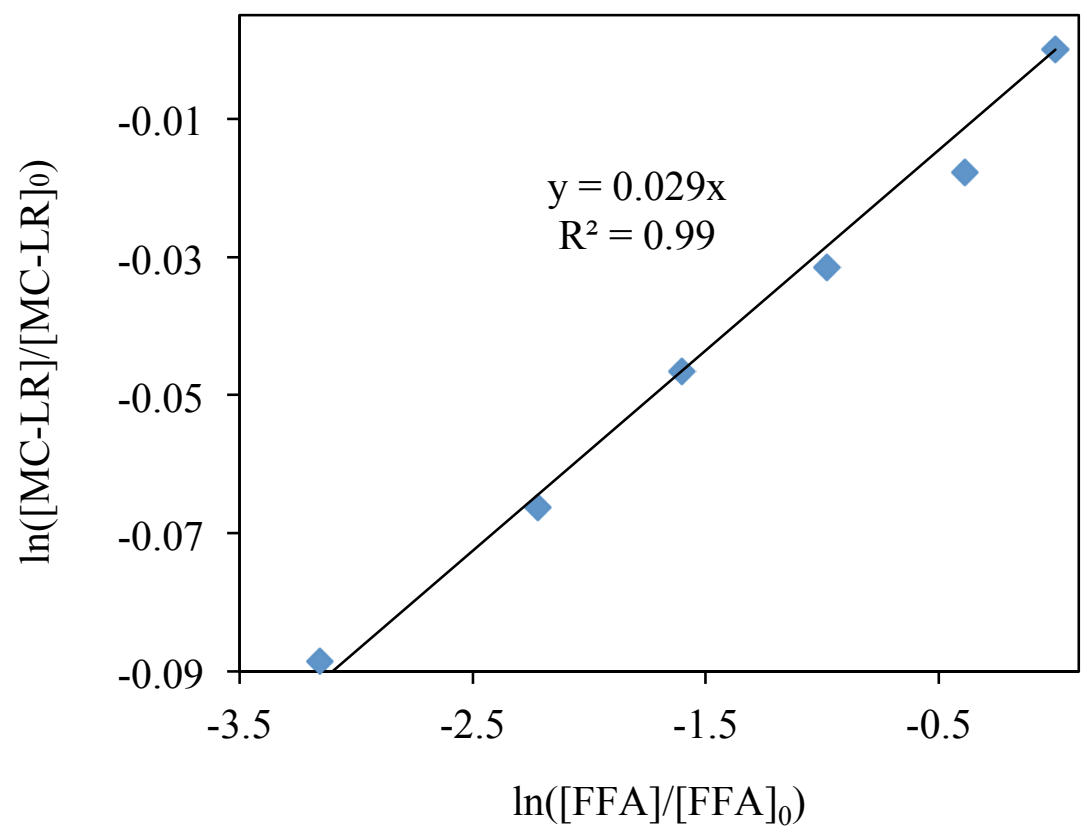

Figure 4.3 Competitive ${ }^{1} \mathrm{O}_{2}$ degradation of MC-LR with FFA

The dissolved organic matter is present in natural surface water, and ${ }^{1} \mathrm{O}_{2}$ and $\bullet \mathrm{OH}$ are formed upon irradiation. Since the formation rate of ${ }^{1} \mathrm{O}_{2}$ is higher by two to three orders of magnitude than $\bullet \mathrm{OH}$, the steady-state concentration of ${ }^{1} \mathrm{O}_{2}$ is $\sim 50-1,400$ fold of -OH (Vione et al., 2010). The reported bimolecular rate constants of ${ }^{1} \mathrm{O}_{2}$ with organic 
compounds in aqueous solution range from $\sim 10^{6}$ to $10^{8} \mathrm{M}^{-1} \mathrm{~s}^{-1}$ (Czaplicka, 2006), whereas $\bullet \mathrm{OH}$ is higher by one to three orders of magnitude than ${ }^{1} \mathrm{O}_{2}$ (Buxton et al., 1988). For MC-LR, the bimolecular rate constant for the reaction of $\bullet \mathrm{OH}$ is $2.3( \pm 0.1) \times 10^{10}$ $\mathrm{M}^{-1} \mathrm{~s}^{-1}$ (Song et al., 2009).

\subsection{Conclusions}

Our results demonstrate that MC-LR is rapidly photodegraded by RB, and the degradation of MC-LR follows the pseudo-first order kinetic model nicely under argonsaturated and oxygen-saturated conditions. The pseudo-first order kinetic rate constant of degradation increases three fold under oxygen-saturated condition compared to argonsaturated condition, demonstrating that ${ }^{1} \mathrm{O}_{2}$ process is the predominant degradation pathway and non- ${ }^{1} \mathrm{O}_{2}$ process (energy transfer) also plays an important role for the degradation of MC-LR. It is consistent with the increase of rate constant in $\mathrm{D}_{2} \mathrm{O}$. The measured bimolecular reaction rate constant between MC-LR and ${ }^{1} \mathrm{O}_{2}$ is $\sim 10^{6} \mathrm{M}^{-1} \mathrm{~s}^{-1}$ from competition kinetics with furfuryl alcohol. 
5 Chromium(VI) Removal by Maghemite Nanoparticles 


\subsection{Abstract}

Maghemite nanoparticles were prepared by a co-precipitation method and characterized by Fourier transform infrared spectroscopy, transmission electron microscopy, X-ray photoelectron spectroscopy, nitrogen adsorption and desorption isotherms. The Brunauer-Emmett-Teller surface area, average particle size, pore volume and porosity of maghemite were $73.8 \mathrm{~m}^{2} \mathrm{~g}^{-1}, 17.2 \pm 4.4 \mathrm{~nm}, 0.246 \mathrm{~cm}^{3} \mathrm{~g}^{-1}$, and $56.3 \%$, respectively. Removal of $\mathrm{Cr}(\mathrm{VI})$ by the maghemite nanoparticles follows a pseudosecond-order kinetic process. Intraparticle diffusion kinetics implies the adsorption of $\mathrm{Cr}(\mathrm{VI})$ onto the maghemite occurs via two distinct phases: the diffusion controlled by external surface followed by an intra-particle diffusion. The equilibrium data was nicely fit to the Langmuir and Langmuir-Freundlich (L-F) models and indicates the adsorption of $\mathrm{Cr}(\mathrm{VI})$ is spontaneous and highly favorable. The heterogeneity index, 0.55 , implies heterogeneous monolayer adsorption. The adsorption $\mathrm{Cr}(\mathrm{VI})$ is favorable under acidic and neutral conditions with maximum removal observed at $\mathrm{pH}$ 4. The adsorption of $\mathrm{Cr}(\mathrm{VI})$ is modestly inhibited by the presence of $\geq 5 \mathrm{ppm}$ humic acid. In summary, the adsorption of $\mathrm{Cr}(\mathrm{VI})$ by maghemite nanoparticles is rapid, can be accurately modeled, and is effective under a variety of conditions. Our results indicate these magnetic materials have promising potential to cleanup $\mathrm{Cr}(\mathrm{VI})$ contaminated waters to acceptable drinking water standards.

\subsection{Keywords}

Maghemite nanoparticles, chromate, adsorption isotherm, kinetic study, $\mathrm{pH}$ effect, humic acid 


\subsection{Introduction}

Chromium is a common drinking water contaminant in the USA because of its wide spread use in industrial processes (Johnson et al., 2006). The use of chromium in wood preservatives, leather tanning, paint formulation, steel fabrication, and metal finishing are the main sources of chromium based pollution. The toxicity and mobility of chromium are strongly dependent on the oxidation state. In nature, chromium exists primarily in two oxidation states (III and VI). $\mathrm{Cr}$ (III), an essential trace element for human beings, may play a role in the metabolism of glucose (Mertz, 1993). Cr(VI) is a more toxic and soluble specie, compared to $\mathrm{Cr}$ (III) which is toxic only at a high concentrations. $\mathrm{CrO}_{4}{ }^{2-}$ and $\mathrm{Cr}_{2} \mathrm{O}_{7}{ }^{2-}$ are the primary forms of $\mathrm{Cr}(\mathrm{VI})$ with $\mathrm{Cr}_{2} \mathrm{O}_{7}{ }^{2-}$ being predominant under strongly acidic conditions and at high $\mathrm{Cr}(\mathrm{VI})$ concentrations in aqueous solutions (Pérez-Candela et al., 1995). Cr(VI) is a human carcinogen and poses a significant threat to the environment and human beings (Quievryn et al., 2002). The World Health Organization (WHO) recommends a maximum allowable level of $50 \mathrm{ppb}$ total chromium for drinking water. The US Environmental Protection Agency established a guideline of $100 \mathrm{ppb}$ maximum contaminant level for total chromium in drinking water (Thomas et al., 2002), while California's office of Environmental Health Hazard Assessment proposed in 1999 a public health goal of $\leq 2.5 \mathrm{ppb}$ for total chromium (Pouran et al., 2008).

Unlike many organic pollutants, chromium species are not removed and/or degraded through typical environmental and biological processes, thus it is critical to develop and identify an effective method for the removal of chromium from industrial wastewater. Water purification technologies must be capable of reducing the level of 
chromium considered safe for human consumption. A number of conventional methods have been employed for the removal of $\mathrm{Cr}(\mathrm{VI})$ from wastewater (Owlad et al., 2009). Adsorption processes can offer significant advantages including availability, profitability, ease of operation and efficiency, in comparison with many conventional methods. A variety of natural and synthetic materials have been used as $\mathrm{Cr}$ (VI) sorbents, including activated carbons, biological materials, zeolites, chitosan, and industrial wastes. Unfortunately, these sorbents can also suffer from a number of disadvantages, including high cost, low adsorption capacity and/or difficulties associated with separation and removal following treatment. The application of magnetic nanoparticles for adsorption is attractive because of their high surface area, easy separation and recovery (Banerjee et al., 2007; Hu et al., 2007). Iron based materials are especially attractive because they are inexpensive and environmentally friendly (Hu et al., 2004; Yavuz et al., 2006). The magnetite form of iron can be oxidized to maghemite under aerated conditions (Chowdhury et al., 2010). Maghemite, a common magnetic material, is a promising adsorbent for heavy metals removal because it is inexpensive, readily available and can be easily separated and recovered (Lin et al., 2012; Roy et al., 2012). While maghemite nanomaterials appear to be promising for $\mathrm{Cr}(\mathrm{VI})$ removal, detailed kinetic and adsorption studies have yet to be reported. Herein we report the synthesis of maghemite nanoparticles by a co-precipitation method. The observed adsorption of $\operatorname{Cr}(\mathrm{VI})$ by maghemite nanoparticles is rapid, accurately model and effective under a variety of conditions. Our results demonstrate these maghemite nanoparticles with high adsorption capacity and magnetic properties are promising materials for the $\mathrm{Cr}(\mathrm{VI})$ removal from aqueous solution. 


\subsection{Materials and methods}

\subsubsection{Materials}

Trace metal grade nitric acid, sodium hydroxide, ferric chloride hexahydrate, ferrous chloride tetrahydrate, $29 \%$ ammonium hydroxide and ethanol were purchased from Fisher. Potassium chromate was obtained from Mallinckrodt. Humic acid was obtained from Fluka. All the chemicals were used without further purification. All the solutions were prepared with Millipore filtered water $(18 \mathrm{M} \Omega \cdot \mathrm{cm})$.

\subsubsection{Preparation of maghemite}

All solutions were purged with argon for 15 min to remove oxygen prior and during reaction. Iron solutions of $\mathrm{FeCl}_{2} \cdot 4 \mathrm{H}_{2} \mathrm{O}(2.0 \mathrm{~g})$ and $\mathrm{FeCl}_{3} \cdot 6 \mathrm{H}_{2} \mathrm{O}(5.4 \mathrm{~g})$ were diluted to $30 \mathrm{~mL}$ with water. The iron mixture was stirred magnetically, gently purged with argon and heated to $80{ }^{\circ} \mathrm{C}$ and then $40 \mathrm{~mL}$ of $15 \%$ diluted ammonium hydroxide solution added dropwise into the mixture over a 20 min time interval. The mixture was aged at $80{ }^{\circ} \mathrm{C}$ for an additional $40 \mathrm{~min}$. The product was rinsed with water then ethanol three times. The samples were separated using a magnet and dried in a vacuum oven at $50{ }^{\circ} \mathrm{C}$ to a constant weight (Darezereshki et al., 2010).

\subsubsection{Characterization}

The dried maghemite samples from a single batch were used for adsorption experiments and characterization using XPS, FTIR and TEM. TEM was used for measurement of the average size. The Fourier transform infrared spectroscopy (FTIR) spectra were collected using a Perkin-Elmer spectrum 100 FTIR spectrometer. Transmission electron microscopy (TEM) was carried out using a Philips CM20 with field emission gun at $200 \mathrm{kV}$ and energy dispersive analysis X-ray (EDAX). X-ray 
photoelectron spectroscopy (XPS) was determined using a PHI 5000 VersaProbe with Al $\mathrm{K} \alpha$ radiation $(1486.6 \mathrm{eV})$ at a takeoff angle at $45^{\circ}$. The binding energies were referenced to the $\mathrm{C} 1 \mathrm{~s}$ core level at $284.8 \mathrm{eV}$. Nitrogen adsorption and desorption isotherms were performed on a Tristar 300 (Micromeritics) porosimeter analyzer. The sample was prepared by purging with nitrogen gas at $150{ }^{\circ} \mathrm{C}$ for $2.0 \mathrm{~h}$ using a Flow Prep 060 (Micromeritics) before analysis.

\subsubsection{Adsorption tests}

Volumetric glassware was used in the preparation and transfer of all $\operatorname{Cr}(\mathrm{VI})$ solutions. Maghemite particles were added to $200 \mathrm{~mL} \mathrm{Cr}(\mathrm{VI})$ solutions at the desired concentration in a $250 \mathrm{~mL}$ Erlenmeyer flask. The experiments were carried out on an orbit shaker (Lab-line instrument Inc., model 3520) with continual mixing at 300 RPM at $\sim 25^{\circ} \mathrm{C}$ in a temperature controlled laboratory. Five $\mathrm{mL}$ of sample were taken at the specific time intervals and filtered through a $0.45 \mu \mathrm{m}$ PTFE filter immediately to remove the suspended particles. To the filtrates, nitric acid was added to yield a nitric acid concentration of $0.2 \%$ prior to analysis. The concentration of chromium was measured using a Perkin-Elmer AA600 atomic absorption spectrophotometer. The current was $25.0 \mathrm{~mA}$, with the wavelength of detection set at $357.9 \mathrm{~nm}$ and slit bandwidth of $0.7 \mathrm{~nm}$ as recommended by the manufacturer. Sample concentrations were determined based on a calibration of the instrument in the range from 1 to $50 \mathrm{ppb}$ of chromium. The reproducibility based on representative triplicate runs was $\pm 5 \%$. 


\subsection{Results and discussion}

\subsubsection{Characterization}

FTIR analysis was employed to determine specific functional groups of the nanoparticles. The most abundant functional group observed in our samples of maghemite was the hydroxyl group with a broad band at $3300 \mathrm{~cm}^{-1}(\mathrm{OH}$ stretching mode), and bands at 1625.3 and $1428.2 \mathrm{~cm}^{-1}$ (OH bending modes). The Fe-O stretching bands appear at 539.2 and $526.8 \mathrm{~cm}^{-1}$ (Cornell et al., 2003). The TEM image of maghemite shows the average size of synthesized maghemite particle is $17.2 \pm 4.4 \mathrm{~nm}$ (Figure. 5.1). The EDAX analysis showed the particles contained $31.28 \% \mathrm{O}, 1.75 \% \mathrm{C}$ and $66.97 \% \mathrm{Fe}(\mathrm{Wt} \%)$.

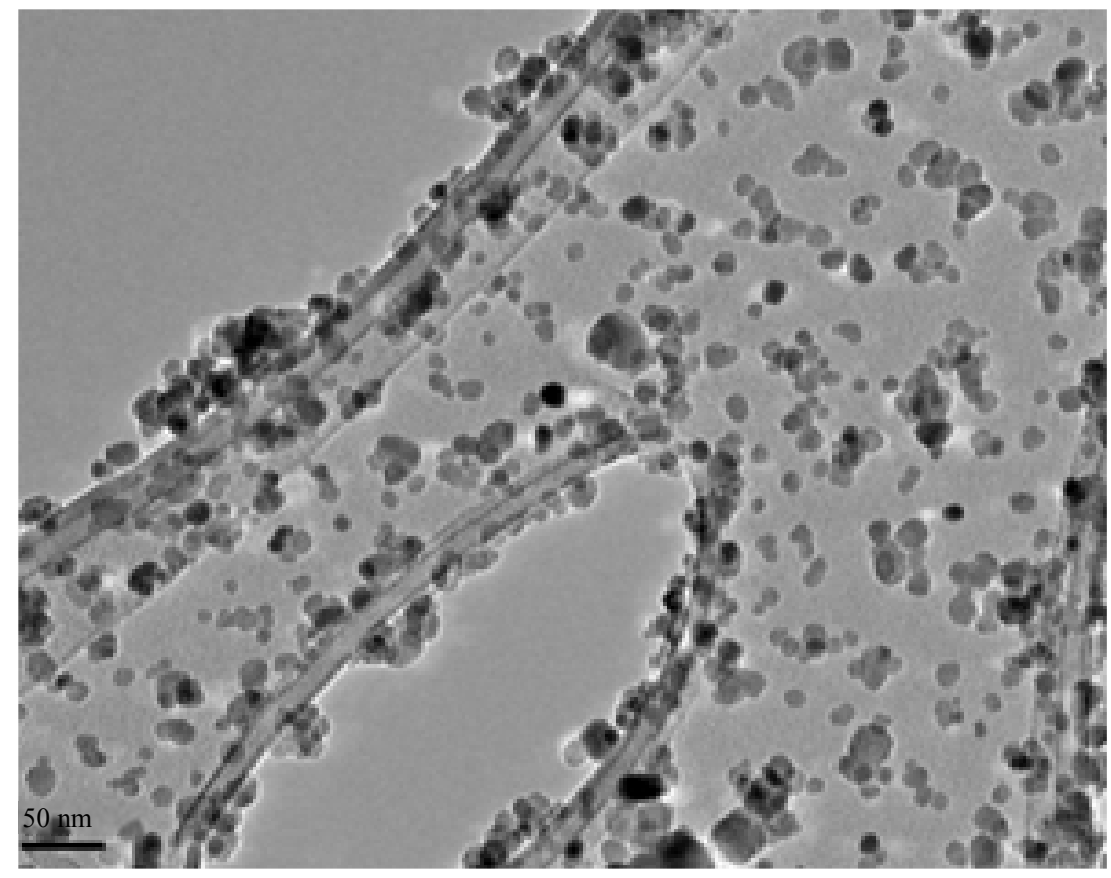

Figure 5.1 TEM image of maghemite

The Brunauer-Emmett-Teller (BET) surface area, pore volume, porosity, BarretJoyner- Halenda $(\mathrm{BJH})$ pore size and distribution were obtained from nitrogen adsorption 
and desorption isotherms. The nitrogen adsorption and desorption isotherms are showed in Figure. 5.2 with a characteristic type $\mathrm{H} 3$ hysteresis loop. The BJH pore size distribution was inserted in Figure. 5.2, and a sharp peak appears at $13.28 \mathrm{~nm}$. The BET surface area, pore volume and porosity are $73.8 \mathrm{~m}^{2} \mathrm{~g}^{-1}, 0.246 \mathrm{~cm}^{3} \mathrm{~g}^{-1}, 56.3 \%$, respectively. The chemical composition was further characterized using XPS. The XPS spectrum is shown in Figure. 5.3. The predominant elements are Fe and O, and small amounts of residual $\mathrm{Cl}$ and $\mathrm{C}$ are also present. The peaks at binding energy of 56, 198.3, 284.8 and $530.4 \mathrm{eV}$ were designated for $\mathrm{Fe}_{3} \mathrm{p}_{3 / 2}, \mathrm{Cl} 2 \mathrm{p}, \mathrm{C} 1 \mathrm{~s}$ and $\mathrm{O} 1 \mathrm{~s}$, respectively. High resolution XPS of Fe2p is inserted in Figure. 5.3. Binding energy of Fe2 $p_{1 / 2}$ is $724.8 \mathrm{eV}$ and binding energy of $\mathrm{Fe} 2 \mathrm{p}_{3 / 2}$ is $711.1 \mathrm{eV}$. The presence of satellite peak at $719 \mathrm{eV}$ is characteristic for maghemite. These results agree with literature values of maghemite particle (Gota et al., 1999; Li et al., 2011). A multiplet analysis of the $\mathrm{Fe} 2 \mathrm{p}_{3 / 2}$ peak indicates again the sample is maghemite (Grosvenor et al., 2004). 


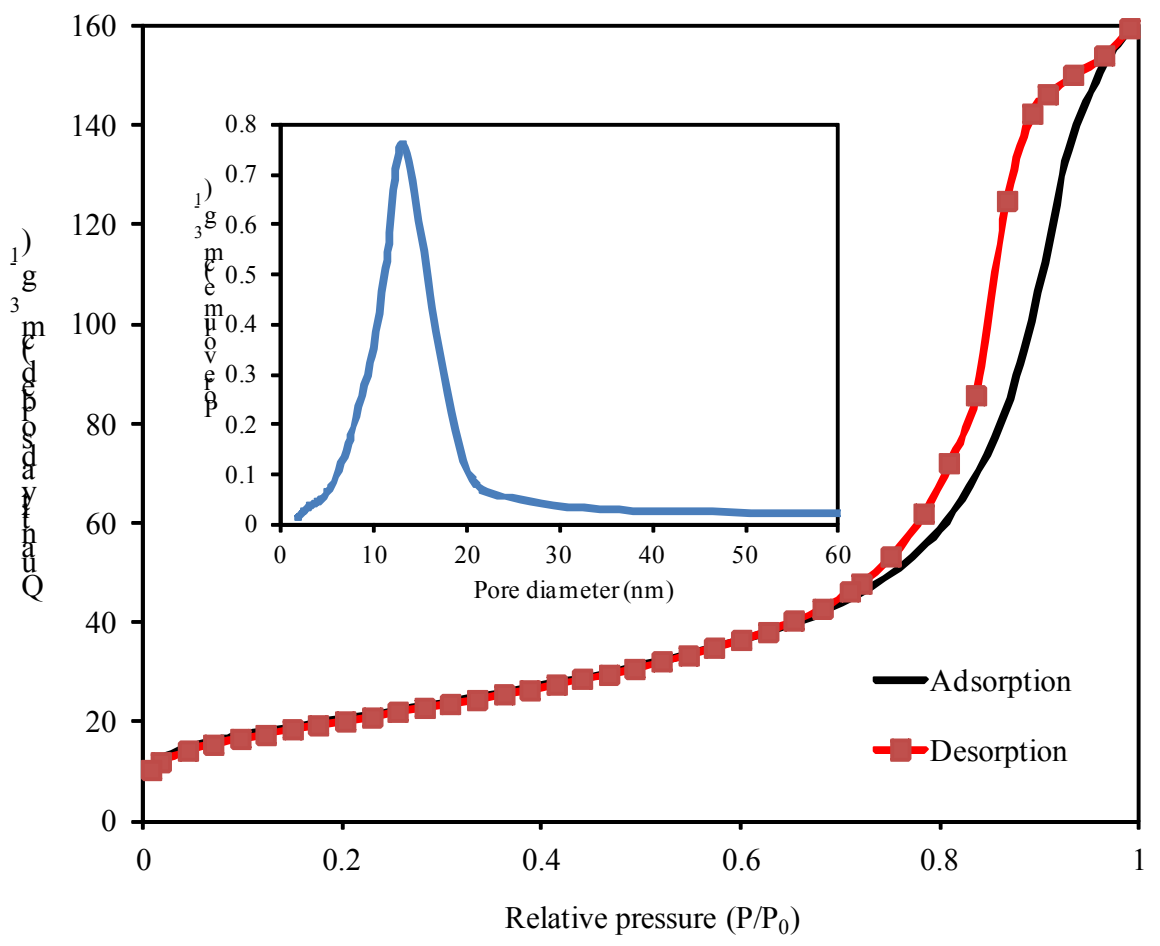

Figure 5.2 Nitrogen adsorption and desorption isotherms. The insert is pore size distribution of maghemite particles

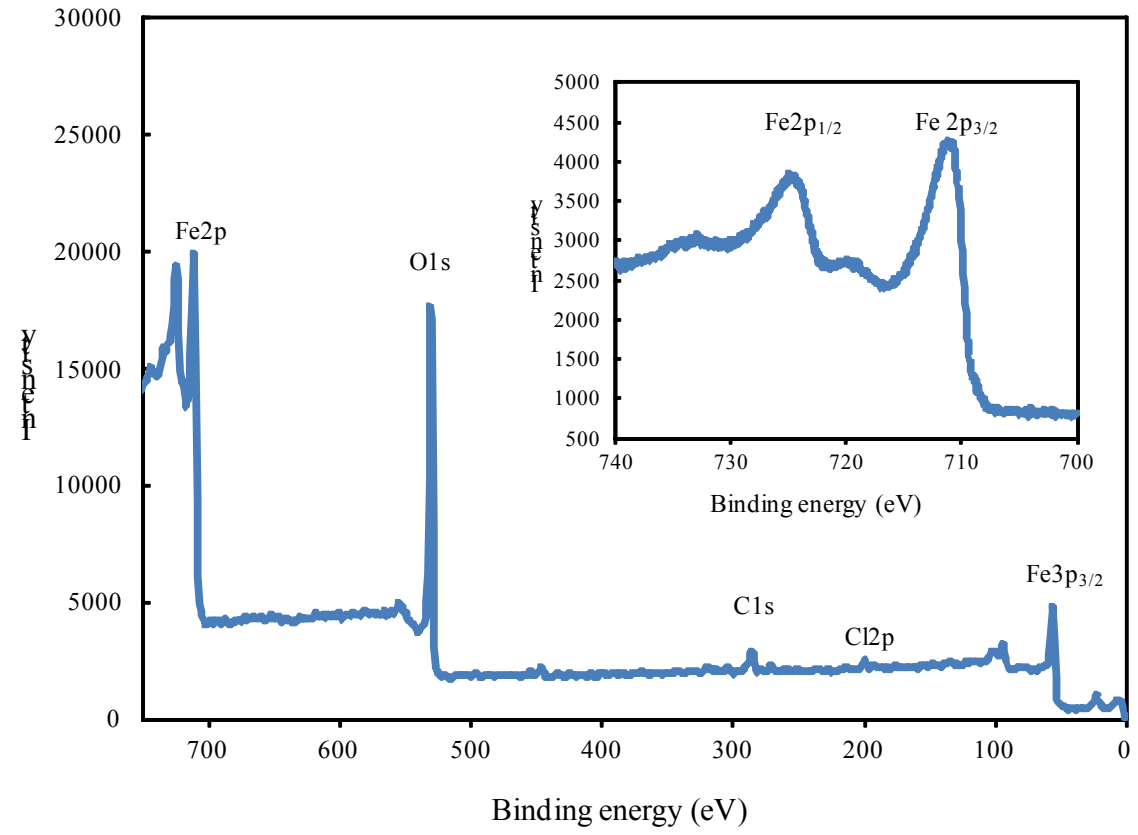

Figure 5.3 XPS of maghemite particles and high resolution XPS of Fe2p core level (the insert) 


\subsubsection{Effect of the concentration of maghemite on $\mathrm{Cr}(\mathrm{VI})$ adsorption}

The Cr(VI) adsorption by maghemite was performed with continuous mixing on an orbit shaker at room temperature and $300 \mathrm{RPM}$. The $\mathrm{Cr}(\mathrm{VI})$ remaining in solution was monitored as a function of maghemite concentration and contact time.

Experiments were run with the initial concentration of $\mathrm{Cr}(\mathrm{VI})$ at $500 \mathrm{ppb}$, while varying the contact time from 0 to $120 \mathrm{~min}$, and initial concentration of maghemite from 0.1 to $1.5 \mathrm{~g} \mathrm{~L}^{-1}$. The adsorption of $\mathrm{Cr}(\mathrm{VI})$ by maghemite particle was rapid in the first 5 min followed by a slow $\mathrm{Cr}(\mathrm{VI})$ adsorption stage at longer contact times as illustrated in Figure. 5.4. At initial maghemite concentrations $\geq 0.3 \mathrm{~g} \mathrm{~L}^{-1}$, the concentration of $\mathrm{Cr}(\mathrm{VI})$ in the aqueous phase was effectively reduced to $100 \mathrm{ppb}$ within $60 \mathrm{~min}$. Under these conditions the concentration of $\mathrm{Cr}$ in solution was reduced within the drinking water guidelines recommended by EPA. The residual $\mathrm{Cr}(\mathrm{VI})$ in solution increased as a function of decreasing concentration of maghemite. Based on the adsorption studies, a

concentration of $0.3 \mathrm{~g} \mathrm{~L}^{-1}$ maghemite was employed for studying the kinetics and equilibrium adsorption isotherms. 


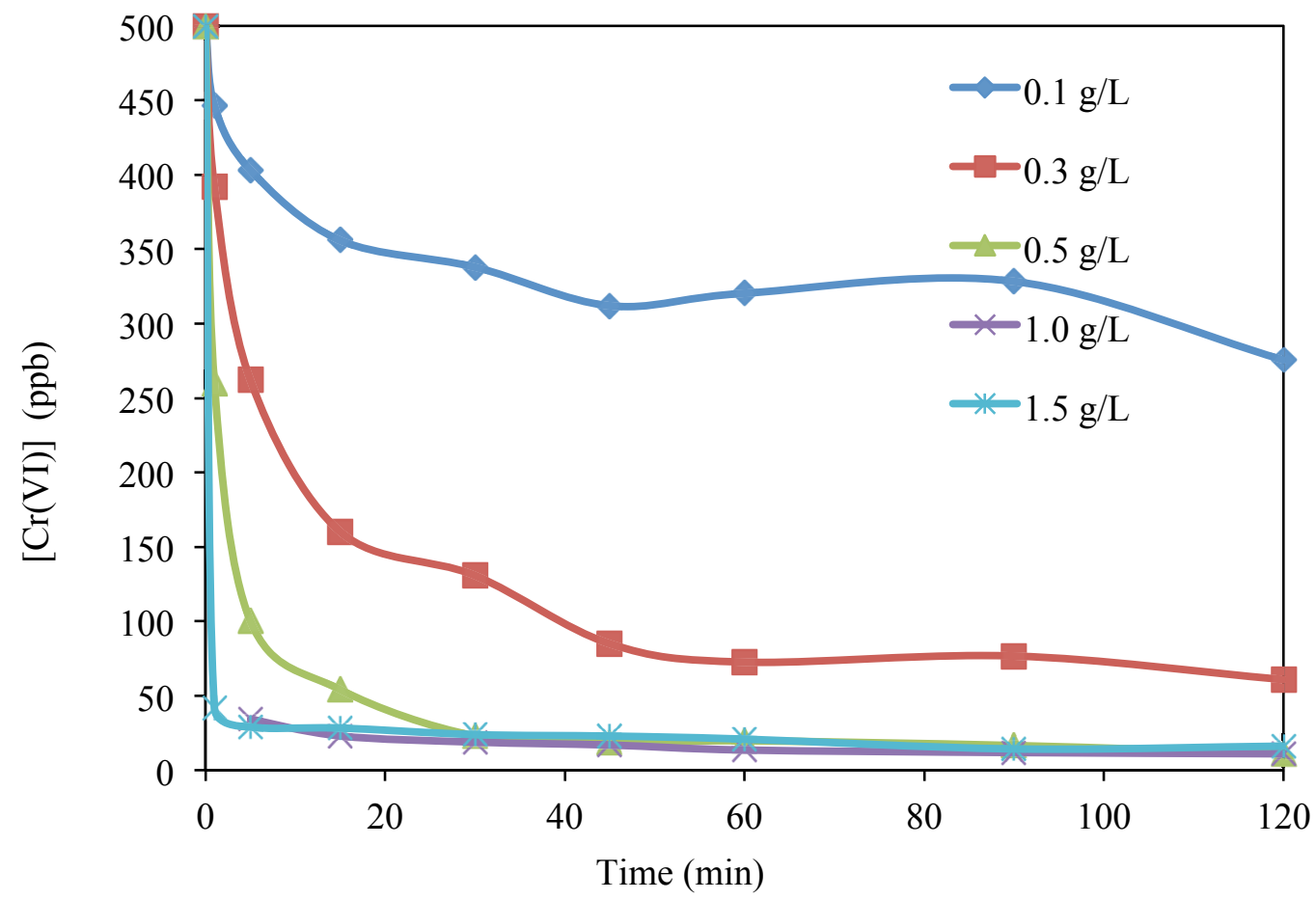

Figure 5.4 Effect of the concentration of maghemite particles on $\mathrm{Cr}(\mathrm{VI})$ adsorption

\subsubsection{Effect of the initial $\mathrm{Cr}(\mathrm{VI})$ concentration and contact time on $\mathrm{Cr}(\mathrm{VI})$ adsorption}

The concentration of $\mathrm{Cr}(\mathrm{VI})$ in the aqueous phase versus the adsorption time at various initial concentrations of $\mathrm{Cr}(\mathrm{VI})$ is illustrated in Figure. 5.5. The adsorption process is rapid for the first 20 min, followed by a slower uptake. The concentration of $\mathrm{Cr}(\mathrm{VI})$ in the aqueous phase at equilibrium gradually increases with increases in the initial concentration of $\mathrm{Cr}(\mathrm{VI})$. After 2 hours, the observed removal efficiency of $\mathrm{Cr}(\mathrm{VI})$ by maghemite at initial $\mathrm{Cr}(\mathrm{VI})$ concentration of $50,100,200,300,400,450$ and $500 \mathrm{ppb}$ were $100 \%, 99.4 \%, 98.5 \%, 97.3 \%, 96.7 \%, 92.8 \%$ and $91.4 \%$, respectively. Under these experimental conditions, the removal efficiency of $\mathrm{Cr}(\mathrm{VI})$ modestly decreased as a function of the increase in initial concentrations of $\mathrm{Cr}(\mathrm{VI})$. 


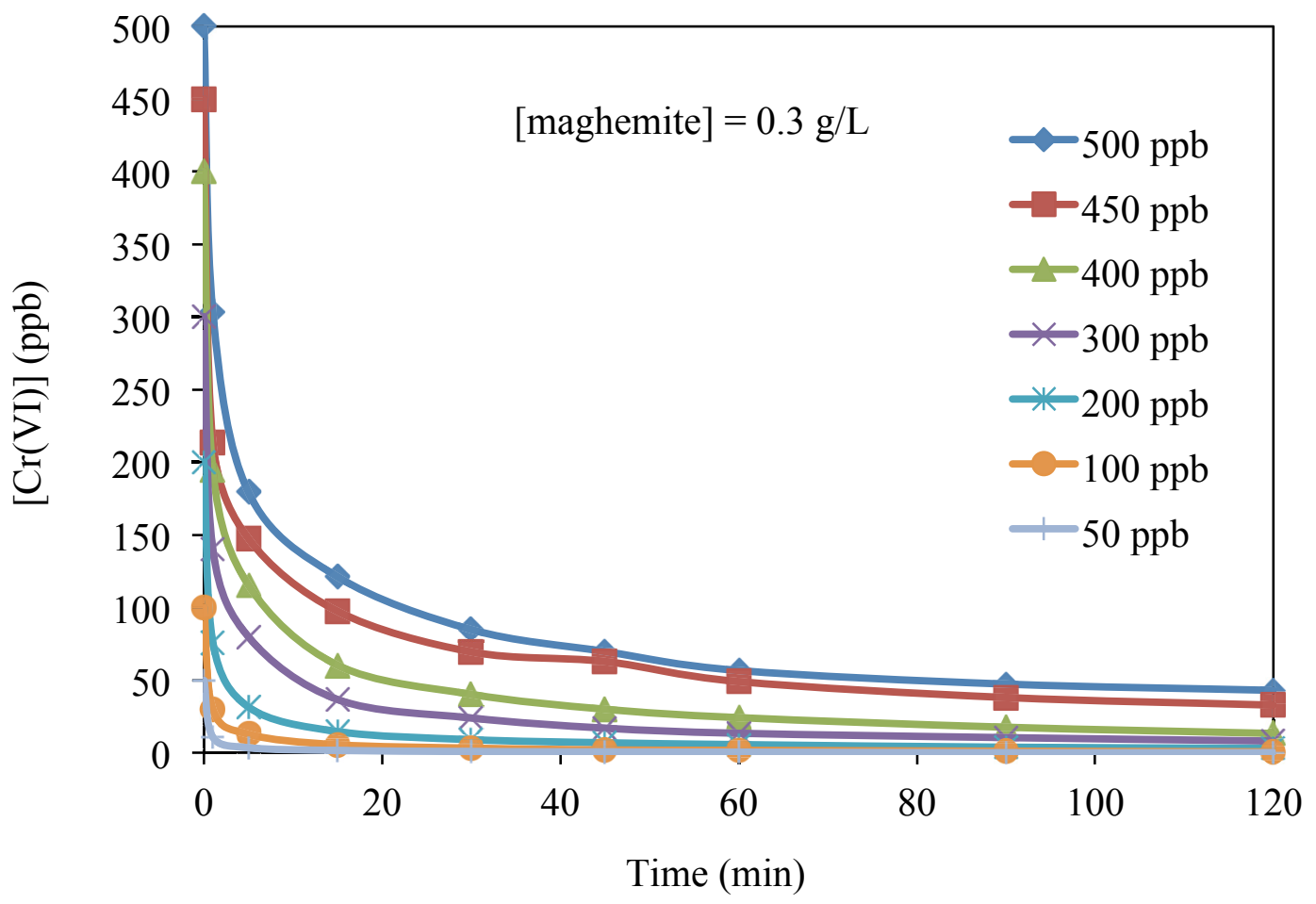

Figure 5.5 Effect of the initial concentration of $\mathrm{Cr}(\mathrm{VI})$ and contact time on $\mathrm{Cr}(\mathrm{VI})$ removal

\subsubsection{Adsorption kinetic study}

\subsubsection{Pseudo-second-order model}

To further investigate the adsorption of $\mathrm{Cr}(\mathrm{VI})$ by co-precipitation prepared maghemite, an adsorption kinetic study was carried out. Application of pseudo-first order kinetic model to experimental data yielded poor results. With this in mind, we applied the pseudo-second-order equation expressed below (Yuan et al., 2010):

$$
d Q_{t} / d t=k_{p}\left(Q_{e^{-}} Q_{t}\right)^{2}
$$

where $k_{p}$ is the rate constant of pseudo-second-order model $\left(\mathrm{g} \mathrm{mg}^{-1} \min ^{-1}\right), t$ is the reaction time (min), $Q_{t}$ is the amount of adsorbate adsorbed per unit mass by maghemite at the specific time $\left(\mathrm{mg} \mathrm{g}^{-1}\right)$, and $Q_{e}$ is the adsorption capacity at adsorption equilibrium $\left(\mathrm{mg} \mathrm{g}^{-1}\right)$, respectively. 
The pseudo-second-order kinetics model nicely simulates the adsorption of $\mathrm{Cr}(\mathrm{VI})$ by maghemite and the resulting kinetic parameters are summarized in Table 5.1. The data indicate the adsorption of $\mathrm{Cr}(\mathrm{VI})$ at each specific initial $\mathrm{Cr}(\mathrm{VI})$ concentration nicely fits the pseudo-second-order model based on the coefficient of determination $\left(\mathrm{R}^{2}\right)$. The mathematical expressions of initial $\mathrm{Cr}(\mathrm{VI})$ concentration $\left(C_{0}\right.$ in ppb) versus $k_{p}$ and $Q_{e}$, and both of with $k_{p}$ and $Q_{e}$ are a function of initial $\mathrm{Cr}(\mathrm{VI})$ concentration, are expressed in Eqs. 5.2 and 5.3. The $k_{p}$ decreased as the increase of initial Cr(VI) concentration, while $Q_{e}$ increased linearly. Substituting Eqs. 5.2 and 5.3 into Eq. 5.1 yields Eq. 5.4, an empirical adsorption kinetics equation. The adsorption rate is a function of $C_{0}$. For a typical second-order kinetic reaction, the rate constants are temperature dependent, and it usually follows the Arrhenius equation. However the rate constants decreased with an increase in the initial $\mathrm{Cr}(\mathrm{VI})$ concentration. Ofomaja suggested that a chemical activation mechanism occurred during the adsorption process for an analogous behavior for adsorption of methylene blue onto palm kernel fibre (Ofomaja, 2007). The adsorption is accurately modeled by pseudo-second-order model at a fixed initial $\mathrm{Cr}(\mathrm{VI})$ concentration under these experimental conditions.

$$
\begin{aligned}
& k_{p}=22,142 C_{o}^{-1.838} \\
& Q_{e}=0.0031 C_{o}+0.0294 \\
& d Q_{t} / d t=22,142 \times C_{o}^{-1.838} \times\left(0.0031 C_{o}+0.0294-Q_{t}\right)^{2}
\end{aligned}
$$


Table 5.1 Kinetic parameters of pseudo-second-order model for adsorption of $\mathrm{Cr}(\mathrm{VI})$ as a function of initial concentration of $\mathrm{Cr}(\mathrm{VI})$

\begin{tabular}{lll}
\hline$C_{0}$ & $k_{p}$ & $\begin{array}{l}Q_{e} \\
(\mathrm{ppb})\end{array}$ \\
\hline 50 & 17.22 & 0.166 \\
$\left(\mathrm{~g} \mathrm{mg}^{-1} \mathrm{~min}^{-1}\right)$ & $\left(\mathrm{g} \mathrm{g}^{-1}\right)$ \\
100 & 4.01 & 0.333 \\
200 & 1.58 & 0.661 \\
300 & 0.62 & 0.984 \\
400 & 0.38 & 1.304 \\
450 & 0.28 & 1.409 \\
500 & 0.23 & 1.551 \\
\hline
\end{tabular}

\subsubsection{Intraparticle diffusion kinetic model}

The intraparticle diffusion kinetic model has also been employed to investigate the adsorption processes (Mall et al., 2006). The model is expressed as:

$$
Q_{t}=k_{i d} t^{1 / 2}+C
$$

where $k_{i d}$ is the intraparticle diffusion rate constant $\left(\mathrm{mg} \mathrm{g}^{-1} \mathrm{~min}^{-1 / 2}\right)$ and $C$, the intercept represents the thickness of boundary layer effect. There is a positive relationship between the value of $C$ and the boundary layer effect that implies the contribution of surface sorption in the rate-controlling step. The intraparticle diffusion plot is given in Figure. 5.6. If the regression of $Q_{\mathrm{t}}$ against $t^{1 / 2}$ is linear and the intercept is 0 , the adsorption rate was exclusively controlled by intraparticle diffusion. As shown in Figure. 5.6, the intercepts were not zero, indicating surface sorption and intraparticle 
diffusion are rate controlling processes (Hameed et al., 2009). The plot suggests that the sorption followed two phases. The first phase is the diffusion controlled by external surface; and the second phase has been assigned to intra-particle diffusion (S. K. Singh et al., 2012).

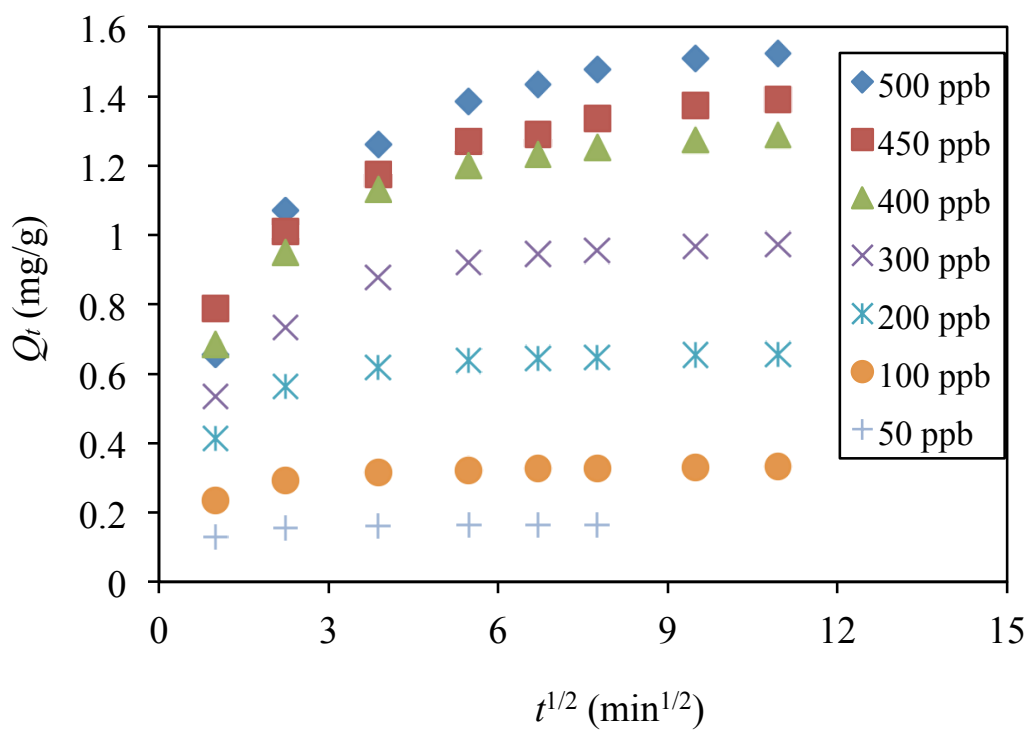

Figure 5.6 Intraparticle diffusion plots for removal of $\mathrm{Cr}(\mathrm{VI})$ by maghemite particles

\subsubsection{Adsorption isotherms}

The adsorption of $\mathrm{Cr}(\mathrm{VI})$ onto maghemite was evaluated using the Freundlich, Langmuir, L-F and Temkin adsorption isotherms. Each of these models involves variations in the extent and different types of adsorption modes. The details of each model are provided in the following section and plots of the experimental data for models are illustrated in Figure. 5.7-5.10.

Freundlich isotherm assumes that the binding sites on the surface of adsorbent are heterogeneous, the adsorption is more difficult as more and more binding sites are occupied by adsorbates and multilayer adsorption can occur. The Freundlich isotherm (Reed et al., 1993) can be represented in the following form: 


$$
Q_{e}=K C_{e}{ }^{1 / n}
$$

where $C_{e}$ is the equilibrium chromium concentration in solution $\left(\mathrm{mg} \mathrm{g}^{-1}\right) . K$ indicates the relative adsorption capacity of the adsorbent and $n$ represents the adsorption intensity. In order to linearize it, the Freundlich isotherm is expressed as:

$$
\log Q e=\log K+1 / n \log C e
$$

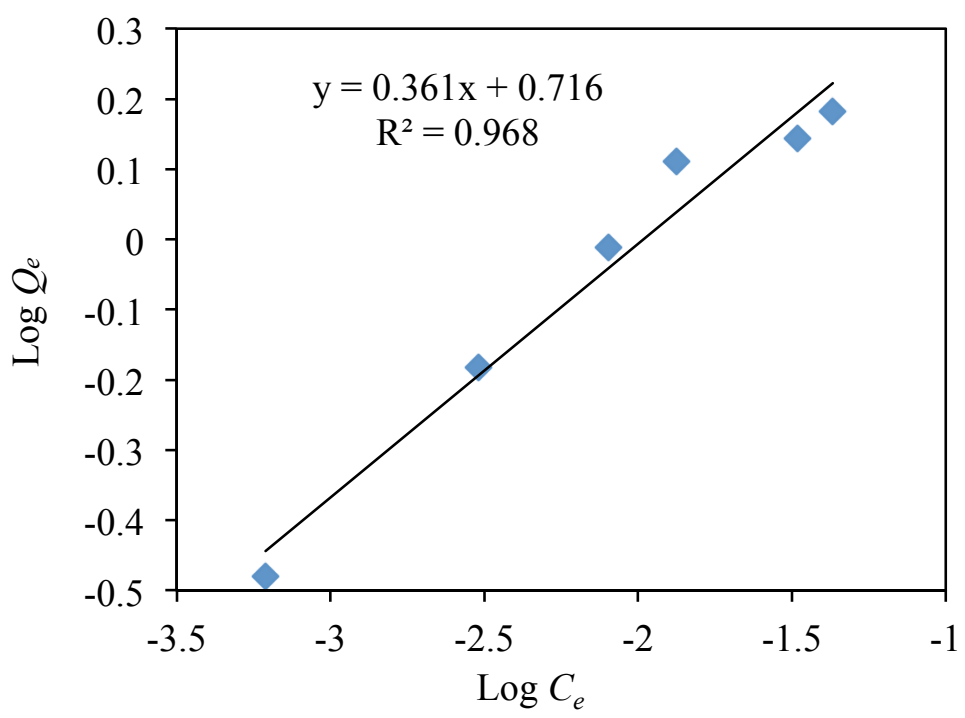

Figure 5.7 Freundlich isotherm illustrating the linear dependence of $\log Q_{e}$ on $\log C_{e}$

The $K$ and $n$ were derived from Figure. 5.7. The value of $K$ is $5.20 \mathrm{mg} \mathrm{g}^{-1}$, while $n$ is 2.77. The Freundlich constant, $n$, can be used to predict the adsorption characteristics. For $n<1$ the adsorption is consider poor, $n$ between a value of 1 and 2 adsorption is defined as moderately difficult with $\mathrm{n}$ values between 2 and 10 is considered good adsorption (Treybal, 1980). The value of $n=2.77$ determined in our studies represents good adsorption. Our results indicate the removal of chromium with small dosages of maghemite is practical. 
Langmuir isotherm equation is derived from the assumption that the adsorbent surface has a fixed number of equivalent binding sites, and the monolayer adsorption occurs without transmigration of adsorbate on the surface of adsorbent isotherm (Reed et al., 1993). The data were modeled with Langmuir adsorption isotherm.

$$
C_{e} / Q_{e}=1 / b Q_{m}+C_{e} / Q_{m}
$$

where $b$ and $Q_{m}$ are the Langmuir adsorption constant $\left(\mathrm{L} \mathrm{mg}^{-1}\right)$ and maximum capacity of adsorbent $\left(\mathrm{mg} \mathrm{g}^{-1}\right)$, respectively. The values of $b$ and $Q_{m}$ are determined from the plot of $C_{e} / Q_{e}$ versus $C_{e}$ (Figure. 5.8). $Q_{m}$ is $1.62 \mathrm{mg} \mathrm{g}^{-1}$, and $b$ is $257.2 \mathrm{~L} \mathrm{mg}^{-1}$.

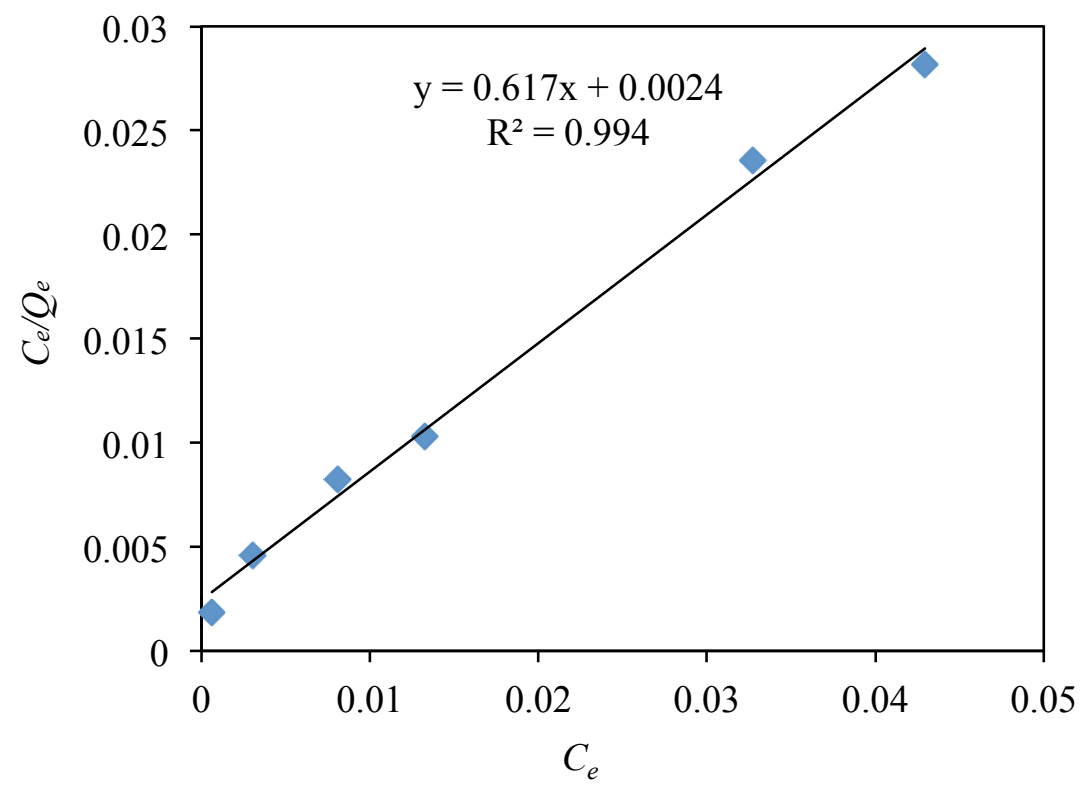

Figure 5.8 Langmuir isotherm illustrating the linear dependence of $C_{e} / Q_{e}$ on $C_{e}$

A dimensionless constant separation factor, $r$, is proposed to predict whether a Langmuir adsorption system is favorable or not. The type of favorability of the absorption isotherm is defined for specific $\mathrm{r}$ values as follows, for $r>1$ unfavorable, $r=1$ is linear, $r$ between 0 and 1 is favorable and $r=0$ irreversible (Wan Ngah et al., 2002). 
The separation factor, $r$, is defined as follow:

$$
r=1 /\left(1+b C_{o}\right)
$$

where $C_{0}$ is the initial concentration of chromium and $b$ is the Langmuir adsorption constant $\left(\mathrm{L} \mathrm{mg}^{-1}\right)$. Since both $b$ and $C_{0}$ are greater than 0 in this study, the value of $r$ lies within the range 0 to 1 . This indicates the adsorption of $\mathrm{Cr}(\mathrm{VI})$ on maghemite particle is highly favorable under the experimental condition used in this study.

Standard Gibbs free energy $\left(\Delta G_{0}, \mathrm{~J} \mathrm{~mol}^{-1}\right)$ can be used to evaluate the spontaneity of an adsorption process. A negative $\Delta G_{0}$ indicates the adsorption occurs spontaneous and is thermodynamically stable, whereas the positive $\Delta G_{0}$ means this process is a disfavored nonspontaneous reaction. The standard Gibbs free energy equation is expressed as following (Ho et al., 2005):

$$
\ln (1 / b)=\Delta G_{0} / R T
$$

where $R$ is the ideal gas constant $\left(8.314 \mathrm{~J} \mathrm{~K}^{-1} \mathrm{~mol}^{-1}\right)$ and $T$ is absolute temperature (K). Since $b$ is $257.2 \mathrm{~L} \mathrm{mg}^{-1}, \Delta G_{0}$ is negative in this study. The result indicates that the adsorption process is spontaneous.

L-F isotherm is the combination of Langmuir and Freundlich isotherms (Umpleby et al., 2001). The experimental data were also modeled with L-F adsorption isotherm.

$$
Q_{e}=Q_{m} k C e^{m} /\left(1+k C_{e}{ }^{m}\right)
$$

where $Q_{m}$ is the total amount of binding sites on the adsorbent surface, $k$ is related to the mean association constant $\left(K_{0}\right), K_{0}=k^{1 / m}$, and $\mathrm{m}$ represents the heterogeneity index of the binding site energy, which varies from 0 to 1 . As $m$ approaches to 1 , the adsorbent is homogeneous and the L-F equation is reduced to Langmuir. For a heterogeneous material, $m<1$, and when either $m$ or $k$ is 0 , the L-F equation can be reduced to 
Freundlich. Therefore, L-F isotherm is able to model both of homogeneous and heterogeneous adsorption systems. The maximum of $\mathrm{R}^{2}$ is obtained from the plot of $1 / Q_{e}$ vs $1 / C_{e}^{m}$ (Figure. 5.9) by solver function of Microsoft Excel 2007, where $m=0.55$. Therefore, the value of $Q_{m}$ is $2.62 \mathrm{mg} \mathrm{g}^{-1}$, and $k$ is equal to $8.42 \mathrm{mg}^{-1}$. The mean association constant is $48.3 \mathrm{mg}^{-1}$.

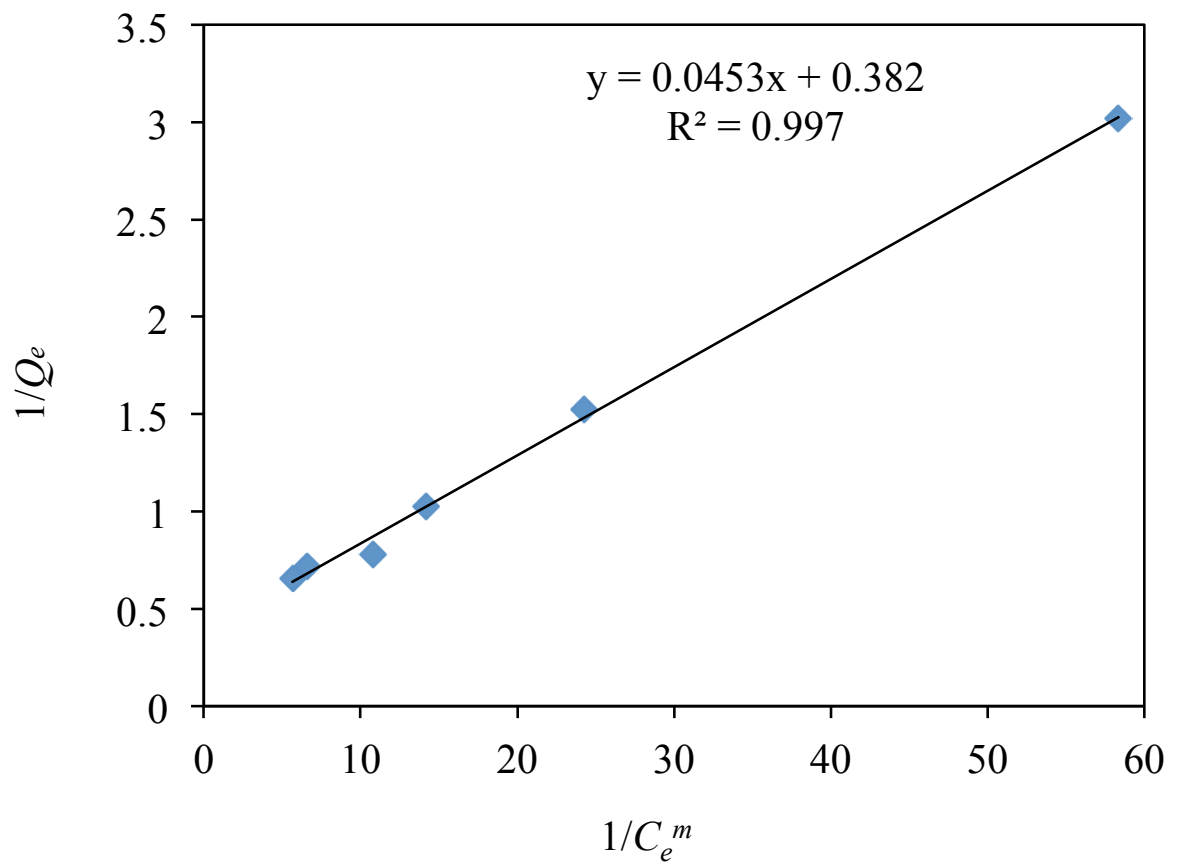

Figure 5.9 L-F isotherm illustrating the linear dependence of $1 / Q_{e}$ on $1 / C_{e}{ }^{\mathrm{m}}$

The Temkin isotherm equation is given as (Özacar et al., 2005):

$$
Q_{e}=\left(R T / b_{i}\right) \ln K_{t}+\left(R T / b_{i}\right) \ln C_{e}
$$

where $K_{t}$ is the Temkin isotherm constant $\left(\mathrm{L} \mathrm{g}^{-1}\right), b_{i}$ is the Temkin constant related to heat of sorption $\left(\mathrm{J} \mathrm{mol}^{-1}\right), R$ is the ideal gas constant $\left(8.314 \mathrm{~J} \mathrm{~K}^{-1} \mathrm{~mol}^{-1}\right)$ and $T$ is the Kelvin temperature (K). The value of $K_{t}$ and $b_{i}$ were obtained by the plotting of $Q_{e}$ vs $\ln C_{e}$ (Figure. 5.10). $K_{t}$ is $4.39 \mathrm{~L} \mathrm{~g}^{-1}$, while $b_{i}$ is $8.64 \mathrm{~kJ} \mathrm{~mol}^{-1}$. 


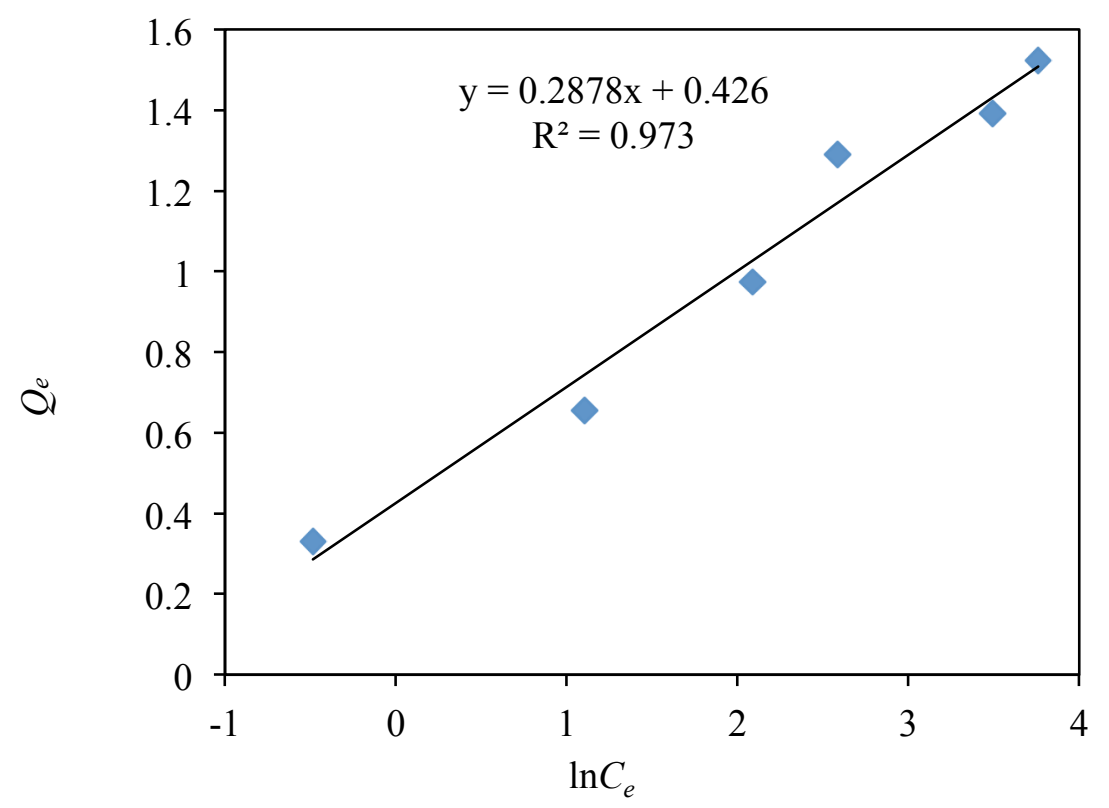

Figure 5.10 Temkin isotherm illustrating the linear dependence of $Q_{e}$ on $\ln C_{e}$

A comparison of $\mathrm{R}^{2}$ was made among four adsorption isotherms. Compared to Langmuir, Freundlich and Temkin adsorption isotherms, L-F isotherm has the highest value of $\mathrm{R}^{2}$, indicating the adsorption of chromium by maghemite fits better with L-F isotherm. The heterogeneity index of L-F isotherm is 0.55 , which is between 0 and 1 . The adsorption has partial adsorption characteristics of Langmuir and Freundlich models. The adsorption fits also the Langmuir model nicely, and it may be due to monolayer adsorption. Therefore, adsorption isotherm studies imply that it is a heterogeneous monolayer adsorption (Lee et al., 1995).

\subsubsection{The effect of $\mathrm{pH}$ on $\mathrm{Cr}(\mathrm{VI})$ adsorption}

The $\mathrm{pH}$ effect on $\mathrm{Cr}(\mathrm{VI})$ adsorption was evaluated over a $\mathrm{pH}$ range from 2 to 10 . $\mathrm{HNO}_{3}$ and $\mathrm{NaOH}$ solutions were used to adjust solution $\mathrm{pH}$. Figure. 5.11 shows the $\mathrm{Cr}(\mathrm{VI})$ removal as a function of $\mathrm{pH}$. Electrostatic interactions can have a pronounced impact on adsorption processes. The $\mathrm{pK}_{\mathrm{a} 1}$ and $\mathrm{pK}_{\mathrm{a} 2}$ of chromic acid are 0.74 and 6.50 , 
respectively. The zero point of charge (ZPC) of maghemite is 6.6 (Cornell et al., 2003). Below the $\mathrm{pH}$ of the ZPC the particle surface becomes positively charged, while $\mathrm{Cr}(\mathrm{VI})$ exists predominantly in dianionic $\left(\mathrm{CrO}_{4}{ }^{2-}\right)$ and mono-anionic $\left(\mathrm{HCrO}_{4}{ }^{-}\right)$forms between $\mathrm{pH}$ $\sim 2$ and 6.5. Thus under mildly acidic conditions, attractive electrostatic interactions between negatively charged $\mathrm{Cr}(\mathrm{VI})$ species and the positive surface lead to favorable adsorption. We observed the removal efficiency of $\mathrm{Cr}(\mathrm{VI})$ increases with the decrease of $\mathrm{pH}$ to 4 . However under strongly acidic conditions the adsorption decreases modestly as the $\mathrm{Cr}(\mathrm{VI})$ speciation becomes dominated by the neutral form $\left(\mathrm{H}_{2} \mathrm{CrO}_{4}\right)$ eliminating the strong electrostatic attraction of negatively charged chromate species and positively charged surface. Above the $\mathrm{pH}$ of $\mathrm{ZPC}$, the particle surface processes an overall negative charge while the dominant species of $\mathrm{Cr}(\mathrm{VI})$ is $\mathrm{CrO}_{4}{ }^{2-}$ (Tandon et al., 1984) and thus under basic conditions electrostatic repulsion exists and poor adsorption is observed. While $\mathrm{pH}$ can have a pronounced influence on the adsorption, effective removal can be achieved over a significant $\mathrm{pH}$ range from 2 to 8 .

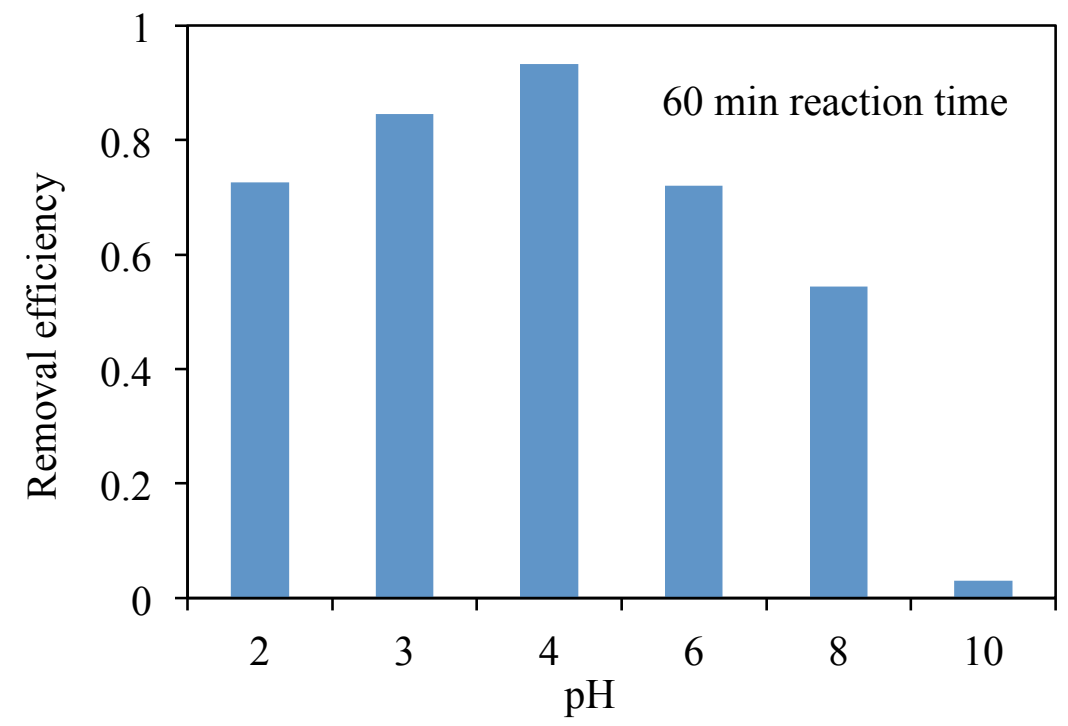

Figure 5.11 Effect of $\mathrm{pH}$ on $\mathrm{Cr}(\mathrm{VI})$ adsorption. $[\mathrm{Cr}(\mathrm{VI})]_{0}=500 \mathrm{ppb}$, $[$ maghemite $]=0.3$ $\mathrm{g} / \mathrm{L}$ 


\subsubsection{Effect of humic acid}

The presence of humic acids in surface waters can have a pronounced effect on iron based water treatment processes (Gu et al., 1994). Humic acids contain carboxylic acid and phenolic functional groups which can engage in ligand exchange and complexation of metal ions (Vermeer et al., 1999). The adsorption of $\operatorname{Cr}(\mathrm{VI})$ by nanoparticles as a function of humic acid concentration is illustrated in Figure. 5.12. The interaction of humic acid with iron oxides can alter the surface property of maghemite nanoparticles and the subsequent adsorption of $\mathrm{Cr}(\mathrm{VI})$. In the presence of $1 \mathrm{ppm}$ humic acid we observed minimal change in the overall adsorption of $\mathrm{Cr}(\mathrm{VI})$. Under such conditions stabilization of the suspension leading to inhibition of particle aggregation, reduction of $\mathrm{Cr}(\mathrm{VI})$ (Wittbrodt et al., 1995), and humic acid complexation of chromate species can contribution to the removal of $\mathrm{Cr}(\mathrm{VI})$ (Uyguner et al., 2004). At intermediate humic acid concentrations the observed $\mathrm{Cr}(\mathrm{VI})$ adsorption also does not change significantly. However as the concentration of humic acid increases the $\mathrm{Cr}(\mathrm{VI})$ adsorption decreases under our experimental conditions. The coating of maghemite nanoparticles with humic acid will increase with humic acid blocking potential adsorption sites for $\mathrm{Cr}(\mathrm{VI})$ and increasing the presence of negatively charged carboxylic groups at the surface essentially decreasing the ZPC of the particles (Illés et al., 2003). Under these conditions repulsion will increase between negatively charged $\mathrm{Cr}(\mathrm{VI})$ and negatively charged humic acid modified surface. At high humic acid concentrations $\mathrm{Cr}(\mathrm{VI})$ adsorption decreased significantly possibly due to humic acid coating the as the iron oxide particle (Hu et al., 2010). The removal of $\mathrm{Cr}(\mathrm{VI})$ can be achieved in the presence of significant levels of humic acid. 


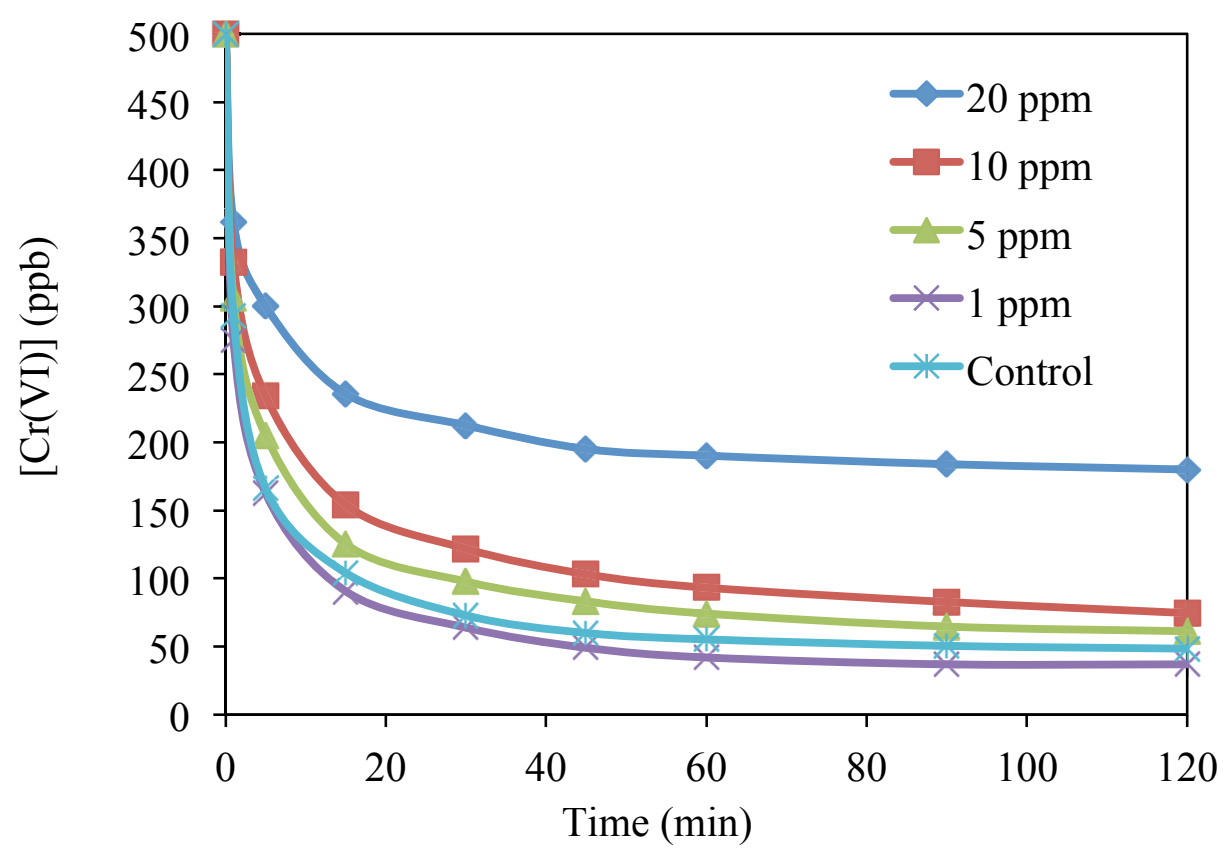

Figure 5.12 Effect of humic acid on $\mathrm{Cr}(\mathrm{VI})$ adsorption. $[\mathrm{Cr}(\mathrm{VI})]_{0}=500$ $\mathrm{ppb},[$ maghemite $]=0.3 \mathrm{~g} / \mathrm{L}$

\subsection{Conclusion}

Magnetic maghemite nanoparticles were synthesized by a co-precipitation method, characterized and employed for $\mathrm{Cr}(\mathrm{VI})$ removal. The adsorption kinetics for $\mathrm{Cr}(\mathrm{VI})$ are accurately modeled by a pseudo-second-order model. The intraparticle diffusion model implies that the adsorption was controlled by surface sorption and intraparticle diffusion, followed by a redox reaction. The adsorption isotherm fits the L-F and Langmuir equations well implying heterogeneous monolayer adsorption. The standard Gibbs free energy, adsorption characteristics and effect of separation factor on isotherm shape indicate that adsorption of $\mathrm{Cr}(\mathrm{VI})$ is spontaneous, favorable and practical. The adsorption under basic condition is weak, but strong under the mildly acidic and neutral conditions often associated with contaminated surface waters. The presence of low concentrations of humic acid does not have a significant impact on the adsorption of $\mathrm{Cr}(\mathrm{VI})$ however at relatively high humic acid concentration (20 ppm) the adsorption of $\mathrm{Cr}(\mathrm{VI})$ can be 
partially inhibited. The maghemite nanoparticles are low-cost, easily prepared, magnetic, and good adsorbents for $\mathrm{Cr}(\mathrm{VI})$ making them a promising material for removal of $\mathrm{Cr}(\mathrm{VI})$ from aqueous solution. 
$6 \mathrm{Cr}(\mathrm{VI})$ Adsorption and Reduction by Humic Acid Coated Magnetite 


\subsection{Abstract}

We report the effective adsorption and reduction of toxic $\operatorname{Cr}(\mathrm{VI})$ to non-toxic $\mathrm{Cr}$ (III) by easily separable humic acid coated magnetite (HA- $\mathrm{Fe}_{3} \mathrm{O}_{4}$ ) nanoparticles. The adsorption fits the Langmuir isotherm model nicely and the extraction of $\mathrm{Cr}(\mathrm{VI})$ from aqueous media by $\mathrm{HA}-\mathrm{Fe}_{3} \mathrm{O}_{4}$ particles follows pseudo-second-order kinetics. The extraction and reduction of $\mathrm{Cr}(\mathrm{VI})$ is effective under acidic, neutral, and basic conditions. Characterization of the $\mathrm{Cr}$ loaded $\mathrm{HA}-\mathrm{Fe}_{3} \mathrm{O}_{4}$ materials by X-ray absorption near edge structure spectroscopy (XANES) demonstrates $\mathrm{Cr}(\mathrm{VI})$ was reduced to $\mathrm{Cr}(\mathrm{III})$ while the valence state of iron core is unchanged. Fe K-edge EXAFS and X-ray diffraction measurements also indicate no detectable transformation of $\mathrm{Fe}_{3} \mathrm{O}_{4}$ core occurs during $\mathrm{Cr}(\mathrm{VI})$ adsorption and reduction. We propose $\mathrm{HA}$ on the surface of $\mathrm{HA}-\mathrm{Fe}_{3} \mathrm{O}_{4}$ is responsible for the reduction of $\mathrm{Cr}(\mathrm{VI})$ to $\mathrm{Cr}(\mathrm{III})$ and not the $\mathrm{Fe}_{3} \mathrm{O}_{4}$ core. The functional groups associated with HA act as ligands leading the Cr(III) complex via a coupled reduction-complexation mechanism. Extended X-ray absorption fine structure spectroscopy (EXAFS) demonstrates the $\mathrm{Cr}(\mathrm{III})$ in the chromium loaded $\mathrm{HA}-\mathrm{Fe}_{3} \mathrm{O}_{4}$ materials has six neighboring oxygen atoms in an octahedral geometry with average bond lengths of $1.98 \AA$. These results demonstrate easily separable $\mathrm{HA}-\mathrm{Fe}_{3} \mathrm{O}_{4}$ particles have promising potential for removal and detoxification of $\mathrm{Cr}(\mathrm{VI})$ in aqueous media.

\subsection{Introduction}

The presence of chromium $(\mathrm{Cr})$ in many aquatic systems and sources of drinking water supply is a serious threat to the environment and human health. The US EPA and World Health Organization have set maximum contaminant limits for total chromium in drinking water of 100 and $50 \mu \mathrm{g} / \mathrm{L}$, respectively (Thomas et al., 2002). Exposure to $\mathrm{Cr}$ 
has detrimental health consequences on humans and has been linked to carcinomas of the respiratory organs, mutations, chromosomal aberrations, and DNA damage (Nordberg et al., 2007). The introduction of chromium into aquatic environments occurs from both natural sources and anthropogenic activities. The world-wide production of chromite is 12.8 million tons in 1999, and estimated 1068 thousand metric tons of chromium are introduced into biosphere annually (Bishnoi et al., 1993). The toxicity, solubility, and mobility of $\mathrm{Cr}$ are highly dependent on the oxidation state. Speciation of $\mathrm{Cr}$ in aqueous media occurs predominately between $\mathrm{Cr}(\mathrm{VI})$ and $\mathrm{Cr}(\mathrm{III})$. Although $\mathrm{Cr}(\mathrm{III})$ is an essential micronutrient in the human body, $\mathrm{Cr}(\mathrm{VI})$ is highly soluble in aqueous media, acutely toxic, mutagenic, and carcinogenic (O'Brien et al., 1995). Reduction of the $\mathrm{Cr}(\mathrm{VI})$ to $\mathrm{Cr}(\mathrm{III})$ is critical in the detoxification of $\mathrm{Cr}(\mathrm{VI})$-contaminated media and effective treatment processes. Treatment strategies and current removal methods typically involve reduction of $\mathrm{Cr}(\mathrm{VI})$ to $\mathrm{Cr}$ (III) followed by adsorption and subsequent separation of the Cr laden absorbent by filtration or other methods (Idris et al., 2010; Owlad et al., 2009).

Iron based materials have received significant attention for environmental applications and treatment of a variety of pollutants and toxins from aqueous solutions (Niu et al., 2011; Yavuz et al., 2006). Iron magnetic nanoparticles (MNPs) are attractive for remediation applications as they possess high surface areas, are inexpensive, and easily separated and recovered by simply applying an external magnetic field. Magnetite, the most magnetic of naturally occurring minerals, is a mixture of $\mathrm{Fe}(\mathrm{II})$ and $\mathrm{Fe}(\mathrm{III})$ and exists in sediments in natural aquatic systems (King et al., 1982). Bare magnetite, $\mathrm{Fe}_{3} \mathrm{O}_{4}$ nanoparticles have been successfully applied for remediation of $\mathrm{Cr}(\mathrm{VI})$-contaminated waters (Hu et al., 2004). The Fe(II) in magnetite can initiate the reduction of $\mathrm{Cr}(\mathrm{VI})$ to 
$\mathrm{Cr}(\mathrm{III})$, and the $\mathrm{Cr}(\mathrm{III})$ can subsequently be chelated by $\mathrm{OH}$ groups at the surface of iron oxide to form an inner-sphere surface complex (Grossl et al., 1997; Kendelewicz et al., 2000). In addition $\mathrm{Cr}(\mathrm{III})$ can form precipitates such as $\mathrm{Cr}(\mathrm{OH})_{3}$ and $\mathrm{Fe}_{\mathrm{x}} \mathrm{Cr}_{1-\mathrm{x}}(\mathrm{OH})_{3}$ in aqueous solutions (Rai et al., 1987; Sass et al., 1987). However the Fe(II) present in magnetite is highly susceptible to auto-oxidation forming Fe(III) materials which can dramatically reduce the associated magnetic properties (Chowdhury et al., 2010). Thus the reduction of $\mathrm{Cr}(\mathrm{VI})$ by $\mathrm{Fe}(\mathrm{II})$ based MNP will lead to the decrease in the magnetic properties of the materials which in turn could make their separation by simple application of a magnetic field not very effective.

Surface modification of MNP iron materials can inhibit their auto-oxidation and increase the adsorption selectivity and capacity. A number of naturally occurring and synthetic organic materials have been employed as coating materials (shells) for magnetite. Humic acid MNPs $\left(\mathrm{HA}-\mathrm{Fe}_{3} \mathrm{O}_{4}\right)$ have been synthesized and are promising materials for the removal of metals and organic contaminants (J.-f. Liu et al., 2008; Niu et al., 2011). The $\mathrm{HA}-\mathrm{Fe}_{3} \mathrm{O}_{4}$ materials are remarkably stable under ambient conditions, resistant to auto-oxidation and maintain their magnetic properties (J.-f. Liu et al., 2008).

Humic acids are derived from plants and microbial residues, and present ubiquitous in aquatic environments. Humic acid has a high affinity to magnetite (Korshin et al., 1997) and the iron core HA shell MNPs are readily synthesized through surface complexation-ligand exchange reactions between $\mathrm{HA}$ and iron oxide. Humic acid materials possess a variety of functional groups, notably carbonyl groups, carboxylic acids, phenolic and hydroxyl groups. Humic acids have high adsorption capacity for metal ions because of the different and large numbers of functional groups which are 
capable of complexing metal ions. Another consequence of coating of magnetite with HA is a reduction in the aggregation of iron oxide particles. The adsorption of HA can insulate the aggregation of magnetite, and the negatively charged functional groups associated with HA can neutralize magnetite particle. Magnetite particles which are completely covered by HA exhibit the characteristic of HA (Hu et al., 2010), low pH of point of zero charge and negatively charged under solution $\mathrm{pH}>3$.

Chromium(VI) removal and reduction by bare Fe based MNPs unfortunately leads to deterioration of the magnetic properties required for simple separation following treatment. $\mathrm{HA}-\mathrm{Fe}_{3} \mathrm{O}_{4}$ hybridized materials have shown tremendous potential for water purification; however, their application for the removal of $\mathrm{Cr}$ has not yet been reported. The $\mathrm{Fe}(\mathrm{II})$ core and $\mathrm{HA}$ can in theory function as reductants for $\mathrm{Cr}(\mathrm{VI})$ under environmental conditions (Buerge et al., 1997; Wittbrodt et al., 1996). We report herein the application of $\mathrm{HA}-\mathrm{Fe}_{3} \mathrm{O}_{4}$ nanoparticles for the removal $\mathrm{Cr}(\mathrm{VI})$ from aqueous solution. Characterization of the $\mathrm{Cr}$ loaded $\mathrm{HA}-\mathrm{Fe}_{3} \mathrm{O}_{4}$ materials show $\mathrm{Cr}(\mathrm{VI})$ is reduced to $\mathrm{Cr}$ (III) by $\mathrm{HA}$ on the surface of $\mathrm{HA}-\mathrm{Fe}_{3} \mathrm{O}_{4}$, and the functional groups associated with $\mathrm{HA}$ act as ligands for $\mathrm{Cr}(\mathrm{III})$ via a coupled reduction-complexation mechanism. $\mathrm{Cr}$ (III) has six neighboring oxygen atoms arranged in an octahedral geometry. Our results provide a fundamental understanding of the chemistry of the $\mathrm{HA}-\mathrm{Fe}_{3} \mathrm{O}_{4}$ in the reductive complexation and immobilization of $\mathrm{Cr}(\mathrm{VI})$ from aqueous media. The HA insulates the iron core from auto-oxidation and electron transfer with $\mathrm{Cr}(\mathrm{VI})$, preserving the magnetic properties of these materials with the HA mediated conversion of carcinogenic $\mathrm{Cr}(\mathrm{VI})$ to non-toxic $\mathrm{Cr}(\mathrm{III})$. The $\mathrm{HA}-\mathrm{Fe}_{3} \mathrm{O}_{4}$ particles are easily separated following treatment by 
application of a magnetic field. Our results demonstrate their tremendous potential for removal and detoxification of $\mathrm{Cr}(\mathrm{VI})$ in aqueous media.

\subsection{Materials and methods}

\subsubsection{Materials}

Potassium chromate $(99.8 \%)$, sodium hydroxide $(99.4 \%)$, trace metal grade nitric acid (67-70\%), ammonium hydroxide (29.15\%), and ferric chloride tetrahydrate $(100.8 \%)$ were purchased from Fisher. Ferrous chloride tetrahydrate $(\geq 99.0 \%)$ and HA (sodium salt, CAS no. 68131-04-4) were obtained from Sigma. All solutions were prepared with Millipore filtered water $(18 \mathrm{M} \Omega \cdot \mathrm{cm})$ produced from a nanopure diamond lab water system (Barnstead Thermolyne Corporation, Dubuque, IA).

\subsubsection{Preparation of bare $\mathrm{Fe}_{3} \mathrm{O}_{4}, \mathrm{HA}-\mathrm{Fe}_{3} \mathrm{O}_{4}$ and $\mathrm{Cr}$-loaded $\mathrm{HA}-\mathrm{Fe}_{3} \mathrm{O}_{4}$}

The bare $\mathrm{Fe}_{3} \mathrm{O}_{4}$ and $\mathrm{HA}-\mathrm{Fe}_{3} \mathrm{O}_{4}$ materials were prepared according to a published method (J.-f. Liu et al., 2008). Iron solutions of $\mathrm{FeCl}_{2} \cdot 4 \mathrm{H}_{2} \mathrm{O}(3.0 \mathrm{~g})$ and $\mathrm{FeCl}_{3} \cdot 6 \mathrm{H}_{2} \mathrm{O}$ $(6.1 \mathrm{~g})$ were dissolved in $100 \mathrm{~mL}$ of water. The iron mixture was heated to $90{ }^{\circ} \mathrm{C}$ in a $250 \mathrm{~mL}$ round bottom flask equipped with a reflux condenser. The reaction solution was magnetically stirred throughout the reaction process. Ten $\mathrm{mL}$ of $25 \%$ ammonium hydroxide and $50 \mathrm{~mL}$ of $1.0 \% \mathrm{HA}$ solution (for $\mathrm{HA}-\mathrm{Fe}_{3} \mathrm{O}_{4}$ synthesis) were added to the mixture rapidly and sequentially. The mixture was aged at $90 \pm 5{ }^{\circ} \mathrm{C}$ for an additional 30 min. The solid products were washed with water and dried to constant weight in a vacuum oven at $\sim 40{ }^{\circ} \mathrm{C}$. The vacuum-dried particles were stored in a vacuum desiccator.

HA- $\mathrm{Fe}_{3} \mathrm{O}_{4}$ particles $(0.5 \mathrm{~g})$ were added to $50 \mathrm{~mL}$ of $1.0 \mathrm{mM}$ potassium chromate solution in a $250 \mathrm{~mL}$ Erlenmeyer flask. The solution $\mathrm{pH}$ was adjusted using $5 \%$ aqueous 
solutions of $\mathrm{NaOH}$ and $\mathrm{HNO}_{3}$. The experiments were carried out on an orbit shaker (Lab-line instrument Inc., model 3520) with continual mixing at 300 revolutions per minute (RPM) for $4 \mathrm{hrs}$ in a temperature-controlled laboratory. Samples were separated from the suspension with a handheld permanent magnet, washed with $\sim 10 \mathrm{~mL}$ water four times, and dried in a vacuum oven at $\sim 40{ }^{\circ} \mathrm{C}$ to constant weight. The total $\mathrm{Cr}$ and dissolved organic carbon in the aqueous phase were measured using an atomic absorption spectrophotometer (AAS) (Perkin-Elmer AA600) (Jiang et al., 2013) and Shimadzu TOC-VCSH total organic carbon analyzer, respectively. For the effect of humic acid on $\mathrm{Cr}$ in aqueous solution, the samples were filterer through Macrosep advance centrifugal devices ( $3 \mathrm{~K}$ molecular weight cut-off) at $5000 \mathrm{RPM}$ to remove residual humic acid, and followed by an AAS measurement.

\subsubsection{Characterizations}

The FTIR spectra of $\mathrm{HA}-\mathrm{Fe}_{3} \mathrm{O}_{4}$ and $\mathrm{Cr}$-loaded $\mathrm{HA}-\mathrm{Fe}_{3} \mathrm{O}_{4}$ were collected using a Perkin-Elmer 100 FTIR spectrometer. Transmission electron microscopy (TEM) measurements were run using a Phillips CM-200 (200 kV). Nitrogen adsorption and desorption isotherms were performed for Brunauer-Emmett-Teller (BET) surface area on a Micromeritics TriStar II 3020 system and $\mathrm{HA}-\mathrm{Fe}_{3} \mathrm{O}_{4}$ was prepared by purging with nitrogen gas at $80{ }^{\circ} \mathrm{C}$ for $4.0 \mathrm{~h}$ before analyses. The total carbon of $\mathrm{HA}-\mathrm{Fe}_{3} \mathrm{O}_{4}$ was measured using a Carlo Erba NA 1500 analyzer. The X-ray diffraction (XRD) analysis was carried out on beamline X14A at National Synchrotron Light Source, Brookhaven National Lab (NSLS, BNL). The storage ring was operated at $3.0 \mathrm{GeV}$ with current $280 \mathrm{~mA}$. The wavelength of incident beam was set at $0.7785 \AA$ by a saggittal-focusing monochromator (Chung et al., 2000). The spot size was $\sim 1.5 \times 1 \mathrm{~mm}$ (horizon vs 
vertical). A sample filled capillary tube $(0.7 \mathrm{~mm}$ diameter) was rotated by a spinner on a six-circle Huber diffractometer. The diffraction peaks in the range $4-46^{\circ}$ were collected using a Si strip position-sensitive detector mounted on the diffractometer. The zeta potential of bare $\mathrm{Fe}_{3} \mathrm{O}_{4}, \mathrm{HA}-\mathrm{Fe}_{3} \mathrm{O}_{4}$ and $\mathrm{Cr}$-loaded $\mathrm{HA}-\mathrm{Fe}_{3} \mathrm{O}_{4}$ were measured at different pH using Malvern zetasizer Nano ZS (Malvern Instruments, UK).

The X-ray absorption spectra (XAS) were obtained on vacuum-dried samples employing a beamline X19A at NSLS. The storage ring was operated under conditions described above for XRD measurements. The relative energy resolution of X19A was approximately $2 \times 10^{-4}$ for Fe $K$-edge $(7112 \mathrm{eV})$ and $\mathrm{Cr} K$-edge $(5989 \mathrm{eV}) \mathrm{XAS}$ measurements, and the harmonics were minimized by detuning double-crystal Si (111) monochromator to obtain a $30 \%$ reduction in the intensity of the incident X-ray. The Fe $K$-edge spectra and $\mathrm{Cr} K$-edge XAS spectra of reference $\mathrm{Cr}$ compounds were collected using a Canberra PIPS-detector in fluorescence mode. Given the relatively low $\mathrm{Cr}$ concentrations, the $\mathrm{Cr} K$-edge XAS spectra at of $\mathrm{Cr}$-loaded $\mathrm{HA}-\mathrm{Fe}_{3} \mathrm{O}_{4}$ samples were measured using a 4-elements Si-drift Vortex detector in fluorescence mode. The incident beam was monitored by an ion chamber filled with nitrogen gas. The X-ray absorption spectra were divided into XANES and EXAFS regions. X-ray absorption near edge structure spectroscopy were analyzed by IFEFFIT and Demeter package (Ravel et al., 2005), while EXAFS were analyzed using WinXAS 3.1 (Ressler, 1998).

\subsection{Results and discussion}

\subsubsection{The $\mathrm{pH}$ effect on adsorption and reduction of $\mathrm{Cr}(\mathrm{VI})$}

We chose to investigate the adsorption and reduction of $\mathrm{Cr}(\mathrm{VI})$ on $\mathrm{HA}-\mathrm{Fe}_{3} \mathrm{O}_{4}$. The synthesized $\mathrm{HA}-\mathrm{Fe}_{3} \mathrm{O}_{4}$ materials employed for removal of toxic $\mathrm{Cr}(\mathrm{VI})$ are 
composed of particles with average diameters of $\sim 15 \mathrm{~nm}$ and BET surface areas 104

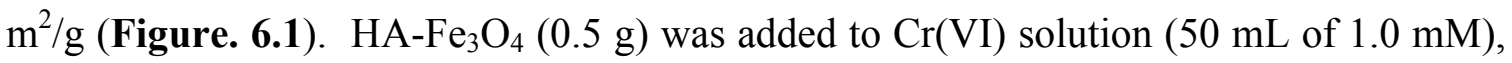
and the $\mathrm{pH}$ was adjusted and the suspension was agitated at $300 \mathrm{RPM}$. After $4 \mathrm{hrs}$ of mixing, the $\mathrm{HA}-\mathrm{Fe}_{3} \mathrm{O}_{4} \mathrm{MNP}$ with adsorbed $\mathrm{Cr}$ were separated using a hand held magnet. The solution was retained for analyses of levels of total carbon (TC) and Cr. The released TC from $\mathrm{HA}-\mathrm{Fe}_{3} \mathrm{O}_{4}$ is an indication of desorbed $\mathrm{HA}$ back into solution from the particles. Only $\leq 2 \% \mathrm{TC}$ was leached under acidic, basic, and neutral conditions. Our results are consistent with a number of reports indicating desorption of HA from such materials is highly unfavorable (J.-f. Liu et al., 2008; Yang et al., 2012). After ultrafitration for the removal of HA, the concentration of Cr did not show any significant difference, indicating that the leaching HA does not have a critical effect on the chromium in the resulting solutions.

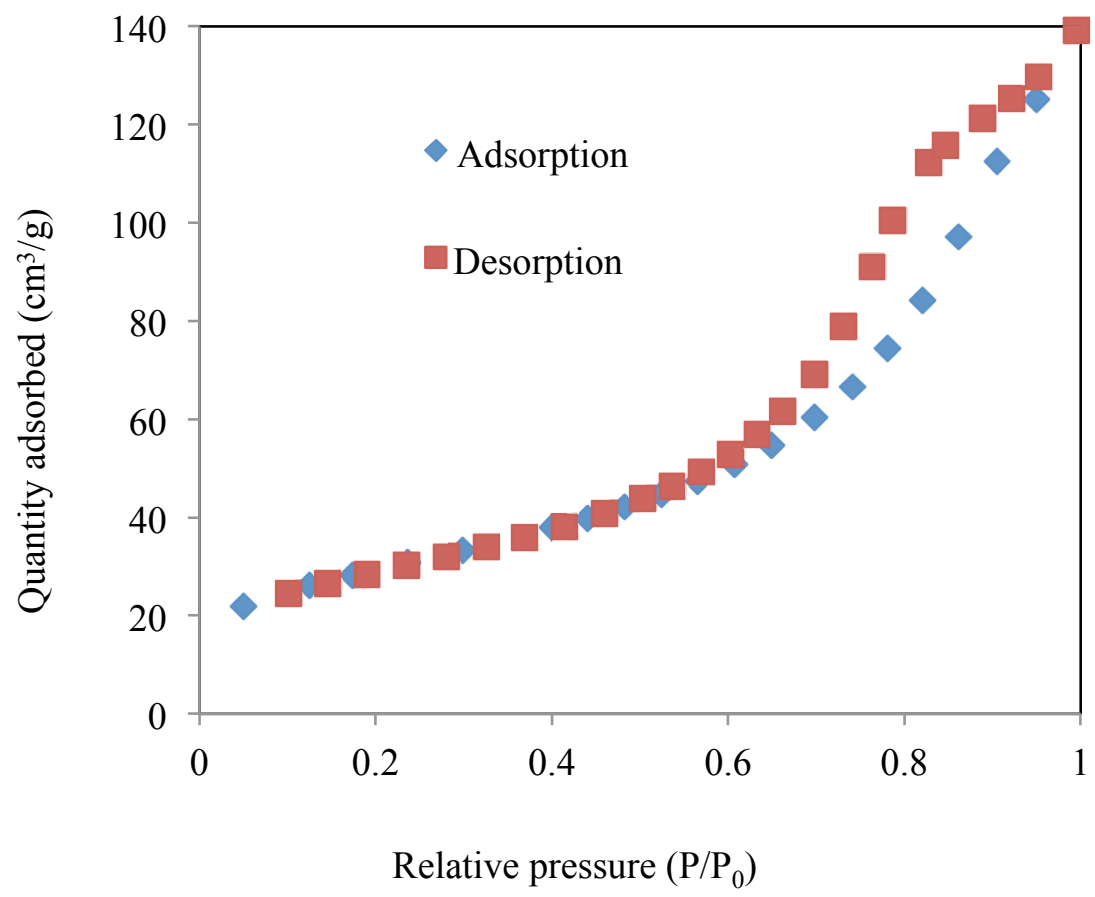

Figure 6.1 Nitrogen adsorption and desorption isotherms of humic acid coated magnetite 
The capacity for the particles to adsorb $\mathrm{Cr}$ was measured under acidic ( $\mathrm{pH} 4)$, neutral $(\mathrm{pH} \mathrm{7})$ and alkaline $(\mathrm{pH} 10)$ conditions. The particles maintained high $\mathrm{Cr}$ removal efficiency, removing $80-90 \%$ of the $\mathrm{Cr}$ from solutions under acidic, neutral and alkaline conditions as illustrated in Figure. 6.2. While there appears to be a slight decrease in the adsorption capacity moving from acidic to alkaline conditions, the overall differences are within the reproducibility of the experiments. The solution $\mathrm{pH}$ often influences the adsorption processes. While under extreme $\mathrm{pH}$ the humic acid materials may be hydrolyzed from the surface, under the typical range of solution $\mathrm{pH}$ (4-10) desorption was insignificant. The observation is consistent with the documented high affinity of HA for magnetite via a ligand exchange reactions ( $\mathrm{Gu}$ et al., 1995). The surface properties of the $\mathrm{HA}-\mathrm{Fe}_{3} \mathrm{O}_{4}$ particles are characteristic of the $\mathrm{HA}$ with respect to the surface charge and the presence of HA inhibits particle aggregation normally observed in the case of unmodified magnetite (Illés et al., 2006). The $\mathrm{pH}$ of zero point charge $\left(\mathrm{pH}_{\mathrm{PZC}}\right)$ of bare magnetite is $\sim 7.6$, while the $\mathrm{pH}_{\mathrm{PZC}}$ of the $\mathrm{HA}-\mathrm{Fe}_{3} \mathrm{O}_{4}$ and $\mathrm{Cr}$ loaded $\mathrm{HA}-\mathrm{Fe}_{3} \mathrm{O}_{4}$ materials was reported to be $\sim 3.3$ (Figure. 6.3), indicating that the adsorption of $\mathrm{Cr}$ does not change the the $\mathrm{pH}_{\mathrm{PZC}}$ of $\mathrm{HA}-\mathrm{Fe}_{3} \mathrm{O}_{4}$. The $\mathrm{HA}-\mathrm{Fe}_{3} \mathrm{O}_{4}$ materials are negatively charged except under strong acidic conditions and effective for adsorption of positively charged ions by electrostatic attraction. The $\mathrm{pKa}_{1}$ and $\mathrm{pKa}_{2}$ of $\mathrm{H}_{2} \mathrm{CrO}_{4}$ are 0.74 and 6.50 , respectively. The common chemical species of $\mathrm{Cr}(\mathrm{VI})$ in aqueous media, $\mathrm{CrO}_{4}{ }^{2-}, \mathrm{HCrO}_{4}{ }^{-}, \mathrm{Cr}_{2} \mathrm{O}_{7}{ }^{2-}$, are negatively charged. While adsorption is often governed by electrostatic repulsion and attraction between adsorbent and adsorbate, our results demonstrate that the repulsive electrostatic interaction between the $\mathrm{HA}-\mathrm{Fe}_{3} \mathrm{O}_{4}$ and $\mathrm{Cr}$ species does not inhibit the removal (extraction) of $\mathrm{Cr}(\mathrm{VI})$ from the solution. 


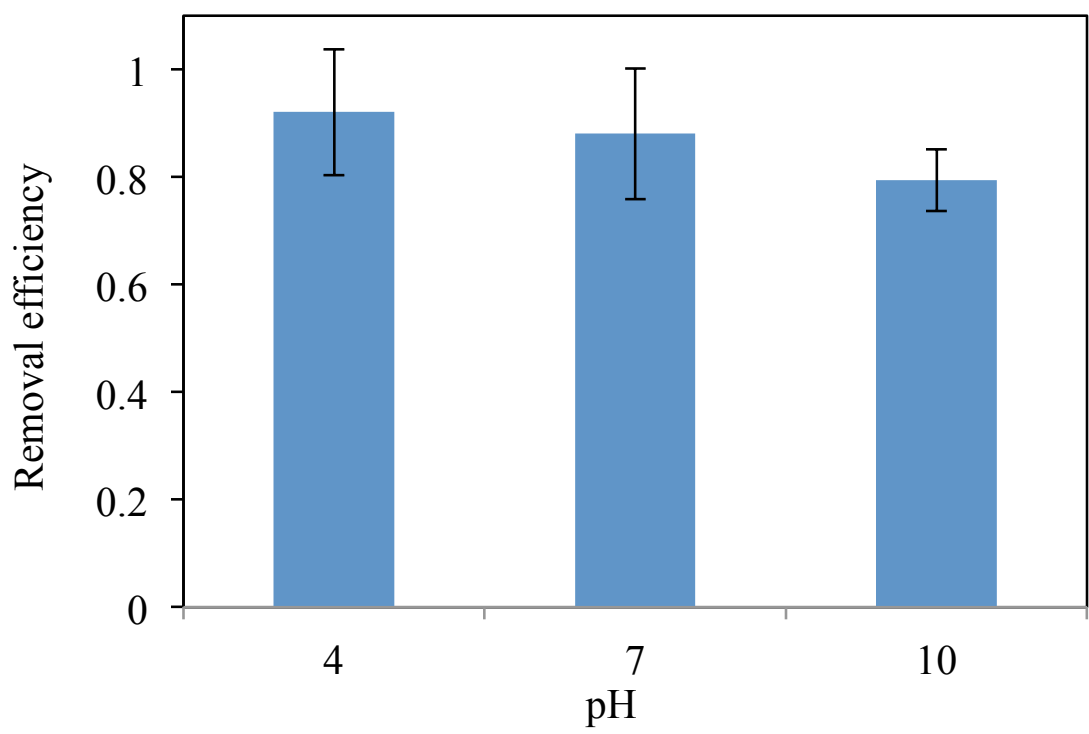

Figure 6.2 Effect of $\mathrm{pH}$ on removal efficiency of chromium by $\mathrm{HA}-\mathrm{Fe}_{3} \mathrm{O}_{4} \cdot[\mathrm{Cr}(\mathrm{VI})]_{0}=1$ $\mathrm{mM},\left[\mathrm{HA}-\mathrm{Fe}_{3} \mathrm{O}_{4}\right]=10 \mathrm{~g} / \mathrm{L}$

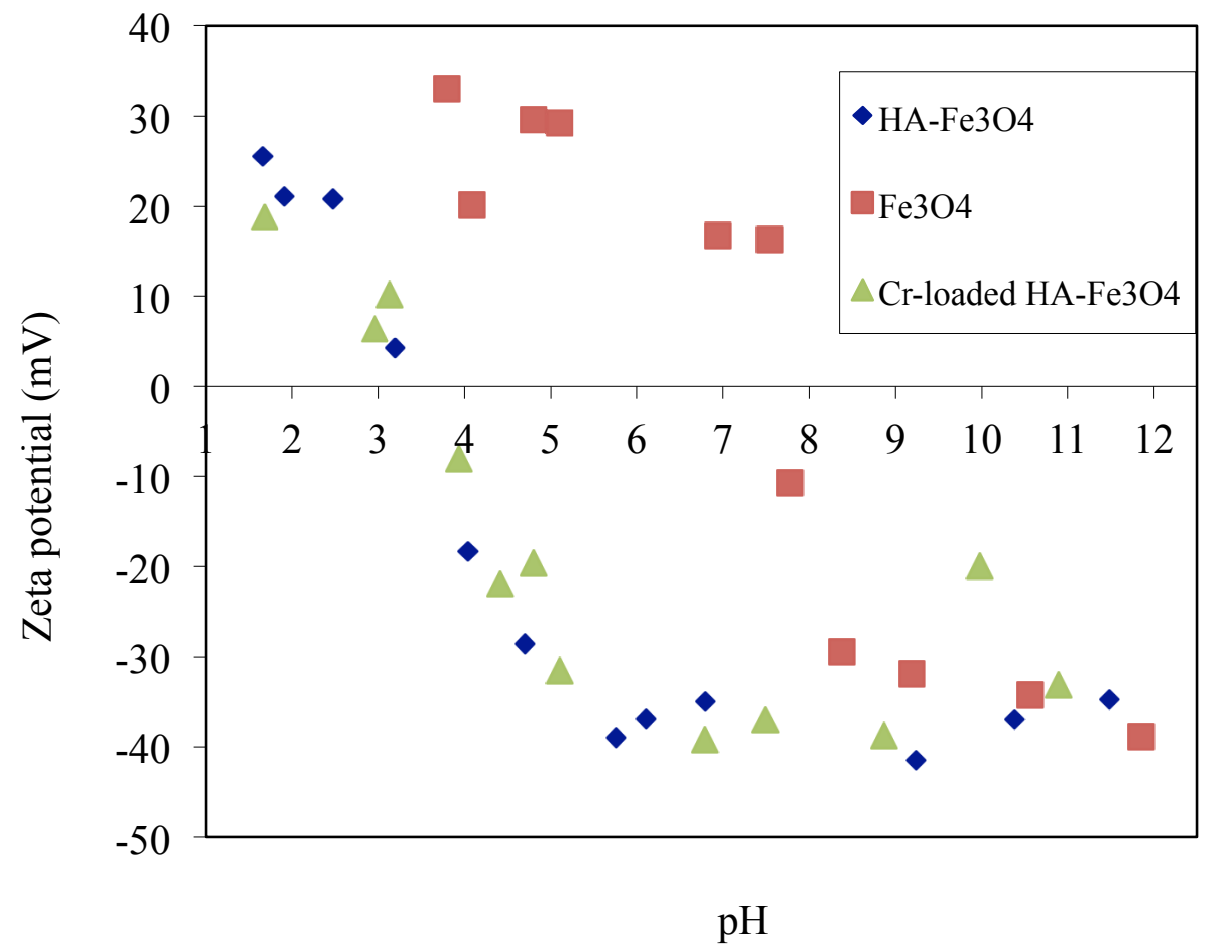

Figure 6.3 Zeta potential of bare $\mathrm{HA}-\mathrm{Fe}_{3} \mathrm{O}_{4}, \mathrm{HA}-\mathrm{Fe}_{3} \mathrm{O}_{4}$, and $\mathrm{Cr}$-loaded $\mathrm{HA}-\mathrm{Fe}_{3} \mathrm{O}_{4}$ at different $\mathrm{pHs}$. 
To better understand the adsorption and complexation involved in the extraction of $\mathrm{Cr}(\mathrm{VI})$ by $\mathrm{HA}-\mathrm{Fe}_{3} \mathrm{O}_{4}$, the speciation of $\mathrm{Cr}$ and $\mathrm{Fe}$ in $\mathrm{Cr}$-loaded $\mathrm{HA}-\mathrm{Fe}_{3} \mathrm{O}_{4}$ were measured using XANES technique. Cr $K$-edge XANES spectra of $\mathrm{Cr}(\mathrm{III}), \mathrm{Cr}(\mathrm{VI})$ and $\mathrm{Cr}(0)$ are provided as references for comparison with $\mathrm{Cr}$-loaded $\mathrm{HA}-\mathrm{Fe}_{3} \mathrm{O}_{4}$ under acidic, neutral and alkaline $\mathrm{pH}$ in Figure. 6.4. The spectra of the $\mathrm{Cr}$-loaded $\mathrm{HA}-\mathrm{Fe}_{3} \mathrm{O}_{4}$ materials are unchanged over the range of $\mathrm{pH}$, the presence of characteristic $\mathrm{Cr}(\mathrm{III})$ features and the absence of the strong pre-edge band for $\mathrm{Cr}(\mathrm{VI})$ and the broad feature of $\operatorname{Cr}(0)$ clearly indicate the predominant specie is $\mathrm{Cr}(\mathrm{III})$ in the Cr-loaded $\mathrm{HA}-\mathrm{Fe}_{3} \mathrm{O}_{4}$. The results confirm that conversion of $\mathrm{Cr}(\mathrm{VI})$ to $\mathrm{Cr}(\mathrm{III})$ is facilitated by the particles. While bare magnetite has been employed for $\mathrm{Cr}(\mathrm{VI})$ reduction(White et al., 1996), the reduction is fast under acidic conditions but decreases significantly with increasing $\mathrm{pH}$ (Polizzotto et al., 2005). Chromium $K$-edge XANES spectra indicate that the change of $\mathrm{pH}$ under our experimental conditions has no significant effect on reduction of $\mathrm{Cr}(\mathrm{VI})$. While a strong $\mathrm{pH}$ dependence is observed for bare $\mathrm{Fe}_{3} \mathrm{O}_{4}$, the extraction and reduction of $\mathrm{Cr}(\mathrm{VI})$ by $\mathrm{HA}-\mathrm{Fe}_{3} \mathrm{O}_{4}$ is minimally influenced by solution $\mathrm{pH}$, suggesting the reduction of $\mathrm{Cr}(\mathrm{VI})$ by these iron substrates follows different mechanisms.

$\mathrm{Fe}(\mathrm{II})$ and HA have similar reduction capacities and are capable of reducing $\mathrm{Cr}(\mathrm{VI})$ (Eary et al., 1991). To determine the involvement of Fe(II) in the core of the HA$\mathrm{Fe}_{3} \mathrm{O}_{4}$ in the reduction of $\mathrm{Cr}(\mathrm{VI})$, iron XANES spectra were obtained Figure. 6.5 demonstrates that no detectable change is observed in the valence states of iron during the reduction of $\mathrm{Cr}$. The result indicates $\mathrm{Fe}(\mathrm{II})$ in $\mathrm{HA}-\mathrm{Fe}_{3} \mathrm{O}_{4}$ is not responsible for $\mathrm{Cr}(\mathrm{VI})$ reduction. We employed a relatively high concentration of HA $(31 \mathrm{~g} / \mathrm{L})$ for the synthesis of the $\mathrm{HA}-\mathrm{Fe}_{3} \mathrm{O}_{4}$ particles. Complete surface coverage of magnetite can be obtained at 
solution concentrations of $20 \mathrm{mg} / \mathrm{L} \mathrm{HA}$ (Hu et al., 2010). Under our experimental conditions it appears the HA effectively insulates the iron core, prohibits the interaction of $\mathrm{Cr}(\mathrm{VI})$ and $\mathrm{Fe}(\mathrm{II})$, and thus $\mathrm{Cr}(\mathrm{VI})$ is reduced by HA (Wittbrodt et al., 1997). HA contains a variety of functional groups, including substituted phenols, $\alpha$-hydroxyl carboxylic acids, oxalic acid, and $\alpha$-carbonyl carboxylic acids, which are capable of initiating the reduction of $\mathrm{Cr}(\mathrm{VI})$ to $\mathrm{Cr}(\mathrm{III})$ (Deng et al., 1996; Elovitz et al., 1995). Chromium(III) can be chelated by the functional groups in HA (Nakayasu et al., 1999; Wittbrodt et al., 1995) and we propose a coupled reduction-complexation mechanism occurs between the functional groups in $\mathrm{HA}$ and $\mathrm{Cr}(\mathrm{VI})$.

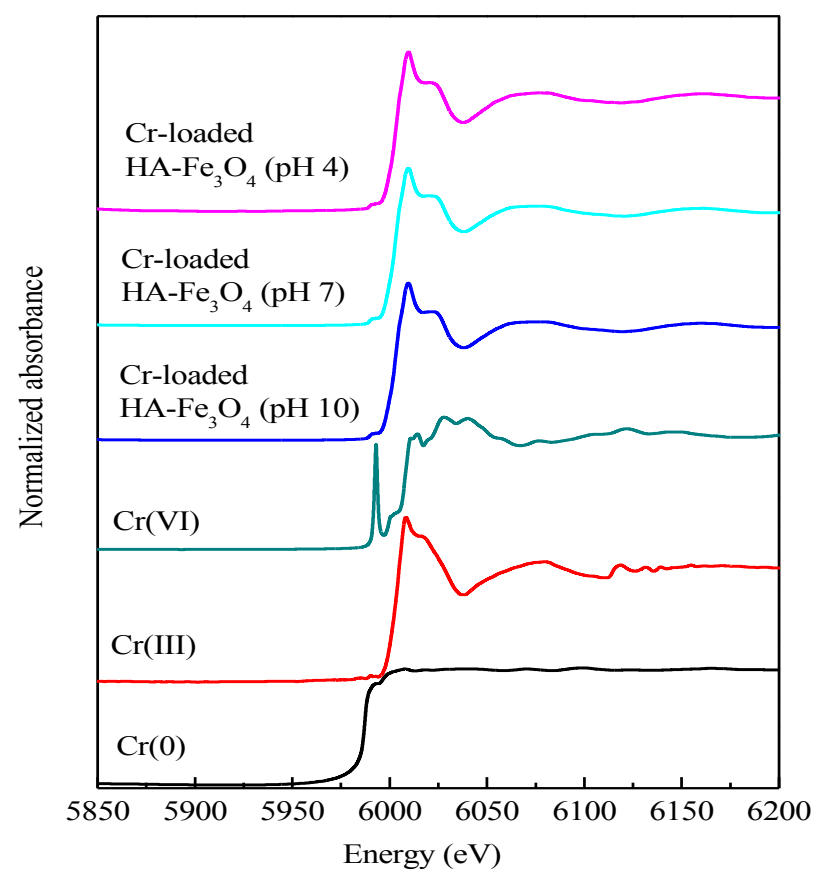

Figure 6.4 $\mathrm{Cr} K$-edge XANES spectra of chromium reference compounds and $\mathrm{Cr}$-loaded $\mathrm{HA}-\mathrm{Fe}_{3} \mathrm{O}_{4}$ at different $\mathrm{pH}$ conditions. 


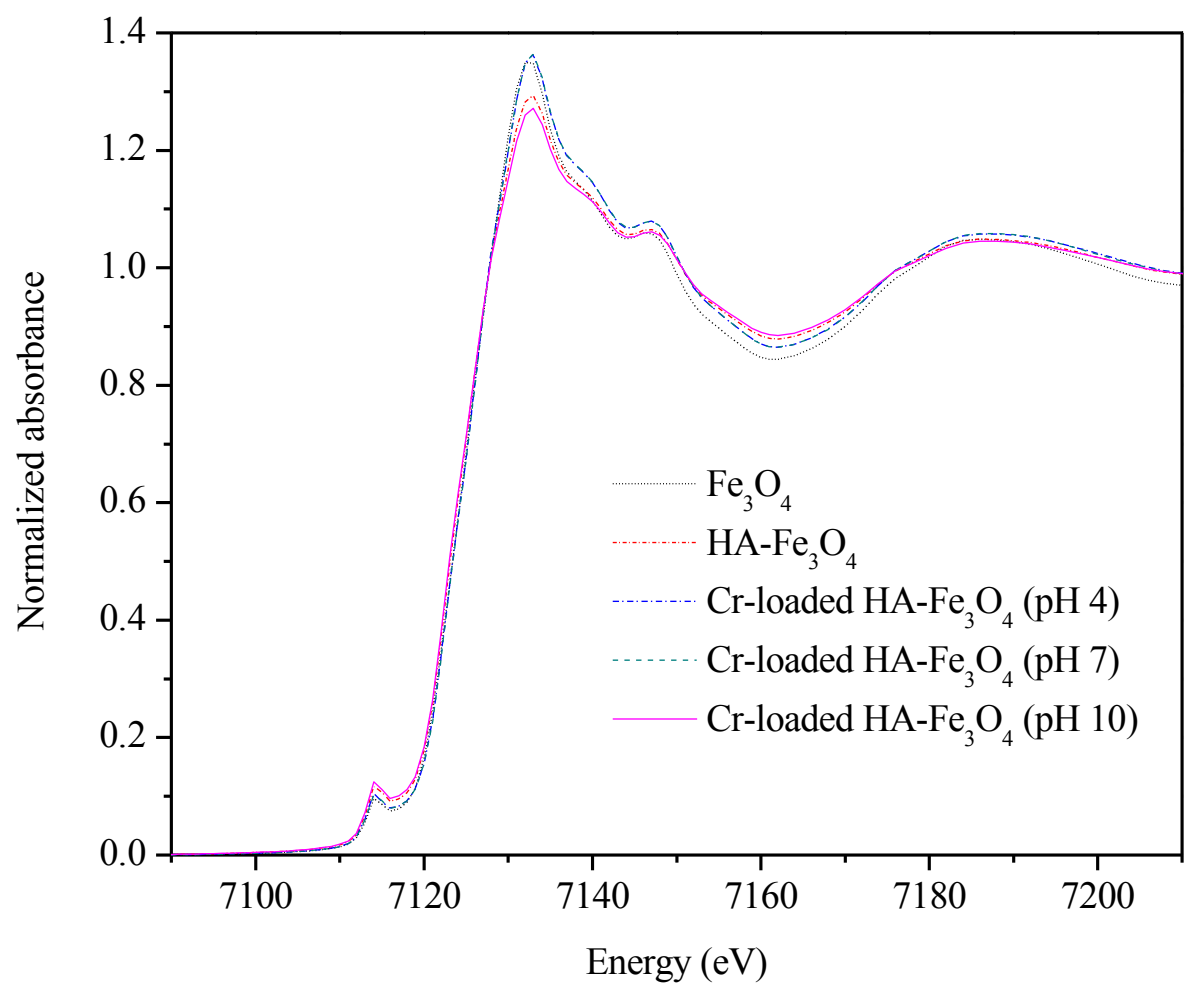

Figure 6.5 $\mathrm{Fe} K$-edge XANES spectra of iron reference compounds and Cr-loaded HA$\mathrm{Fe}_{3} \mathrm{O}_{4}$ at different $\mathrm{pH}$ conditions

\subsubsection{The local coordination environment}

EXAFS was carried out for determination of coordination number $(\mathrm{N})$, bond length $(\mathrm{R})$ and the Debye-Waller value $\left(\sigma^{2}\right)$ of $\mathrm{Cr}$ in $\mathrm{Cr}$-loaded $\mathrm{HA}-\mathrm{Fe}_{3} \mathrm{O}_{4}$ (Figure. 6.6-A, 6.7-A, and Table 6.1). The typical bond lengths of $\mathrm{Cr}(\mathrm{III})-\mathrm{O}$ and $\mathrm{Cr}(\mathrm{VI})-\mathrm{O}$ are $1.98 \pm$ $0.01 \AA$ and $1.63 \pm 0.03 \AA$ (Peterson et al., 1996), respectively. The measured $\mathrm{Cr}-\mathrm{O}$ bond links in the $\mathrm{Cr}$ loaded $\mathrm{HA}-\mathrm{Fe}_{3} \mathrm{O}_{4}$ materials are identical to the literature values for $\mathrm{Cr}(\mathrm{III})$ O bonds, summarized in Table 6.1. The bond length further demonstrates $\operatorname{Cr}(\mathrm{VI})$ is reduced to $\mathrm{Cr}(\mathrm{III})$ upon adsorption to $\mathrm{HA}-\mathrm{Fe}_{3} \mathrm{O}_{4}$ materials. The local coordination environment of $\mathrm{Cr}(\mathrm{III})$ is the same at different solution $\mathrm{pH}$ under our experimental 
conditions. The coordination number of $\mathrm{Cr}(\mathrm{III})$ is 6, likely an octahedral geometry (Lytle et al., 1998) as proposed in Figure. 6.8. Given the heterogeneous mixture of functional groups in HA, we anticipate a variety of ligands are involved in the complexation of $\mathrm{Cr}(\mathrm{III})$. The carboxylate, quinone and phenolic groups are abundant in HA and have an affinity to complex with a central $\mathrm{Cr}(\mathrm{III})$ atom.
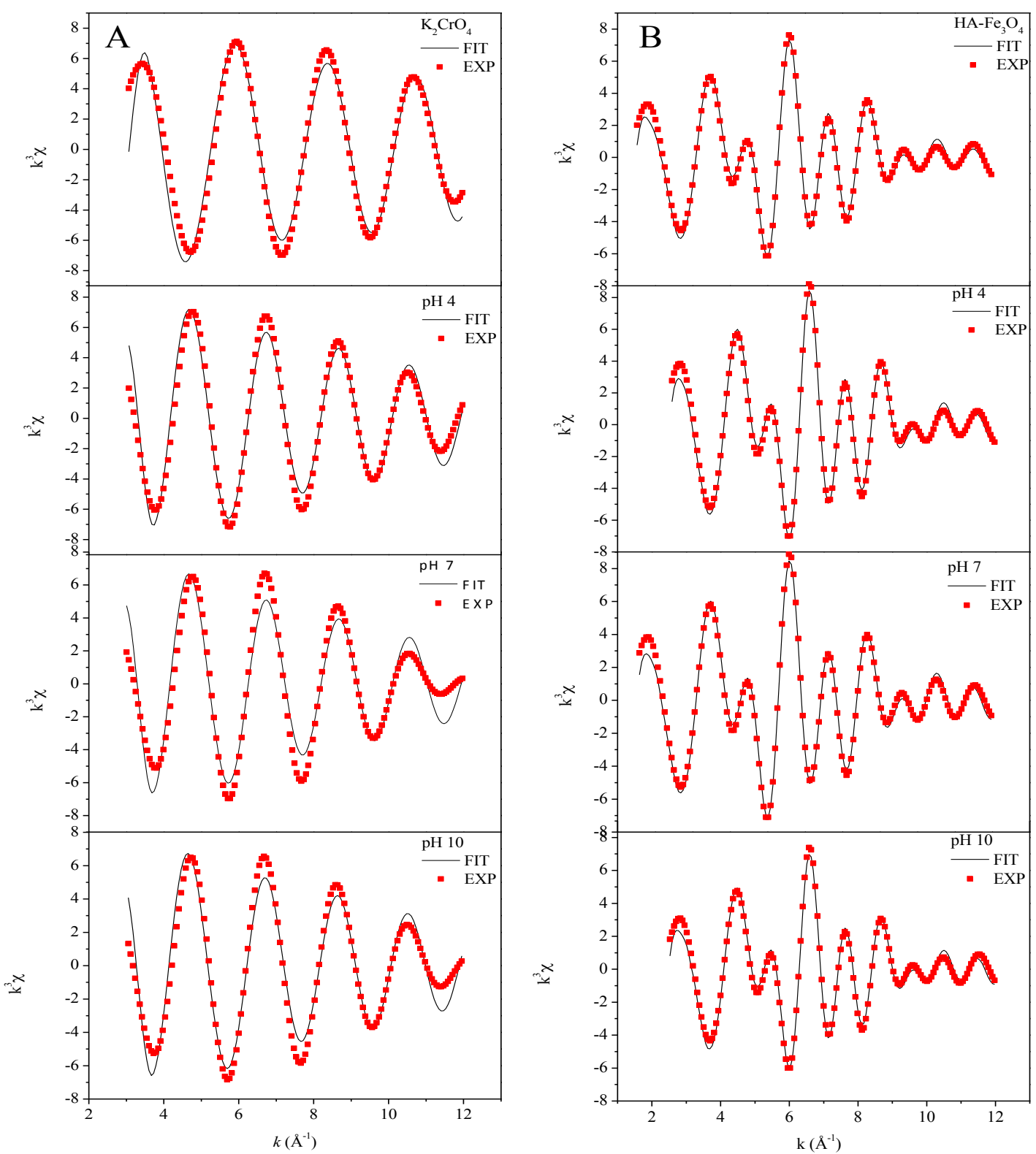

Figure $6.6 \mathrm{k}^{3}$-weighted $\mathrm{Cr}(\mathrm{A})$ and $\mathrm{Fe}(\mathrm{B}) \mathrm{K}$-edge EXAFS spectra 

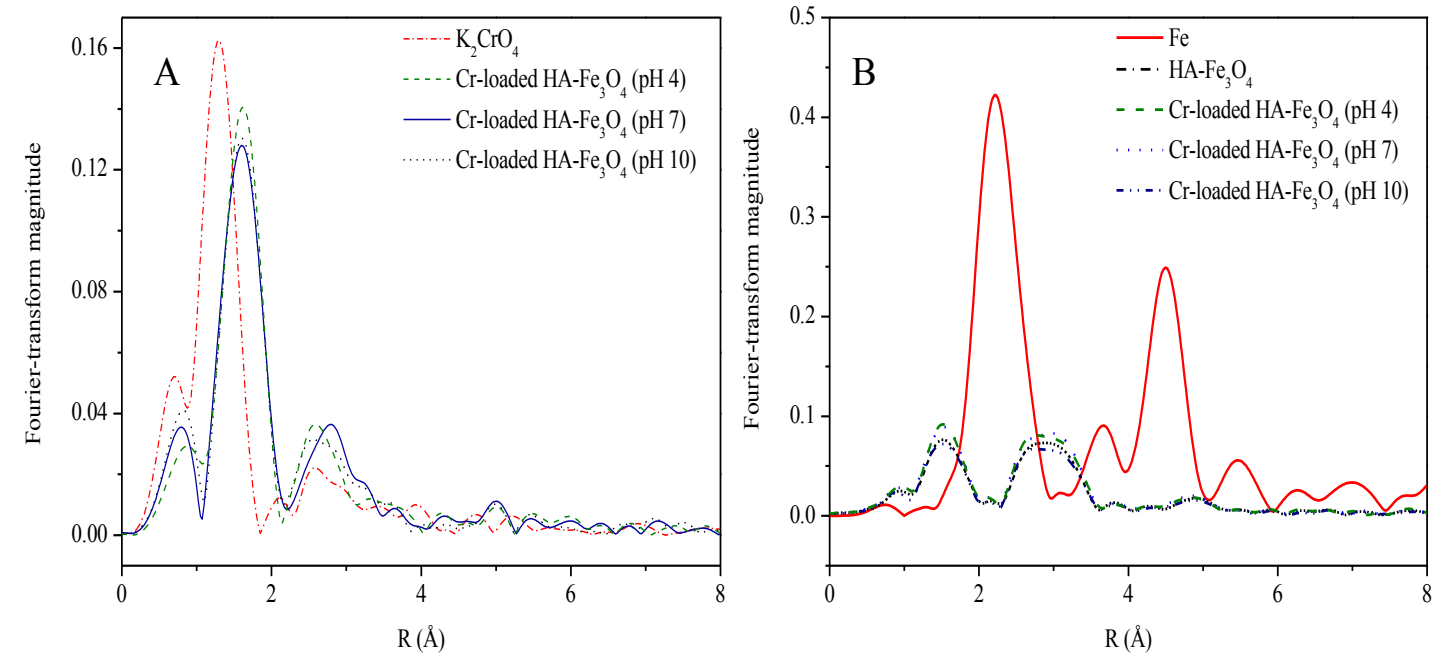

Figure 6.7 Fourier-transform spectral of $\mathrm{Cr}(\mathrm{A})$ and $\mathrm{Fe}(\mathrm{B})$ resulting in a radial structure function

Table 6.1 Chromium K-edge EXAFS fitting parameters

\begin{tabular}{ccccc}
\hline sample & bond & $\mathrm{N}$ & $\mathrm{R}(\AA)$ & $\sigma^{2}\left(\AA^{2}\right)$ \\
\hline $\mathrm{K}_{2} \mathrm{CrO}_{4}$ & $\mathrm{Cr}-\mathrm{O}$ & 4.0 & 1.65 & 0.0010 \\
Cr-loaded $\mathrm{HA}-\mathrm{Fe}_{3} \mathrm{O}_{4}(\mathrm{pH} 4)$ & $\mathrm{Cr}-\mathrm{O}$ & 6.4 & 1.98 & 0.0030 \\
Cr-loaded $\mathrm{HA}-\mathrm{Fe}_{3} \mathrm{O}_{4}(\mathrm{pH} 7)$ & $\mathrm{Cr}-\mathrm{O}$ & 6.2 & 1.98 & 0.0038 \\
Cr-loaded $\mathrm{HA}-\mathrm{Fe}_{3} \mathrm{O}_{4}(\mathrm{pH} 10)$ & $\mathrm{Cr}-\mathrm{O}$ & 6.3 & 1.98 & 0.0034
\end{tabular}

The coordination number $(\mathrm{N})$, bond length $(\mathrm{R})$ and the Debye-Waller value $\left(\sigma^{2}\right)$ from the least-square fit of EXAFS spectra. $\mathrm{N}$ values were referenced against model compound $\mathrm{K}_{2} \mathrm{CrO}_{4}$. Estimated errors for $\mathrm{N}$ approximately $20 \%, \mathrm{R} 0.01 \AA$.

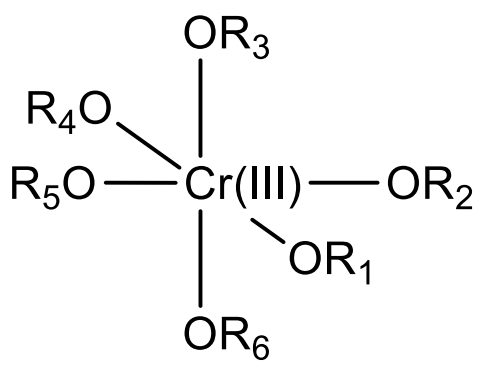

Figure 6.8 The proposed surface structure of adsorbed $\mathrm{Cr}$ on $\mathrm{HA}-\mathrm{Fe}_{3} \mathrm{O}_{4}$ 


\subsubsection{Crystal transformation}

The FTIR analysis was employed to study the binding of HA on magnetite surface (Figure. 6.9). The free $\mathrm{C}=\mathrm{O}$ stretching peak typically occurs $\sim 1700 \mathrm{~cm}^{-1}$, however upon complexation with $\mathrm{Fe}_{3} \mathrm{O}_{4}$ the $\mathrm{C}=\mathrm{O}_{\mathrm{HA}}$ bond is weakened and the IR band shifts to the right. The observed peak at $\sim 1560 \mathrm{~cm}^{-1}$ is assigned to the $\mathrm{C}=\mathrm{O}_{\mathrm{HA}}$ and is indicative of complexation of the $\mathrm{C}=\mathrm{O}_{\mathrm{HA}}$ by the magnetite surface (J.-f. Liu et al., 2008). Humic acid has a high binding affinity to magnetite, and subsequent desorption is very difficult (Gu et al., 1994). The adsorption of $\mathrm{Cr}$ does not appear to affect the interaction between $\mathrm{HA}$ and $\mathrm{Fe}_{3} \mathrm{O}_{4}$ under acidic, neutral and alkaline $\mathrm{pH}$ conditions as indicated by the unchanged $\mathrm{C}=\mathrm{O}$ band.

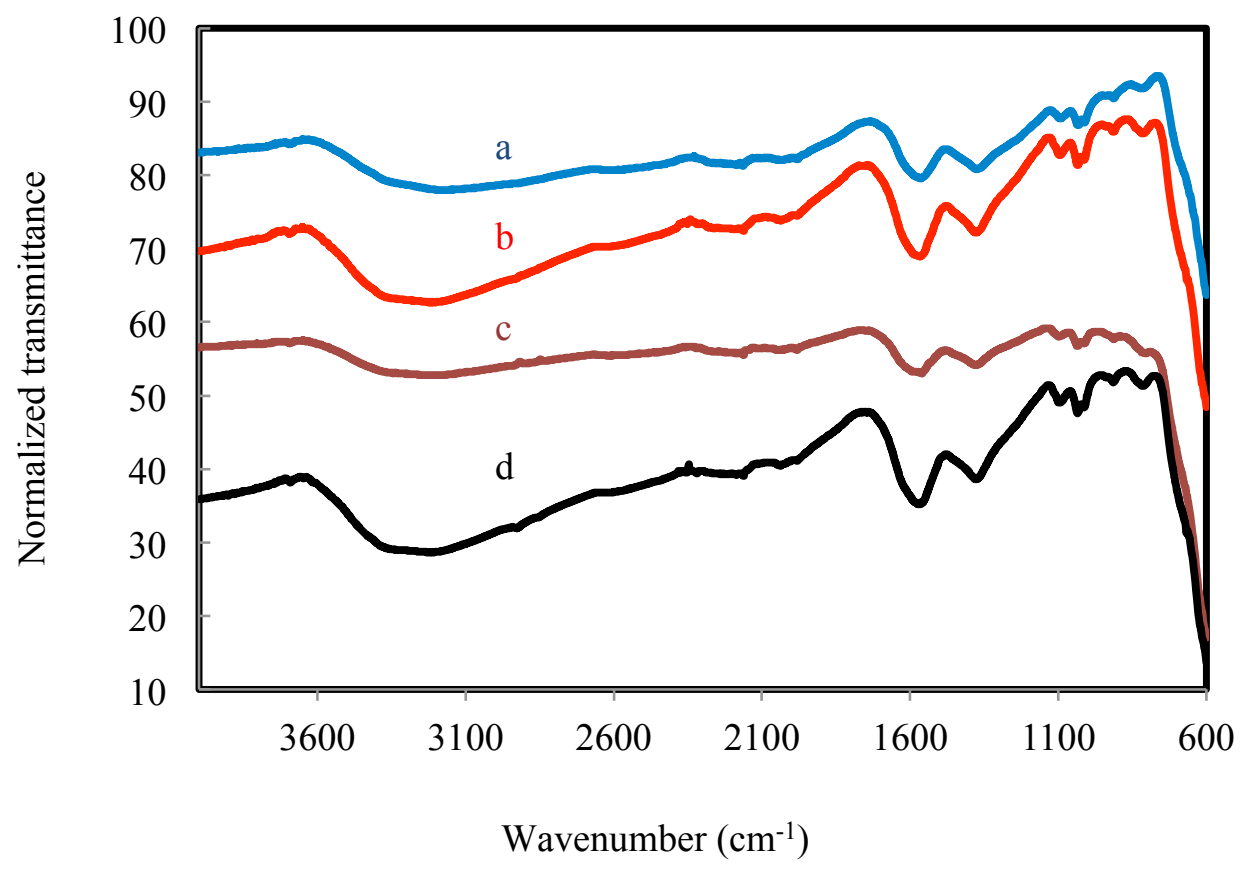

Figure 6.9 FTIR of $\mathrm{HA}-\mathrm{Fe}_{3} \mathrm{O}_{4}$ and $\mathrm{Cr}$-loaded $\mathrm{HA}-\mathrm{Fe}_{3} \mathrm{O}_{4}$ particles: (a) $\mathrm{HA}-\mathrm{Fe}_{3} \mathrm{O}_{4}$, (b) $\mathrm{Cr}$ loaded $\mathrm{HA}-\mathrm{Fe}_{3} \mathrm{O}_{4}(\mathrm{pH} 4)$, (c) Cr-loaded $\mathrm{HA}-\mathrm{Fe}_{3} \mathrm{O}_{4}\left(\mathrm{pH}\right.$ 7), and (d) $\mathrm{Cr}$-loaded $\mathrm{HA}-\mathrm{Fe}_{3} \mathrm{O}_{4}$ (pH 10) 
X-ray diffraction was employed to assess the crystal lattice of $\mathrm{Fe}_{3} \mathrm{O}_{4}$ core in HA$\mathrm{Fe}_{3} \mathrm{O}_{4}$ after loading with $\mathrm{Cr}(\mathrm{VI})$. The peak position and relative intensity match the literature well and demonstrate no change in lattice of iron core is observed (Figure. 6.10) (Sun et al., 2002). The XRD spectra show no detectable difference between the original $\mathrm{HA}-\mathrm{Fe}_{3} \mathrm{O}_{4}$ and Cr-loaded $\mathrm{HA}-\mathrm{Fe}_{3} \mathrm{O}_{4}$, and iron XANES (Figure. 6.5), imply no transformation from magnetite to maghemite during extraction of $\mathrm{Cr}(\mathrm{VI})$. The dissolution of maghemite can lead to the formation of goethite (Polizzotto et al., 2005); however we did not detect goethite under our experimental conditions. Fe $K$-edge EXAFS (Figure. 6.6-B, 6.7-B, and Table 6.2) indicate there was no significant difference in the iron core of the original $\mathrm{HA}-\mathrm{Fe}_{3} \mathrm{O}_{4}$ and $\mathrm{Cr}$-loaded $\mathrm{HA}-\mathrm{Fe}_{3} \mathrm{O}_{4}($ Kobayashi et al., 1995). Therefore, the iron core of $\mathrm{HA}-\mathrm{Fe}_{3} \mathrm{O}_{4}$ is unchanged during $\mathrm{Cr}$ adsorption and reduction processes.

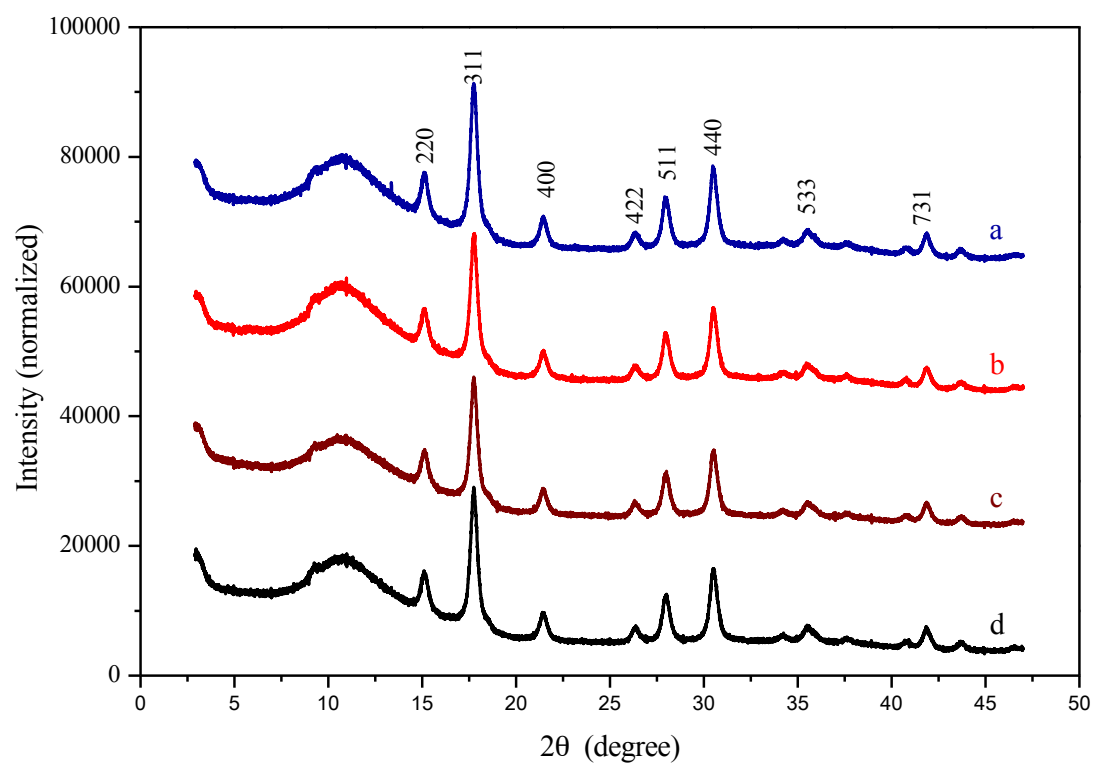

Figure 6.10 XRD patterns of $\mathrm{HA}-\mathrm{Fe}_{3} \mathrm{O}_{4}$ and $\mathrm{Cr}$-loaded $\mathrm{HA}-\mathrm{Fe}_{3} \mathrm{O}_{4}$ particles: (a) HA$\mathrm{Fe}_{3} \mathrm{O}_{4}$, (b) Cr-loaded HA-Fe $\mathrm{O}_{4}\left(\mathrm{pH}\right.$ 4), (c) Cr-loaded HA-Fe ${ }_{3} \mathrm{O}_{4}(\mathrm{pH}$ 7), and (d) Crloaded $\mathrm{HA}-\mathrm{Fe}_{3} \mathrm{O}_{4}(\mathrm{pH} 10)$. 
Table 6.2 Iron K-edge EXAFS fitting parameters

\begin{tabular}{|c|c|c|c|c|c|}
\hline sample & shell & bond & $\mathrm{N}$ & $\mathrm{R}(\AA)$ & $\sigma^{2}\left(\AA^{2}\right)$ \\
\hline \multirow[t]{4}{*}{$\mathrm{HA}-\mathrm{Fe}_{3} \mathrm{O}_{4}$} & 1 & $\mathrm{Fe}-\mathrm{O}$ & 4.4 & 1.95 & 0.011 \\
\hline & 2 & $\mathrm{Fe}-\mathrm{Fe}$ & 2.9 & 3.00 & 0.011 \\
\hline & 3 & $\mathrm{Fe}-\mathrm{Fe}$ & 7.1 & 3.46 & 0.011 \\
\hline & 4 & $\mathrm{Fe}-\mathrm{O}$ & 7.3 & 3.52 & 0.021 \\
\hline \multirow{4}{*}{$\begin{array}{l}\text { Cr-loaded } \\
(\mathrm{pH} \mathrm{4)}\end{array}$} & 1 & $\mathrm{Fe}-\mathrm{O}$ & 4.8 & 1.95 & 0.010 \\
\hline & 2 & $\mathrm{Fe}-\mathrm{Fe}$ & 2.9 & 2.99 & 0.009 \\
\hline & 3 & $\mathrm{Fe}-\mathrm{Fe}$ & 8.4 & 3.47 & 0.011 \\
\hline & 4 & $\mathrm{Fe}-\mathrm{O}$ & 6.1 & 3.52 & 0.014 \\
\hline \multirow{4}{*}{$\begin{array}{l}\text { Cr-loaded } \\
\text { (pH 7) }\end{array}$} & 1 & Fe-O & 4.8 & 1.95 & 0.010 \\
\hline & 2 & $\mathrm{Fe}-\mathrm{Fe}$ & 2.9 & 2.99 & 0.010 \\
\hline & 3 & $\mathrm{Fe}-\mathrm{Fe}$ & 7.9 & 3.46 & 0.010 \\
\hline & 4 & $\mathrm{Fe}-\mathrm{O}$ & 5.9 & 3.51 & 0.012 \\
\hline \multirow{4}{*}{$\begin{array}{l}\text { Cr-loaded } \\
\text { (pH 10) }\end{array}$} & 1 & $\mathrm{Fe}-\mathrm{O}$ & 4.2 & 1.95 & 0.011 \\
\hline & 2 & $\mathrm{Fe}-\mathrm{Fe}$ & 2.7 & 2.99 & 0.010 \\
\hline & 3 & $\mathrm{Fe}-\mathrm{Fe}$ & 6.9 & 3.47 & 0.011 \\
\hline & 4 & $\mathrm{Fe}-\mathrm{O}$ & 8.1 & 3.53 & 0.029 \\
\hline
\end{tabular}

The coordination number $(\mathrm{N})$, bond length $(\mathrm{R})$ and the Debye-Waller value $\left(\sigma^{2}\right)$ from the least-square fit of EXAFS spectra. Estimated errors for $\mathrm{N}$ approximately $20 \%, \mathrm{R} 0.01 \AA$.

\subsubsection{Adsorption kinetics and adsorption isotherm}

The adsorption kinetics and adsorption isotherm were conducted at a constant HA- $\mathrm{Fe}_{3} \mathrm{O}_{4}$ concentration $(0.8 \mathrm{~g} / \mathrm{L})$ while varying initial $\mathrm{Cr}(\mathrm{VI})$ concentrations from 1-5 ppm without adjusting $\mathrm{pH}$. The adsorption equilibrium was achieved by shaking the HA$\mathrm{Fe}_{3} \mathrm{O}_{4}$ suspension at $300 \mathrm{RPM}$ for 120 min, and experimental results followed a pseudosecond order kinetics nicely based on the coefficient of determinations $\left(R^{2}\right)$ of the plots of $t / Q_{t}$ versus $t\left(\mathrm{R}^{2}>0.98\right)$.

$$
d Q_{t} / d t=k_{p}\left(Q_{e}-Q_{t}\right)^{2}
$$

where $k_{p}$ is the rate constant of pseudo-second-order model $(\mathrm{g} /(\mathrm{mg} \cdot \min )), t$ is the reaction time ( $\mathrm{min}$ ), $Q_{t}$ is the amount of adsorbate adsorbed per unit mass by $\mathrm{HA}-\mathrm{Fe}_{3} \mathrm{O}_{4}$ at the specific time $(\mathrm{mg} / \mathrm{g})$, and $Q_{e}$ is the adsorption capacity at adsorption equilibrium $(\mathrm{mg} / \mathrm{g})$, respectively. 
The kinetic results were analyzed using an intraparticle diffusion model, indicating that the adsorption of $\mathrm{Cr}(\mathrm{VI})$ occurs in two phases: the surface adsorption and intraparticle diffusion, followed by a redox reaction (Figure. 6.11).

$$
\mathrm{Q}_{\mathrm{t}}=\mathrm{k}_{\mathrm{id}} \mathrm{t}^{1 / 2}+\mathrm{C}
$$

where $\mathrm{C}$ is the intercept and $\mathrm{k}_{\mathrm{id}}$ is the intraparticle diffusion rate constant.

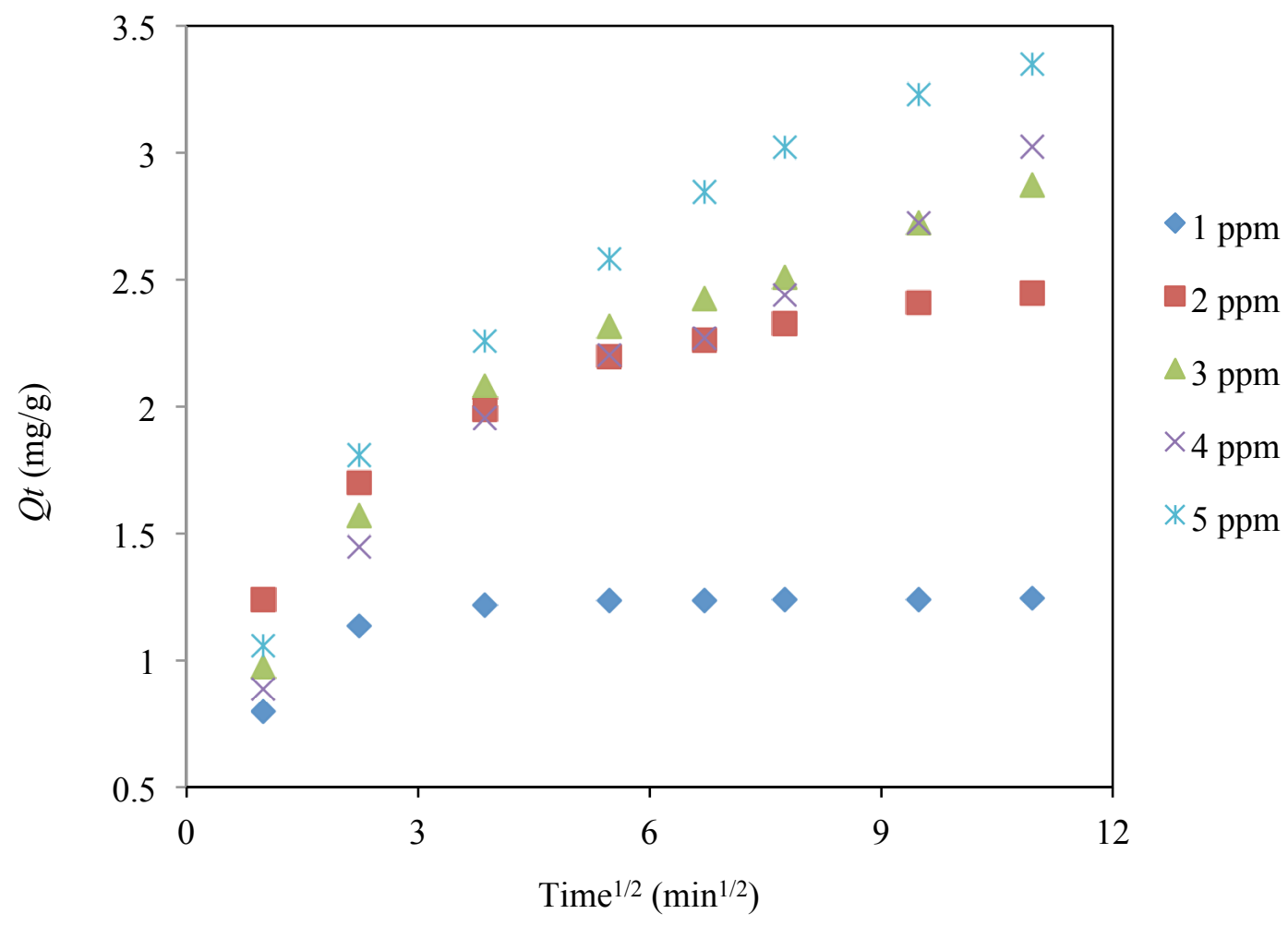

Figure 6.11 Intraparticle diffusion plots

Langmuir adsorption model was employed to assess the adsorption capacity of $\mathrm{HA}-\mathrm{Fe}_{3} \mathrm{O}_{4}$ for $\mathrm{Cr}$. Langmuir adsorption isotherm assumes that the adsorbent surface has a specific number of equivalent sorption sites, and the monolayer adsorption occurs without interaction between sorption sites. The data were modeled with Langmuir adsorption isotherm (Jiang et al., 2013). 


$$
\frac{C_{e}}{Q_{e}}=\frac{1}{b Q_{m}}+\left(\frac{1}{Q_{m}}\right) C_{e}
$$

where $b$ and $Q_{m}$ are the Langmuir adsorption constant $(\mathrm{L} / \mathrm{mg})$ and maximum capacity of

adsorbent ( $\left.\mathrm{mg} \mathrm{g}^{-1}\right)$, respectively. The values of $b$ and $Q_{m}$ are determined from the plot of $C_{e} / Q_{e}$ versus $C_{e}$. The plot exhibits a good coefficient of correlation $\left(\mathrm{R}^{2}=99 \%\right)$. In the current study, $Q_{m}=3.37 \mathrm{mg} / \mathrm{g}$, and $b=23146 \mathrm{~L} / \mathrm{mg}$, indicating a high chromium bonding strength on $\mathrm{HA}-\mathrm{Fe}_{3} \mathrm{O}_{4}$ that is likely due to the formation of octahedral complex.

\subsection{Implications for $\mathrm{Cr}(\mathrm{VI})$ detoxification in natural aquatic systems.}

Since $\mathrm{Cr}(\mathrm{VI})$ is toxic and carcinogenic, the reduction of $\mathrm{Cr}(\mathrm{VI})$ to non-toxic $\mathrm{Cr}(\mathrm{III})$ is highly desirable for treatment of $\mathrm{Cr}(\mathrm{VI})$-contaminated water. Magnetite $\left(\mathrm{Fe}_{3} \mathrm{O}_{4}\right)$ and HA are capable of reducing $\mathrm{Cr}(\mathrm{VI})$. Magnetite effectively reduces $\mathrm{Cr}(\mathrm{VI})$ but the process diminishes the associated magnetic properties. HA alone may be effective for extraction of $\mathrm{Cr}(\mathrm{VI})$ from aqueous media, however recovery of the toxin loaded HA materials is difficult. The $\mathrm{HA}-\mathrm{Fe}_{3} \mathrm{O}_{4}$ materials are robust and easily separable. We have demonstrated the effective adsorption and extraction of $\mathrm{Cr}(\mathrm{VI})$ from aqueous media by $\mathrm{HA}-\mathrm{Fe}_{3} \mathrm{O}_{4}$ materials. The $\mathrm{Cr}$ loaded $\mathrm{HA}-\mathrm{Fe}_{3} \mathrm{O}_{4}$ materials maintain magnetic properties and are easily separated by applying a magnetic field. The extraction of $\mathrm{Cr}(\mathrm{VI})$ is effective under acidic, neutral and basic conditions. Characterization of $\mathrm{Cr}$ loaded HA$\mathrm{Fe}_{3} \mathrm{O}_{4}$ materials demonstrate $\mathrm{Cr}(\mathrm{VI})$ is reduced to non-toxic $\mathrm{Cr}(\mathrm{III})$ by $\mathrm{HA}$ to form an octahedral complex within the $\mathrm{HA}-\mathrm{Fe}_{3} \mathrm{O}_{4}$ materials. These easily separable materials have a high capacity for $\mathrm{Cr}(\mathrm{VI})$ adsorption and initiate reductive-complexation leading to an immobilized $\mathrm{Cr}(\mathrm{III})$ complex. $\mathrm{HA}-\mathrm{Fe}_{3} \mathrm{O}_{4}$ appear to have remarkable potential for the treatment of $\mathrm{Cr}(\mathrm{VI})$-contaminated water. 
7 General Summary 
Photocatalytic processes and magnetic iron oxide materials were employed for water treatment. The reactive oxygen species, which are generated by photoexcited $\mathrm{TiO}_{2}$ materials and rose bengal, effective degrades a variety of contaminant in aqueous solution. The reactive oxygen species include hydroxyl radical, singlet oxygen, superoxide anion radical and hydrogen peroxide. The magnetic iron oxide materials are used for removal of chromium(VI).

The rates of formations, steady-state concentrations, and kinetic parameters of hydroxyl radical and singlet oxygen produced by various $\mathrm{TiO}_{2}$ photocatalysts under UV or Vis irradiations were measured using selective chemical probes. Due to the extremely high reaction rate of $\cdot \mathrm{OH}$, its steady-state concentration is lower by 3-4 orders of magnitude than singlet oxygen. Hydroxyl radical is a predominant reactive oxygen species, and its generation is highly dependent on experimental conditions. The generation of hydroxyl radical by hollow glass microspheres coated with photocatalytic $\mathrm{TiO}_{2}\left(\mathrm{HGM}-\mathrm{TiO}_{2}\right)$ is optimized using response surface methodology. The 3D response surface graphs of hydroxyl radical yield and average hydroxyl radical generation rate indicated that optimum conditions of loading of $\mathrm{HGM}-\mathrm{TiO}_{2}$, concentration of terephthalate acid and irradiation time were $8.0 \mathrm{~g} / \mathrm{L}, 4.0 \mathrm{mM}$, and $20 \mathrm{~min}$, respectively. The optimal conditions were applied for the degradation of dimethyl phthalate (DMP). $\mathrm{HGM}-\mathrm{TiO}_{2}$ photocatalysis leads to the rapid destruction of DMP and there is a linear correlation between the DMP destruction and hydroxyl radical production. Conventional water treatment methods are often not effective or not practical for the removal of MCLR. Fortunately, advanced oxidation processes have exhibited an attractive performance. ${ }^{1} \mathrm{O}_{2}$ can play an important role in the environmental fate and detoxification of MC-LR, so 
we employed rose bengal (RB), a singlet oxygen $\left({ }^{1} \mathrm{O}_{2}\right)$ sensitizer, to study the photooxidative destruction of microcystin-LR (MC-LR). The degradation of MC-LR in presence of $500 \mu \mathrm{M}$ RB follows the pseudo-first order kinetic model nicely, and rate constant of degradation increase three fold under oxygen-saturated condition compared to argon-saturated condition, demonstrating that photo-oxidation is the predominant degradation process. The measured bimolecular reaction rate constant between MC-LR and ${ }^{1} \mathrm{O}_{2}$ is $\sim 10^{6} \mathrm{M}^{-1} \mathrm{~s}^{-1}$ based on competition kinetics with furfuryl alcohol.

Chromium(VI) is one common heavy metal in waste water, and the classic adsorbent need a time consuming separation process after treatment. Magnetic iron oxide materials are promising for chromium(VI) removal, since it can be easily separated by a magnetic field. Two magnetic materials, maghemite and humic acid coated magnetite, were synthesized, characterized and applied for the treatment of chromium(VI) contaminated water. The adsorption of chromium(VI) by maghemite and humic acid coated magnetite follow a pseudo-second-order kinetic process, and the adsorption of chromium(VI) is accurate modeling using adsorption isotherms. The solution $\mathrm{pH}$ and presence of humic acid influence adsorption behavior of maghemite, but there is a little effect of solution $\mathrm{pH}$ on adsorption by humic acid coated magnetite. Humic acid coated magnetite can adsorb and reduce chromium(VI) to non-toxic chromium (III). The functional groups associated with humic acid act as ligands leading the $\mathrm{Cr}(\mathrm{III})$ complex via a coupled reduction-complexation mechanism. Extended X-ray absorption fine structure spectroscopy (EXAFS) demonstrates the $\mathrm{Cr}(\mathrm{III})$ in the chromium loaded $\mathrm{HA}-\mathrm{Fe}_{3} \mathrm{O}_{4}$ materials has six neighboring oxygen atoms in an octahedral geometry with average bond lengths of $1.98 \AA$. 


\section{REFERENCES}

Agrawal, A., Kumar, V., and Pandey, B. (2006). Remediation Options for the Treatment of Electroplating and Leather Tanning Effluent Containing Chromium-a Review. Mineral Processing and Extractive Metallurgy Review, 27 (2): 99-130.

Aksu, Z. (2005). Application of Biosorption for the Removal of Organic Pollutants: a Review. Process Biochemistry, 40 (3): 997-1026.

Ambashta, R. D., and Sillanpää, M. (2010). Water Purification Using Magnetic Assistance: A Review. Journal of Hazardous Materials, 180 (1-3): 38-49.

Anderson, R. A. (1997). Chromium as an Essential Nutrient for Humans. Regulatory Toxicology and Pharmacology, 26 (1): S35-S41.

Anger, G., Halstenberg, J., Hochgeschwender, K., Scherhag, C., Korallus, U., Knopf, H., Schmidt, P., and Ohlinger, M. (2000). Chromium Compounds. In Ullmann's Encyclopedia of Industrial Chemistry: Wiley-VCH Verlag GmbH \& Co. KGaA.

Antoniou, M. G., de la Cruz, A. A., and Dionysiou, D. D. (2010). Degradation of Microcystin-LR Using Sulfate Radicals Generated Through Photolysis, Thermolysis and $\mathrm{e}^{-}$Transfer Mechanisms. Applied Catalysis B: Environmental, 96 (3-4): 290-298.

Antoniou, M. G., Shoemaker, J. A., De la Cruz, A. A., and Dionysiou, D. D. (2008). LC/MS/MS Structure Elucidation of Reaction Intermediates Formed During the $\mathrm{TiO}_{2}$ Photocatalysis of Microcystin-LR. Toxicon, 51 (6): 1103-1118.

Ardon, M., and Plane, R. A. (1959). The Formation of a Dinuclear Cr(III) Species by Oxidation of Chromous Solutions. Journal of the American Chemical Society, 81 (13): 3197-3200.

Arslan-Alaton, I., Tureli, G., and Olmez-Hanci, T. (2009). Treatment of Azo Dye Production Wastewaters Using Photo-Fenton-Like Advanced Oxidation Processes: Optimization by Response Surface Methodology. Journal of Photochemistry and Photobiology A: Chemistry, 202 (2): 142-153.

Auffan, M., Pedeutour, M., Rose, J., Masion, A., Ziarelli, F., Borschneck, D., Chaneac, C., Botta, C., Chaurand, P., and Labille, J. (2010). Structural Degradation at the Surface of a $\mathrm{TiO}_{2}$-Based Nanomaterial Used in Cosmetics. Environmental Science and Technology, 44 (7): 2689-2694.

Babel, S., and Kurniawan, T. A. (2003). Low-cost Adsorbents for Heavy Metals Uptake from Contaminated Water: a Review. Journal of Hazardous Materials, 97 (1-3): 219-243.

Bandala, E. R., Martínez, D., Martínez, E., and Dionysiou, D. D. (2004). Degradation of Microcystin-LR Toxin by Fenton and Photo-Fenton Processes. Toxicon, 43 (7): 829-832. 
Banerjee, S. S., and Chen, D.-H. (2007). Fast Removal of Copper Ions by Gum Arabic Modified Magnetic Nano-Adsorbent. Journal of Hazardous Materials, 147 (3): 792-799.

Barnhart, J. (1997a). Chromium Chemistry and Implications for Environmental Fate and Toxicity. Soil and Sediment Contamination, 6 (6): 561-568.

Barnhart, J. (1997b). Occurrences, Uses, and Properties of Chromium. Regulatory Toxicology and Pharmacology, 26 (1): S3-S7.

Bartlett, R., and Kimble, J. (1976). Behavior of Chromium in Soils: II. Hexavalent Forms. Journal of Environmental Quality, 5 (4): 383-386.

Bauer, M. J., and Herrmann, R. (1997). Estimation of the Environmental Contamination by Phthalic Acid Esters Leaching from Household Wastes. Science of The Total Environment, 208 (1-2): 49-57.

Bell, A., and Matijević, E. (1975). Complex Chemistry of Hydrous Chromium (III) Oxide Sol Formation. Journal of Inorganic and Nuclear Chemistry, 37 (4): 907-912.

Berg, M., Tran, H. C., Nguyen, T. C., Pham, H. V., Schertenleib, R., and Giger, W. (2001). Arsenic Contamination of Groundwater and Drinking Water in Vietnam: a Human Health Threat. Environmental Science and Technology, 35 (13): 2621-2626.

Bishnoi, N. R., Chugh, L. K., and Sawhney, S. K. (1993). Effect of Chromium on Photosynthesis, Respiration and Nitrogen Fixation in Pea (Pisum sativum L.) Seedlings. Journal of Plant Physiology, 142 (1): 25-30.

Bokare, A. D., and Choi, W. (2010). Chromate-Induced Activation of Hydrogen Peroxide for Oxidative Degradation of Aqueous Organic Pollutants. Environmental Science and Technology, 44 (19): 7232-7237.

Bove, F., Shim, Y., and Zeitz, P. (2002). Drinking Water Contaminants and Adverse Pregnancy Outcomes: a Review. Environmental Health Perspectives, 110 (Suppl 1): 6174.

Bove, F. J., Fulcomer, M. C., Klotz, J. B., Esmart, J., Dufficy, E. M., and Savrin, J. E. (1995). Public Drinking Water Contamination and Birth Outcomes. American Journal of Epidemiology, 141 (9): 850-862.

Box, G. E., and Wilson, K. (1951). On the Experimental Attainment of Optimum Conditions. Journal of the Royal Statistical Society. Series B (Methodological), 13 (1): 145.

Brito, F., Ascanio, J., Mateo, S., Hernández, C., Araujo, L., Gili, P., Martín-Zarza, P., Domínguez, S., and Mederos, A. (1997). Equilibria of Chromate(VI) Species in Acid Medium and ab initio Studies of These Species. Polyhedron, 16 (21): 3835-3846. 
Buerge, I. J., and Hug, S. J. (1997). Kinetics and pH Dependence of Chromium(VI) Reduction by Iron(II). Environmental Science and Technology, 31 (5): 1426-1432.

Burgos, M., and Langlet, M. (1999). The Sol-Gel Transformation of TIPT Coatings: a FTIR Study. Thin Solid Films, 349 (1): 19-23.

Buxton, G. V., Greenstock, C. L., Helman, W. P., and Ross, A. B. (1988). Critical Review of Rate Constants for Reactions of Hydrated Electrons, Hydrogen Atoms and Hydroxyl Radicals. Journal of Physical and Chemical Reference Data 17: 513-886.

Cao, L., Gao, Z., Suib, S. L., Obee, T. N., Hay, S. O., and Freihaut, J. D. (2000). Photocatalytic Oxidation of Toluene on Nanoscale $\mathrm{TiO}_{2}$ Catalysts: Studies of Deactivation and Regeneration. Journal of Catalysis, 196 (2): 253-261.

Carmichael, W. W., and An, J. (1999). Using an Enzyme Linked Immunosorbent assay (ELISA) and a Protein Phosphatase Inhibition Assay (PPIA) for the Detection of Microcystins and Nodularins. Natural Toxins, 7 (6): 377-385.

Changseok, H., Joel, A., Suresh, C. P., Rachel, F., Polycarpos, F., Byrne, J. A., Patrick, S. M. D., Hyeok, C., Wenjun, J., Kevin, O. S., and Dionysios, D. D. (2013). Chapter Green Nanotechnology: Development of Nanomaterials for Environmental and Energy Applications. In Sustainable Nanotechnology and the Environment: Advances and Achievements (Vol. 1124, pp. 201-229): American Chemical Society.

Chen, X., Yang, X., Yang, L., Xiao, B., Wu, X., Wang, J., and Wan, H. (2010). An Effective Pathway for the Removal of Microcystin LR via Anoxic Biodegradation in Lake Sediments. Water Research, 44 (6): 1884-1892.

Chen, Y.-H., Chen, L.-L., and Shang, N.-C. (2009). Photocatalytic Degradation of Dimethyl Phthalate in an Aqueous Solution with Pt-Soped $\mathrm{TiO}_{2}$-Coated Magnetic PMMA Microspheres. Journal of Hazardous Materials, 172 (1): 20-29.

Chernousov, P., Golubev, O., and Yusfin, Y. S. (2003). Analysis of the Movement of Chromium in Natural and Anthropogenic Media. Metallurgist, 47 (5): 226-231.

Choi, H., Antoniou, M. G., Pelaez, M., De la Cruz, A. A., Shoemaker, J. A., and Dionysiou, D. D. (2007). Mesoporous Nitrogen-Doped $\mathrm{TiO}_{2}$ for the Photocatalytic Destruction of the Cyanobacterial Toxin Microcystin-LR under Visible Light Irradiation. Environmental Science and Technology, 41 (21): 7530-7535.

Choi, W. (2006). Pure and Modified $\mathrm{TiO}_{2}$ Photocatalysts and Their Environmental Applications. Catalysis Surveys from Asia, 10 (1): 16-28.

Chorus, I., and Bartram, J. (1999). Toxic Cyanobacteria in Water: A Guide to Their Public Health Consequences, Monitoring and Management: Spon Press. 
Chowdhury, S. R., and Yanful, E. K. (2010). Arsenic and Chromium Removal by Mixed Magnetite-Maghemite Nanoparticles and the Effect of Phosphate on Removal. Journal of Environmental Management, 91 (11): 2238-2247.

Chung, K.-S., Bai, J., Sparks, C. J., and Ice, G. E. (2000). Increased Performance with 12-mrad Sagittal-Focusing Monochromator. AIP Conference Proceedings, 521 (1): 234237.

Coelho, C., Guyot, G., ter Halle, A., Cavani, L., Ciavatta, C., and Richard, C. (2011). Photoreactivity of Humic Substances: Relationship Between Fluorescence and Singlet Oxygen Production. Environmental Chemistry Letters, 9 (3): 447-451.

Cornell, R. M., and Schwertmann, U. (2003). The Iron Oxides: Structure, Properties, Reactions, Occurrences and Uses. Second, Completely Revised and Extended Edition: WILEY-VCH VerlagGmbH \& Co. KGaA, Weinheim.

Cornish, B. J., Lawton, L. A., and Robertson, P. K. (2000). Hydrogen Peroxide Enhanced Photocatalytic Oxidation of Microcystin-LR Using Titanium Dioxide. Applied Catalysis B: Environmental, 25 (1): 59-67.

Cory, R. M., Cotner, J. B., and McNeill, K. (2008). Quantifying Interactions between Singlet Oxygen and Aquatic Fulvic Acids. Environmental Science and Technology, 43 (3): 718-723.

Czaplicka, M. (2006). Photo-Degradation of Chlorophenols in the Aqueous Solution. Journal of Hazardous Materials, 134 (1): 45-59.

Darezereshki, E., Ranjbar, M., and Bakhtiari, F. (2010). One-Step Synthesis of Maghemite $\left(\gamma-\mathrm{Fe}_{2} \mathrm{O}_{3}\right)$ Nano-Particles by Wet Chemical Method. Journal of Alloys and Compounds, 502 (1): 257-260.

Deng, B., and Stone, A. T. (1996). Surface-Catalyzed Chromium(VI) Reduction: Reactivity Comparisons of Different Organic Reductants and Different Oxide Surfaces. Environmental Science and Technology, 30 (8): 2484-2494.

Deng, Y., Qi, D., Deng, C., Zhang, X., and Zhao, D. (2008). Superparamagnetic HighMagnetization Microspheres with an $\mathrm{Fe}_{3} \mathrm{O}_{4} @ \mathrm{SiO}_{2}$ Core and Perpendicularly Aligned Mesoporous $\mathrm{SiO}_{2}$ Shell for Removal of Microcystins. Journal of the American Chemical Society, 130 (1): 28-29.

DeRosa, M. C., and Crutchley, R. J. (2002). Photosensitized Singlet Oxygen and Its Applications. Coordination Chemistry Reviews, 233: 351-371.

Diaz-Uribe, C. E., Daza, M. C., Martínez, F., Páez-Mozo, E. A., Guedes, C. L. B., and Di Mauro, E. (2010). Visible Light Superoxide Radical Anion Generation by Tetra(4- 
carboxyphenyl)porphyrin/ $\mathrm{TiO}_{2}$ : EPR Characterization. Journal of Photochemistry and Photobiology A: Chemistry, 215 (2-3): 172-178.

Ding, B., Kim, H., Kim, C., Khil, M., and Park, S. (2003). Morphology and Crystalline Phase Study of Electrospun $\mathrm{TiO}_{2}-\mathrm{SiO}_{2}$ Nanofibres. Nanotechnology, 14 (5): 532.

Dixit, S., and Hering, J. G. (2003). Comparison of Arsenic(V) and Arsenic(III) Sorption onto Iron Oxide Minerals: Implications for Arsenic Mobility. Environmental Science and Technology, 37 (18): 4182-4189.

Eary, L., and Rai, D. (1991). Chromate Reduction by Subsurface Soils Under Acidic Conditions. Soil Science Society of America Journal, 55 (3): 676-683.

Elovitz, M. S., and Fish, W. (1995). Redox Interactions of Cr(VI) and Substituted Phenols: Products and Mechanism. Environmental Science and Technology, 29 (8): 1933-1943.

Eremia, S. A. V., Chevalier-Lucia, D., Radu, G.-L., and Marty, J.-L. (2008). Optimization of Hydroxyl Radical Formation Using $\mathrm{TiO}_{2}$ as Photocatalyst by Response Surface Methodology. Talanta, 77 (2): 858-862.

Fang, X., Mark, G., and von Sonntag, C. (1996). OH Radical Formation by Ultrasound in Aqueous Solutions Part I: the Chemistry Underlying the Terephthalate Dosimeter. Ultrasonics Sonochemistry, 3 (1): 57-63.

Fenwick, A. (2006). Waterborne Infectious Diseases-Could They Be Consigned to History? Science, 313 (5790): 1077-1081.

Firouzabadi, H., Iranpoor, N., Kiaeezadeh, F., and Toofan, J. (1986). Chromium (VI) Based Oxidants-1: Chromium Peroxide Complexes as Versatile, Mild, and Efficient Oxidants in Organic Synthesis. Tetrahedron, 42 (2): 719-725.

Fowler, B. A., Nordberg, G. F., Nordberg, M., and Friberg, L. (2011). Handbook on the Toxicology of Metals: Access Online via Elsevier.

Fox, M. A., and Dulay, M. T. (1993). Heterogeneous Photocatalysis. Chemical Reviews, 93 (1): 341-357.

Fu, H., Zhang, L., Zhang, S., Zhu, Y., and Zhao, J. (2006). Electron Spin Resonance Spin-Trapping Detection of Radical Intermediates in $\mathrm{N}$-Doped $\mathrm{TiO}_{2}$-Assisted Photodegradation of 4-Chlorophenol. The Journal of Physical Chemistry B, 110 (7): 3061-3065.

Gatrell, A. C., and Elliott, S. J. (2009). Geographies of Health: an Introduction: John Wiley \& Sons. 
Gochfeld, M. (1991). Setting the Research Agenda for Chromium Risk Assessment. Environmental Health Perspectives, 92: 3-5.

Gota, S., Guiot, E., Henriot, M., and Gautier-Soyer, M. (1999). Atomic-Oxygen-Assisted MBE Growth of $\alpha-\mathrm{Fe}_{2} \mathrm{O}_{3}$ on $\alpha-\mathrm{Al}_{2} \mathrm{O}_{3}(0001)$ : Metastable $\mathrm{FeO}(111)$-like Phase at Subnanometer Thicknesses. Physical Review B, 60 (20): 14387-14395.

Graham, D., Kisch, H., Lawton, L. A., and Robertson, P. K. (2010). The Degradation of Microcystin-LR Using Doped Visible Light Absorbing Photocatalysts. Chemosphere, 78 (9): 1182-1185.

Grossl, P. R., Eick, M., Sparks, D. L., Goldberg, S., and Ainsworth, C. C. (1997). Arsenate and Chromate Retention Mechanisms on Goethite. 2. Kinetic Evaluation Using a Pressure-Jump Relaxation Technique. Environmental Science and Technology, 31 (2): $321-326$.

Grosvenor, A., Kobe, B., Biesinger, M., and McIntyre, N. (2004). Investigation of Multiplet Splitting of Fe 2p XPS Spectra and Bonding in Iron Compounds. Surface and Interface Analysis, 36 (12): 1564-1574.

Gu, B., Schmitt, J., Chen, Z., Liang, L., and McCarthy, J. F. (1994). Adsorption and Desorption of Natural Organic Matter on Iron Oxide: Mechanisms and Models. Environmental Science and Technology, 28 (1): 38-46.

Gu, B., Schmitt, J., Chen, Z., Liang, L., and McCarthy, J. F. (1995). Adsorption and Desorption of Different Organic Matter Fractions on Iron Oxide. Geochimica et Cosmochimica Acta, 59 (2): 219-229.

Haag, W. R., Gassman, E., and Braun, A. (1984). Singlet Oxygen in Surface WatersPart I: Furfuryl Alcohol as a Trapping Agent. Chemosphere, 13 (5): 631-640.

Haag, W. R., and Hoigne, J. (1986). Singlet Oxygen in Surface Waters. 3. Photochemical Formation and Steady-State Concentrations in Various Types of Waters. Environmental Science and Technology, 20 (4): 341-348.

Haag, W. R., and Yao, C. D. (1992). Rate Constants for Reaction of Hydroxyl Radicals with Several Drinking Water Contaminants. Environmental Science and Technology, 26 (5): 1005-1013.

Hameed, B., Salman, J., and Ahmad, A. (2009). Adsorption Isotherm and Kinetic Modeling of 2, 4-D Pesticide on Activated Carbon Derived from Date Stones. Journal of Hazardous Materials, 163 (1): 121-126.

Han, C., Pelaez, M., Likodimos, V., Kontos, A. G., Falaras, P., O'Shea, K., and Dionysiou, D. D. (2011). Innovative Visible Light-Activated Sulfur Doped $\mathrm{TiO}_{2}$ Films for Water Treatment. Applied Catalysis B: Environmental, 107 (1): 77-87. 
Hansen, B. G., Van Haelst, A. G., Van Leeuwen, K., and Van Der Zandt, P. (1999). Priority Setting for Existing Chemicals: European Union Risk Ranking Method. Environmental Toxicology and Chemistry, 18 (4): 772-779.

Heisler, J., Glibert, P. M., Burkholder, J. M., Anderson, D. M., Cochlan, W., Dennison, W. C., Dortch, Q., Gobler, C. J., Heil, C. A., and Humphries, E. (2008). Eutrophication and Harmful Algal Blooms: a Scientific Consensus. Harmful Algae, 8 (1): 3-13.

Hepburn, D. D., Xiao, J., Bindom, S., Vincent, J. B., and O'Donnell, J. (2003). Nutritional Supplement Chromium Picolinate Causes Sterility and Lethal Mutations in Drosophila Melanogaster. Proceedings of the National Academy of Sciences, 100 (7): 3766-3771.

Hingston, J., Collins, C., Murphy, R., and Lester, J. (2001). Leaching of Chromated Copper Arsenate Wood Preservatives: a Review. Environmental Pollution, 111 (1): 5366.

Hirakawa, T., Nakaoka, Y., Nishino, J., and Nosaka, Y. (1999). Primary Passages for Various $\mathrm{TiO}_{2}$ Photocatalysts Studied by Means of Luminol Chemiluminescent Probe. The Journal of Physical Chemistry B, 103 (21): 4399-4403.

Ho, Y.-S., and Ofomaja, A. E. (2005). Kinetics and Thermodynamics of Lead Ion Sorption on Palm Kernel Fibre from Aqueous Solution. Process Biochemistry, 40 (11): 3455-3461.

Hoffmann, M. M., Darab, J. G., and Fulton, J. L. (2001). An Infrared and X-ray Absorption Study of the Equilibria and Structures of Chromate, Bichromate, and Dichromate in Ambient Aqueous Solutions. The Journal of Physical Chemistry A, 105 (10): 1772-1782.

Hoffmann, M. R., Martin, S. T., Choi, W., and Bahnemann, D. W. (1995). Environmental Applications of Semiconductor Photocatalysis. Chemical Reviews, 95 (1): 69-96.

Hu, J.-D., Zevi, Y., Kou, X.-M., Xiao, J., Wang, X.-J., and Jin, Y. (2010). Effect of Dissolved Organic Matter on the Stability of Magnetite Nanoparticles under Different $\mathrm{pH}$ and Ionic Strength Conditions. Science of the Total Environment, 408 (16): 3477-3489.

Hu, J., Lo, I., and Chen, G. (2004). Removal of Cr(VI) by Magnetite. Water Science and Technology, 50 (12): 139-146.

Hu, J., Lo, I., and Chen, G. (2007). Comparative Study of Various Magnetic Nanoparticles for Cr(VI) Removal. Separation and Purification Technology, 56 (3): 249256. 
Hu, W., Li, L., Li, G., Tang, C., and Sun, L. (2009). High-Quality Brookite $\mathrm{TiO}_{2}$ Flowers: Synthesis, Characterization, and Dielectric Performance. Crystal Growth and Design, 9 (8): 3676-3682.

Ibarra, J., Munoz, E., and Moliner, R. (1996). FTIR Study of the Evolution of Coal Structure During the Coalification Process. Organic Geochemistry, 24 (6): 725-735.

Idris, A., Hassan, N., Mohd Ismail, N. S., Misran, E., Yusof, N. M., Ngomsik, A.-F., and Bee, A. (2010). Photocatalytic Magnetic Separable Beads for Chromium(VI) Reduction. Water Research, 44 (6): 1683-1688.

Illés, E., and Tombácz, E. (2003). The Role of Variable Surface Charge and Surface Complexation in the Adsorption of Humic Acid on Magnetite. Colloids and Surfaces A: Physicochemical and Engineering Aspects, 230 (1): 99-109.

Illés, E., and Tombácz, E. (2006). The Effect of Humic Acid Adsorption on pHDependent Surface Charging and Aggregation of Magnetite Nanoparticles. Journal of Colloid and Interface Science, 295 (1): 115-123.

Ishibashi, K., Fujishima, A., Watanabe, T., and Hashimoto, K. (2000a). Detection of Active Oxidative Species in $\mathrm{TiO}_{2}$ Photocatalysis Using the Fluorescence Technique. Electrochemistry Communications, 2 (3): 207-210.

Ishibashi, K., Fujishima, A., Watanabe, T., and Hashimoto, K. (2000b). Quantum Yields of Active Oxidative Species Formed on $\mathrm{TiO}_{2}$ Photocatalyst. Journal of Photochemistry and Photobiology A: Chemistry, 134 (1-2): 139-142.

Jackson, N., Wang, C., Luo, Z., Schwitzgebel, J., Ekerdt, J., Brock, J., and Heller, A. (1991). Attachment of $\mathrm{TiO}_{2}$ Powders to Hollow Glass Microbeads: Activity of the $\mathrm{TiO}_{2^{-}}$ Coated Beads in the Photoassisted Oxidation of Ethanol to Acetaldehyde. Journal of the Electrochemical Society, 138 (12): 3660-3664.

Jaleel, V., and Kannan, T. S. (1983). Hydrothermal Synthesis of Chromium Dioxide Powders and Their Characterisation. Bulletin of Materials Science, 5 (3-4): 231-246.

Jiang, W., Pelaez, M., Dionysiou, D. D., Entezari, M. H., Tsoutsou, D., and O'Shea, K. (2013). Chromium(VI) Removal by Maghemite Nanoparticles. Chemical Engineering Journal, 222: 527-533.

Johnson, J., Schewel, L., and Graedel, T. (2006). The Contemporary Anthropogenic Chromium Cycle. Environmental Science and Technology, 40 (22): 7060-7069.

Jones, K. C., and De Voogt, P. (1999). Persistent Organic Pollutants (POPs): State of the Science. Environmental Pollution, 100 (1): 209-221. 
Kado, Y., Hahn, R., and Schmuki, P. (2011). Surface Modification of $\mathrm{TiO}_{2}$ Nanotubes by Low Temperature Thermal Treatment in $\mathrm{C}_{2} \mathrm{H}_{2}$ Atmosphere. Journal of Electroanalytical Chemistry, 662 (1): 25-29.

Kearns, D. R. (1971). Physical and Chemical Properties of Singlet Molecular Oxygen. Chemical Reviews, 71 (4): 395-427.

Kendelewicz, T., Liu, P., Doyle, C. S., and Brown Jr, G. E. (2000). Spectroscopic Study of the Reaction of Aqueous $\mathrm{Cr}(\mathrm{VI})$ with $\mathrm{Fe}_{3} \mathrm{O}_{4}(111)$ Surfaces. Surface Science, 469 (23): 144-163.

Khare, B. N., Meyyappan, M., Cassell, A. M., Nguyen, C. V., and Han, J. (2002). Functionalization of Carbon Nanotubes Using Atomic Hydrogen from a Glow Discharge. Nano Letters, 2 (1): 73-77.

King, J., Banerjee, S. K., Marvin, J., and Özdemir, Ö. (1982). A Comparison of Different Magnetic Methods for Determining the Relative Grain Size of Magnetite in Natural Materials: Some Results from Lake Sediments. Earth and Planetary Science Letters, 59 (2): 404-419.

Kobayashi, K., Maruyama, H., Maeda, H., Iwazumi, T., Kawata, H., and Yamazaki, H. (1995). Magnetic EXAFS Study of Pure Fe and Fe-Oxides at Fe K-edge. Physica B: Condensed Matter, 208: 779-780.

Korshin, G. V., Benjamin, M. M., and Sletten, R. S. (1997). Adsorption of Natural Organic Matter (NOM) on Iron Oxide: Effects on NOM Composition and Formation of Organo-Halide Compounds During Chlorination. Water Research, 31 (7): 1643-1650.

Kwan, W. P., and Voelker, B. M. (2003). Rates of Hydroxyl Radical Generation and Organic Compound Oxidation in Mineral-Catalyzed Fenton-Like Systems. Environmental Science and Technology, 37 (6): 1150-1158.

Lamb Iv, J. C., Chapin, R. E., Teague, J., Davis Lawton, A., and Reel, J. R. (1987). Reproductive Effects of Four Phthalic Acid Esters in the Mouse. Toxicology and Applied Pharmacology, 88 (2): 255-269.

Lawton, L. A., Robertson, P. K., Cornish, B. J., and Jaspars, M. (1999). Detoxification of Microcystins (Cyanobacterial Hepatotoxins) Using $\mathrm{TiO}_{2}$ Photocatalytic Oxidation. Environmental Science and Technology, 33 (5): 771-775.

Lee, C., Low, K., and Kek, K. (1995). Removal of Chromium from Aqueous Solution. Bioresource Technology, 54 (2): 183-189.

Léonard, A., and Lauwerys, R. R. (1980). Carcinogenicity and Mutagenicity of Chromium. Mutation Research/Reviews in Genetic Toxicology, 76 (3): 227-239. 
Levine, A. D., and Asano, T. (2004). Peer Reviewed: Recovering Sustainable Water from Wastewater. Environmental Science and Technology, 38 (11): 201A-208A.

Li, G., Bai, R., and Zhao, X. (2008). Coating of $\mathrm{TiO}_{2}$ Thin Films on the Surface of $\mathrm{SiO}_{2}$ Microspheres: Toward Industrial Photocatalysis. Industrial and Engineering Chemistry Research, 47 (21): 8228-8232.

Li, P., Jiang, E., and Bai, H. (2011). Fabrication of Ultrathin Epitaxial $\gamma-\mathrm{Fe}_{2} \mathrm{O}_{3}$ Films by Reactive Sputtering. Journal of Physics D: Applied Physics, 44 (7): 075003.

Li, W., Li, D., Lin, Y., Wang, P., Chen, W., Fu, X., and Shao, Y. (2012). Evidence for the Active Species Involved in the Photodegradation Process of Methyl Orange on $\mathrm{TiO}_{2}$. The Journal of Physical Chemistry C, 116 (5): 3552-3560.

Liao, L.-F., Lien, C.-F., Shieh, D.-L., Chen, M.-T., and Lin, J.-L. (2002). FTIR Study of Adsorption and Photoassisted Oxygen Isotopic Exchange of Carbon Monoxide, Carbon Dioxide, Carbonate, and Formate on $\mathrm{TiO}_{2}$. The Journal of Physical Chemistry B, 106 (43): 11240-11245.

Lin, S., Lu, D., and Liu, Z. (2012). Removal of Arsenic Contaminants with Magnetic $\gamma$ $\mathrm{Fe}_{2} \mathrm{O}_{3}$ Nanoparticles. Chemical Engineering Journal, 211-212: 46-52.

Lin, Z.-P., Ikonomou, M. G., Jing, H., Mackintosh, C., and Gobas, F. A. (2003). Determination of Phthalate Ester Congeners and Mixtures by LC/ESI-MS in Sediments and Biota of an Urbanized Marine Inlet. Environmental Science and Technology, 37 (10): 2100-2108.

Linsebigler, A. L., Lu, G., and Yates Jr, J. T. (1995). Photocatalysis on $\mathrm{TiO}_{2}$ Surfaces: Principles, Mechanisms, and Selected Results. Chemical Reviews, 95 (3): 735-758.

Liu, C., Sun, R., and Ye, J. (2006). Structural and Thermal Characterization of Sugarcane Bagasse Phthalates Prepared with Ultrasound Irradiation. Polymer Degradation and Stability, 91 (2): 280-288.

Liu, J.-f., Zhao, Z.-s., and Jiang, G.-b. (2008). Coating $\mathrm{Fe}_{3} \mathrm{O}_{4}$ Magnetic Nanoparticles with Humic Acid for High Efficient Removal of Heavy Metals in Water. Environmental Science and Technology, 42 (18): 6949-6954.

Liu, Z., Zhang, X., Nishimoto, S., Jin, M., Tryk, D. A., Murakami, T., and Fujishima, A. (2008). Highly Ordered $\mathrm{TiO}_{2}$ Nanotube Arrays with Controllable Length for Photoelectrocatalytic Degradation of Phenol. The Journal of Physical Chemistry C, 112 (1): 253-259.

Louit, G., Foley, S., Cabillic, J., Coffigny, H., Taran, F., Valleix, A., Renault, J. P., and Pin, S. (2005). The Reaction of Coumarin with the $\mathrm{OH}$ Radical Revisited: Hydroxylation 
Product Analysis Determined by Fluorescence and Chromatography. Radiation Physics and Chemistry, 72 (2): 119-124.

Lytle, C. M., Lytle, F. W., Yang, N., Qian, J.-H., Hansen, D., Zayed, A., and Terry, N. (1998). Reduction of $\mathrm{Cr}(\mathrm{VI})$ to $\mathrm{Cr}(\mathrm{III})$ by Wetland Plants: Potential for in situ Heavy Metal Detoxification. Environmental Science and Technology, 32 (20): 3087-3093.

Mall, I. D., Srivastava, V. C., and Agarwal, N. K. (2006). Removal of Orange-G and Methyl Violet Dyes by Adsorption onto Bagasse Fly Ash-Kinetic Study and Equilibrium Isotherm Analyses. Dyes and Pigments, 69 (3): 210-223.

Malmqvist, B., and Rundle, S. (2002). Threats to the Running Water Ecosystems of the World. Environmental Conservation, 29 (2): 134-153.

Mason, T., Lorimer, J., Bates, D., and Zhao, Y. (1994). Dosimetry in Sonochemistry: the Use of Aqueous Terephthalate Ion as a Fluorescence Monitor. Ultrasonics Sonochemistry, 1 (2): S91-S95.

Matsumoto, M., Hirata-Koizumi, M., and Ema, M. (2008). Potential Adverse Effects of Phthalic Acid Esters on Human Health: a Review of Recent Studies on Reproduction. Regulatory Toxicology and Pharmacology, 50 (1): 37-49.

Matuana, L. M., Kamdem, D. P., and Zhang, J. (2001). Photoaging and Stabilization of Rigid PVC/Wood-Fiber Composites. Journal of Applied Polymer Science, 80 (11): 19431950.

Mertz, W. (1993). Chromium in Human Nutrition: a Review. Journal of Nutrition, 123 (4): 626-633.

Miller, W. L., and Kester, D. R. (1988). Hydrogen Peroxide Measurement in Seawater by (p-hydroxyphenyl) Acetic Acid Dimerization. Analytical Chemistry, 60 (24): 2711-2715.

Minella, M., Faga, M. G., Maurino, V., Minero, C., Pelizzetti, E., Coluccia, S., and Martra, G. (2009). Effect of Fluorination on the Surface Properties of Titania P25 Powder: An FTIR Study. Langmuir, 26 (4): 2521-2527.

Montgomery, M. A., and Elimelech, M. (2007). Water and Sanitation in Developing Countries: Including Health in the Equation. Environmental Science and Technology, 41 (1): $17-24$.

Morris, B. W., Blumsohn, A., Mac Neil, S., and Gray, T. A. (1992). The Trace Element Chromium - a Role in Glucose Homeostasis. The American Journal of Clinical Nutrition, 55 (5): 989-991. 
Nakayasu, K., Fukushima, M., Sasaki, K., Tanaka, S., and Nakamura, H. (1999). Comparative Studies of the Reduction Behavior of Chromium(VI) by Humic Substances and Their Precursors. Environmental Toxicology and Chemistry, 18 (6): 1085-1090.

Nikolaou, A., Meric, S., and Fatta, D. (2007). Occurrence Patterns of Pharmaceuticals in Water and Wastewater Environments. Analytical and Bioanalytical Chemistry, 387 (4): 1225-1234.

Niu, H., Zhang, D., Zhang, S., Zhang, X., Meng, Z., and Cai, Y. (2011). Humic Acid Coated $\mathrm{Fe}_{3} \mathrm{O}_{4}$ Magnetic Nanoparticles as Highly Efficient Fenton-Like Catalyst for Complete Mineralization of Sulfathiazole. Journal of Hazardous Materials, 190 (1-3): 559-565.

Nordberg, G. F., Fowler, B. A., Nordberg, M., and Friberg, L. (2007). Handbook on the Toxicology of Metals. Academic, Burlington.

Nordstrom, D. K. (2002). Public Health. Worldwide Occurrences of Arsenic in Ground Water. Science, 296 (5576): 2143-2145.

Nosaka, Y., Daimon, T., Nosaka, A. Y., and Murakami, Y. (2004). Singlet Oxygen Formation in Photocatalytic $\mathrm{TiO}_{2}$ Aqueous Suspension. Physical Chemistry Chemical Physics, 6 (11): 2917-2918.

O'Brien, P., and Kortenkamp, A. (1995). The Chemistry Underlying Chromate Toxicity. Transition Metal Chemistry, 20 (6): 636-642.

O'Shea, K. E., and Dionysiou, D. D. (2012). Advanced Oxidation Processes for Water Treatment. The Journal of Physical Chemistry Letters, 3 (15): 2112-2113.

Ofomaja, A. E. (2007). Kinetics and Mechanism of Methylene Blue Sorption onto Palm Kernel Fibre. Process Biochemistry, 42 (1): 16-24.

Oliveira, L. C., Rios, R. V., Fabris, J. D., Sapag, K., Garg, V. K., and Lago, R. M. (2003). Clay-Iron Oxide Magnetic Composites for the Adsorption of Contaminants in Water. Applied Clay Science, 22 (4): 169-177.

Oliveira, L. C. A., Rios, R. V. R. A., Fabris, J. D., Garg, V., Sapag, K., and Lago, R. M. (2002). Activated Carbon/Iron Oxide Magnetic Composites for the Adsorption of Contaminants in Water. Carbon, 40 (12): 2177-2183.

Olness, A. (1995). Water Quality: Prevention, Identification and Management of Diffuse Pollution. Journal of Environmental Quality, 24 (2): 383-383.

Owlad, M., Aroua, M. K., Daud, W. A. W., and Baroutian, S. (2009). Removal of Hexavalent Chromium-Contaminated Water and Wastewater: a Review. Water, Air, and Soil Pollution, 200 (1-4): 59-77. 
Özacar, M., and Şengil, İ. A. (2005). Adsorption of Metal Complex Dyes from Aqueous Solutions by Pine Sawdust. Bioresource Technology, 96 (7): 791-795.

Parilti, N. B., Demirel, C. S. U., and Bekbolet, M. (2011). Response Surface Methodological Approach for the Assessment of the Photocatalytic Degradation of NOM. Journal of Photochemistry and Photobiology A: Chemistry, 225 (1): 26-35.

Pavia, D. L., Lampman, G. M., Kriz, G. S., and Vyvyan, J. R. (2009). Introduction to Spectroscopy. 4th Edition: Brooks/Cole, Cengage Learning.

Pelaez, M., Antoniou, M. G., He, X., Dionysiou, D. D., Armah, A., Tsimeli, K., Triantis, T., Hiskia, A., Kaloudis, T., and Williams, C. (2010). Sources and Occurrence of Cyanotoxins Worldwide. In Xenobiotics in the Urban Water Cycle (pp. 101-127): Springer.

Pelaez, M., de la Cruz, A. A., Stathatos, E., Falaras, P., and Dionysiou, D. D. (2009). Visible Light-Activated N-F-Codoped $\mathrm{TiO}_{2}$ Nanoparticles for the Photocatalytic Degradation of Microcystin-LR in Water. Catalysis Today, 144 (1-2): 19-25.

Pérez-Candela, M., Martín-Martínez, J., and Torregrosa-Maciá, R. (1995). Chromium(VI) Removal with Activated Carbons. Water Research, 29 (9): 2174-2180.

Peterson-Roth, E., Reynolds, M., Quievryn, G., and Zhitkovich, A. (2005). Mismatch Repair Proteins are Activators of Toxic Responses to Chromium-DNA Damage. Molecular and Cellular Biology, 25 (9): 3596-3607.

Peterson, M. L., Brown, G. E., and Parks, G. A. (1996). Direct XAFS Evidence for Heterogeneous Redox Reaction at the Aqueous Chromium/Magnetite Interface. Colloids and Surfaces A: Physicochemical and Engineering Aspects, 107: 77-88.

Polizzotto, M. L., Harvey, C. F., Sutton, S. R., and Fendorf, S. (2005). Processes Conducive to the Release and Transport of Arsenic into Aquifers of Bangladesh. Proceedings of the National Academy of Sciences of the United States of America, 102 (52): 18819-18823.

Pouran, H. M., Fotovat, A., Haghnia, G., Halajnia, A., and Chamsaz, M. (2008). A Case Study: Chromium Concentration and Its Species in a Calcareous Soil Affected by Leather Industries Effluents. World Applied Sciences Journal, 5 (4): 484-489.

Quievryn, G., Messer, J., and Zhitkovich, A. (2002). Carcinogenic Chromium(VI) Induces Cross-Linking of Vitamin C to DNA in vitro and in Human Lung A549 Cells. Biochemistry, 41 (9): 3156-3167.

Rai, D., Sass, B. M., and Moore, D. A. (1987). Chromium(III) Hydrolysis Constants and Solubility of Chromium(III) Hydroxide. Inorganic Chemistry, 26 (3): 345-349. 
Ravel, B., and Newville, M. (2005). ATHENA, ARTEMIS, HEPHAESTUS: Data Analysis for X-ray Absorption Spectroscopy Using IFEFFIT. Journal of Synchrotron Radiation, 12 (4): 537-541.

Reed, B. E., and Matsumoto, M. R. (1993). Modeling Cadmium Adsorption by Activated Carbon Using the Langmuir and Freundlich Isotherm Expressions. Separation Science and Technology, 28 (13-14): 2179-2195.

Reitsema, R. H., and Allphin, N. L. (1962). Chromate Oxidation of Alkylaromatic Compounds. The Journal of Organic Chemistry, 27 (1): 27-28.

Rengifo-Herrera, J. A., Pierzchała, K., Sienkiewicz, A., Forró, L., Kiwi, J., and Pulgarin, C. (2009). Abatement of Organics and Escherichia coli by N, S Co-doped $\mathrm{TiO}_{2}$ Under UV and Visible Light. Implications of the Formation of Singlet oxygen $\left({ }^{1} \mathrm{O}_{2}\right)$ Under Visible Light. Applied Catalysis B: Environmental, 88 (3-4): 398-406.

Ressler, T. (1998). WinXAS: a Program for X-ray Absorption Spectroscopy Data Analysis under MS-Windows. Journal of Synchrotron Radiation, 5 (2): 118-122.

Richard, F. C., and Bourg, A. (1991). Aqueous Geochemistry of Chromium: a Review. Water Research, 25 (7): 807-816.

Robertson, P. K., Lawton, L. A., and Cornish, B. J. (1999). The Involvement of Phycocyanin Pigment in the Photodecomposition of the Cyanobacterial Toxin, Microcystin-LR. Journal of Porphyrins and Phthalocyanines, 3 (07): 544-551.

Roy, A., and Bhattacharya, J. (2012). Removal of $\mathrm{Cu}(\mathrm{II}) \mathrm{Zn}(\mathrm{II})$ and $\mathrm{Pb}$ (II) from Water Using Microwave-Assisted Synthesized Maghemite Nanotubes. Chemical Engineering Journal, 211-212: 493-500.

Saliba, R., Gauthier, H., Gauthier, R., and Petit-Ramel, M. (2000). Adsorption of Copper(II) and Chromium(III) Ions onto Amidoximated Cellulose. Journal of Applied Polymer Science, 75 (13): 1624-1631.

Sass, B. M., and Rai, D. (1987). Solubility of Amorphous Chromium(III)-Iron(III) Hydroxide Solid Solutions. Inorganic Chemistry, 26 (14): 2228-2232.

Satoh, N., Fukuda, S., Takizawa, M., Furuta, Y., Kashiwamura, M., and Inuyama, Y. (1994). Chromium-Induced Carcinoma in the Nasal Region. A report of Four Cases. Rhinology, 32 (1): 47-50.

Schwarz, P. F., Turro, N. J., Bossmann, S. H., Braun, A. M., Wahab, A.-M. A. A., and Duerr, H. (1997). A New Method to Determine the Generation of Hydroxyl Radicals in Illuminated $\mathrm{TiO}_{2}$ Suspensions. The Journal of Physical Chemistry B, 101 (36): 71277134. 
Serpone, N., and Emeline, A. V. (2012). Semiconductor Photocatalysis-Past, Present, and Future Outlook. The Journal of Physical Chemistry Letters, 3 (5): 673-677.

Shawwa, A. R., and Smith, D. W. (2001). Kinetics of Microcystin-LR Oxidation by Ozone. Ozone Science and Engineering, 23 (2): 161-170.

Simonich, S. L., and Hites, R. A. (1995). Organic Pollutant Accumulation in Vegetation. Environmental Science and Technology, 29 (12): 2905-2914.

Singh, B. P., Nayak, S., Samal, S., Bhattacharjee, S., and Besra, L. (2012). The role of Poly(Methacrylic Acid) Conformation on Dispersion Behavior of Nano $\mathrm{TiO}_{2}$ Powder. Applied Surface Science, 258 (8): 3524-3531.

Singh, S. K., Townsend, T. G., Mazyck, D., and Boyer, T. H. (2012). Equilibrium and Intra-Particle Diffusion of Stabilized Landfill Leachate onto Micro-and Meso-Porous Activated Carbon. Water Research, 46 (2): 491-499.

Song, W., Bardowell, S., and O'Shea, K. E. (2007). Mechanistic Study and the Influence of Oxygen on the Photosensitized Transformations of Microcystins (Cyanotoxins). Environmental Science and Technology, 41 (15): 5336-5341.

Song, W., Teshiba, T., Rein, K., and O'Shea, K. E. (2005). Ultrasonically Induced Degradation and Detoxification of Microcystin-LR (Cyanobacterial Toxin). Environmental Science and Technology, 39 (16): 6300-6305.

Song, W., Xu, T., Cooper, W. J., Dionysiou, D. D., Cruz, A. A. d. 1., and O 'Shea, K. E. (2009). Radiolysis Studies on the Destruction of Microcystin-LR in Aqueous Solution by Hydroxyl Radicals. Environmental Science and Technology, 43 (5): 1487-1492.

Song, W., Yan, S., Cooper, W. J., Dionysiou, D. D., and O'Shea, K. E. (2012). Hydroxyl Radical Oxidation of Cylindrospermopsin (Cyanobacterial Toxin) and Its Role in the Photochemical Transformation. Environmental Science and Technology, 46 (22): 1260812615.

Stales, C. A., Peterson, D. R., Parkerton, T. F., and Adams, W. J. (1997). The Environmental Fate of Phthalate Esters: A Literature Review. Chemosphere, 35 (4): 667749.

Stearns, D. M., Wise, J. P., Patierno, S. R., and Wetterhahn, K. E. (1995). Chromium(III) Picolinate Produces Chromosome Damage in Chinese Hamster Ovary Cells. The FASEB Journal, 9 (15): 1643-1648.

Stomberg, R. (1962). Crystal Structure of Peroxochromates, $\mathrm{CrO}_{5} \cdot \mathrm{C}_{5} \mathrm{H}_{5} \mathrm{~N}$. Nature, 196: 570-571. 
Stylidi, M., Kondarides, D. I., and Verykios, X. E. (2004). Visible Light-Induced Photocatalytic Degradation of Acid Orange 7 in Aqueous $\mathrm{TiO}_{2}$ Suspensions. Applied Catalysis B: Environmental, 47 (3): 189-201.

Sun, J., Qiao, L., Sun, S., and Wang, G. (2008). Photocatalytic Degradation of Orange G on Nitrogen-Doped $\mathrm{TiO}_{2}$ Catalysts under Visible Light and Sunlight Irradiation. Journal of Hazardous Materials, 155 (1-2): 312-319.

Sun, S., and Zeng, H. (2002). Size-Controlled Synthesis of Magnetite Nanoparticles. Journal of the American Chemical Society, 124 (28): 8204-8205.

Swinehart, J. H., and Castellan, G. W. (1964). The Kinetics of the Chromate-Dichromate Reaction as Studied by a Relaxation Method. Inorganic Chemistry, 3 (2): 278-280.

Tandon, R., Crisp, P., Ellis, J., and Baker, R. (1984). Effect of pH on Chromium(VI) Species in Solution. Talanta, 31 (3): 227-228.

Thomas, D., Rohrer, J., Jackson, P., Pak, T., and Scott, J. (2002). Determination of Hexavalent Chromium at the Level of the California Public Health Goal by Ion Chromatography. Journal of Chromatography A, 956 (1): 255-259.

Treybal, R. E. (1980). Mass-transfer Operations: McGraw-Hill New York.

Tuutijärvi, T., Lu, J., Sillanpää, M., and Chen, G. (2009). As(V) Adsorption on Maghemite Nanoparticles. Journal of Hazardous Materials, 166 (2-3): 1415-1420.

Umpleby, R. J., Baxter, S. C., Chen, Y., Shah, R. N., and Shimizu, K. D. (2001). Characterization of Molecularly Imprinted Polymers with the Langmuir-Freundlich Isotherm. Analytical Chemistry, 73 (19): 4584-4591.

US Food Nutrition Board. Recommended Dietary Allowances. (1989). National Academy of Sciences/National Research Council Report and Circular Series, 115.

Uyguner, C. S., and Bekbolet, M. (2004). Evaluation of Humic Acid, Chromium(VI) and $\mathrm{TiO}_{2}$ Ternary System in Relation to Adsorptive Interactions. Applied Catalysis B: Environmental, 49 (4): 267-275.

Valentine, R. L., and Wang, H. A. (1998). Iron Oxide Surface Catalyzed Oxidation of Quinoline by Hydrogen Peroxide. Journal of Environmental Engineering, 124 (1): 31-38.

Vermeer, A. W., McCulloch, J. K., van Riemsdijk, W. H., and Koopal, L. K. (1999). Metal Ion Adsorption to Complexes of Humic Acid and Metal Oxides: Deviations from the Additivity Rule. Environmental Science and Technology, 33 (21): 3892-3897.

Viessman, W., Hammer, M. J., and Perez, E. M. (2009). Water Supply and Pollution Control: Pearson Prentice Hall. 
Vione, D., Bagnus, D., Maurino, V., and Minero, C. (2010). Quantification of Singlet Oxygen and Hydroxyl Radicals upon UV Irradiation of Surface Water. Environmental Chemistry Letters, 8 (2): 193-198.

Wan Ngah, W., Endud, C., and Mayanar, R. (2002). Removal of Copper(II) Ions from Aqueous Solution onto Chitosan and Cross-Linked Chitosan Beads. Reactive and Functional Polymers, 50 (2): 181-190.

Wang, C., and Gardinali, P. R. (2013). Detection and Occurrence of Microconstituents in Reclaimed Water used for Irrigation-a Potentially Overlooked Source. Analytical and Bioanalytical Chemistry, 405 (18): 5925-5935.

Wang, C., Zhang, X., Liu, H., Li, X., Li, W., and Xu, H. (2009). Reaction Kinetics of Photocatalytic Degradation of Sulfosalicylic Acid Using $\mathrm{TiO}_{2}$ Microspheres. Journal of Hazardous Materials, 163 (2-3): 1101-1106.

Wang, I. J., Hsu, Y. J., and Tian, J. H. (1991). Synthesis and Properties of Some Pyridone Chromium Complex Azo Dyes. Dyes and Pigments, 16 (2): 83-91.

Wang, J., Ma, T., Zhang, Z., Zhang, X., Jiang, Y., Sun, W., Li, R., and Zhang, P. (2007). Investigation on the Transition Crystal of Ordinary Rutile $\mathrm{TiO}_{2}$ Powder by Microwave Irradiation in Hydrogen Peroxide Solution and Its Sonocatalytic Activity. Ultrasonics Sonochemistry, 14 (5): 575-582.

Wehrli, B., Ibric, S., and Stumm, W. (1990). Adsorption Kinetics of Vanadyl (IV) and Chromium (III) to Aluminum Oxide: Evidence for a Two-Step Mechanism. Colloids and surfaces, 51: 77-88.

White, A. F., and Peterson, M. L. (1996). Reduction of Aqueous Transition Metal Species on the Surfaces of Fe(II)-Containing Oxides. Geochimica et Cosmochimica Acta, 60 (20): 3799-3814.

WHO. (1998). Guidelines for Drinking-Water Quality. Geneva: World Health Organization.

Wittbrodt, P., and Palmer, C. (1997). Reduction of Cr(VI) by Soil Humic Acids. European Journal of Soil Science, 48 (1): 151-162.

Wittbrodt, P. R., and Palmer, C. D. (1995). Reduction of Cr(VI) in the Presence of Excess Soil Fulvic Acid. Environmental Science and Technology, 29 (1): 255-263.

Wittbrodt, P. R., and Palmer, C. D. (1996). Effect of Temperature, Ionic strength, Background Electrolytes, and Fe(III) on the Reduction of Hexavalent Chromium by Soil Humic Substances. Environmental Science and Technology, 30 (8): 2470-2477. 
Wu, R., Qu, J., and Chen, Y. (2005). Magnetic Powder MnO- $\mathrm{Fe}_{2} \mathrm{O}_{3}$ Composite- a Novel Material for the Removal of Azo-Dye from Water. Water Research, 39 (4): 630-638.

Wu, Y., Zhang, S., Guo, X., and Huang, H. (2008). Adsorption of Chromium(III) on Lignin. Bioresource Technology, 99 (16): 7709-7715.

Yang, S., Zong, P., Ren, X., Wang, Q., and Wang, X. (2012). Rapid and Highly Efficient Preconcentration of $\mathrm{Eu}$ (III) by Core-Shell Structured $\mathrm{Fe}_{3} \mathrm{O}_{4} @$ @ Humic Acid Magnetic Nanoparticles. ACS Applied Materials and Interfaces, 4 (12): 6891-6900.

Yavuz, C. T., Mayo, J., William, W. Y., Prakash, A., Falkner, J. C., Yean, S., Cong, L., Shipley, H. J., Kan, A., and Tomson, M. (2006). Low-Field Magnetic Separation of Monodisperse $\mathrm{Fe}_{3} \mathrm{O}_{4}$ Nanocrystals. Science, 314 (5801): 964-967.

Ye, S.-y., Tian, Q.-m., Song, X.-1., and Luo, S.-c. (2009). Photoelectrocatalytic Degradation of Ethylene by a Combination of $\mathrm{TiO}_{2}$ and Activated Carbon Felts. Journal of Photochemistry and Photobiology A: Chemistry, 208 (1): 27-35.

Yogi, C., Kojima, K., Wada, N., Tokumoto, H., Takai, T., Mizoguchi, T., and Tamiaki, H. (2008). Photocatalytic Degradation of Methylene Blue by $\mathrm{TiO}_{2}$ Film and Au Particles$\mathrm{TiO}_{2}$ Composite Film. Thin Solid Films, 516 (17): 5881-5884.

Yuan, P., Liu, D., Fan, M., Yang, D., Zhu, R., Ge, F., Zhu, J., and He, H. (2010). Removal of Hexavalent Chromium [Cr(VI)] from Aqueous Solutions by the DiatomiteSupported/Unsupported Magnetite Nanoparticles. Journal of Hazardous Materials, 173 (1-3): 614-621.

Zhai, J., Yang, T., Zhang, L., and Yao, X. (1999). The Optical Waveguiding Properties of $\mathrm{TiO}_{2}-\mathrm{SiO}_{2}$ Composite Films Prepared by the Sol-Gel Process. Ceramics International, 25 (7): 667-670. 
VITA

WENJUN JIANG

Born, Laiyang, Shandong, China

2001-2005 Bachelor of Science in Chemistry

Central China Normal University

Wuhan, Hubei, China

2005-2008 Master of Science in Inorganic Chemistry

Graduate University of Chinese Academy of Sciences

Beijing, China

2008-present Doctoral Candidate

Florida International University

Miami, Florida, USA

\section{PUBLICATIONS AND PRESENTATIONS}

Wenjun Jiang, Miguel Pelaez, Dionysios D. Dionysiou, Mohammad H. Entezari, Dimitra Tsoutsou, Kevin O'Shea (2013). Chromium(VI) removal by maghemite nanoparticles. Chemical Engineering Journal. 222 (15), 527-533.

Wenjun Jiang, Jeffrey A. Joens, Dionysios D. Dionysiou, Kevin E. O’Shea (2013). Optimization of photocatalytic performance of $\mathrm{TiO}_{2}$ coated glass microspheres using response surface methodology and the application for degradation of dimethyl phthalate. Journal of Photochemistry and Photobiology A: Chemistry. 262, 7-13.

Changseok Han, Joel Andersen, Suresh C. Pillai, Rachel Fagan, Polycarpos Falaras, J. Anthony Byrne, Patrick S.M. Dunlop, Hyeok Choi, Wenjun Jiang, Kevin O'Shea, Dionysios D. Dionysiou. Chapter green nanotechnology: development of nanomaterials for environmental and energy applications, in Sustainable Nanotechnology and the Environment: Advances and Achievements, N. Shamim and V. K. Sharma (eds.), ACS Symposium Series, American Chemical Society, Washington, DC, USA, 2013, Chapter 12, pp. 201-229.

Wenjun Jiang, Quan Cai, Wei Xu, Mingwei Yang, Yong Cai, Dionysios D. Dionysiou, Kevin E. O'Shea. Cr (VI) adsorption and reduction by humic acid coated magnetite. (in preparation for Environmental Science and Technology.)

Shan Zheng, Wenjun Jiang, Yong Cai, Dionysios D. Dionysiou, Kevin E. O'Shea (2013). Adsorption and photocatalytic degradation of aromatic organoarsenic compounds in $\mathrm{TiO}_{2}$ suspension. Catalysis Today. http://dx.doi.org/10.1016/j.cattod.2013.09.040 
Wei Bai, Chengcheng Zhang, Wenjun Jiang, Zhiyong Zhang, Yuliang Zhao (2009). Progress in studies on environmental behaviors and toxicological effects of nanomaterials. Asian Journal of Ecotoxicology.4, 174-182.

Zijie Li, Zhiyong Zhang, Wenjun Jiang, Ming Yu, Yunlong Zhou, Yuliang Zhao, Zhifang Cai (2008). Direct measurement of lanthanum uptake and distribution in intermodal cell of Chara. Plant Science. 174, 496-501.

Wenjun Jiang, Zhiyong Zhang, Zijie Li, Ming Yu, Yunlong Zhou, Zhifang Cai (2008). Effects of $\mathrm{LaCl}_{3}$ on absorption of mineral nutrients in intermodal cell of Chara. Journal of the Chinese Rare Earth Society. 26, 797-800.

Wenjun Jiang, Zijie Li, Zhiyong Zhang, Jing Zhang, Tao Liu, Ming Yu, Yunlong Zhou, Zhifang Cai (2008). Distribution in internodal cells of Chara and the bonding states with the cell wall of lanthanum. Acta Chimica Sinica. 66, 1740-1744.

Xiao He, Zhiyong Zhang, Liuxing Feng, Zijie Li, Wenjun Jiang, Yuliang Zhao, Zhifang Cai (2007). Neurotoxicity evaluation of long-term low-level ytterbium chloride exposure. Journal of the Chinese Rare Earth Society. 25, 349- 354.

Zijie Li, Wenjun Jiang, Ming Yu, Yunlong Zhou, Yuliang Zhao, Zhifang Cai, Zhiyong Zhang (2006). Effects of $\mathrm{LaCl}_{3}$ on photosynthetic pigment contents and antioxidative enzyme activities in Chara. Journal of the Chinese Rare Earth Society. 24, 192- 195.

Wenjun Jiang, Linfei Zhu, Virender K. Sharma, Sudha Rani Batchu, Piero R. Gardinali, Dionysios D. Dionysiou, Kevin E. O'Shea. Oxidation of microcystin-LR by ferrate(VI): intermediates, degradation pathways and toxicity assessments. 247th ACS National Meeting. Dallas, TX, March 16-20, 2014.

Wenjun Jiang, Quan Cai, Wei Xu, Yong Cai, Dionysios D. Dionysiou, Kevin E. O'Shea. $\mathrm{Cr}(\mathrm{VI})$ adsorption and reduction by humic acid coated magnetite. The 19th International Conference on Advanced Oxidation Technologies for Treatment of Water, Air and Soil. San Diego, CA, November 17-21, 2013.

Wenjun Jiang, Dionysios D. Dionysiou, Kevin E. O'Shea. Photocatalytic degradation of microcystin-LR by rose bengal. The 7th Symposium on Harmful Algae in the U.S. Sarasota, FL. October 27-31, 2013.

Lin Chen, Wenjun Jiang, Dionysios D. Dionysiou, Mohammad H. Entezari, Kevin E. O'Shea. Magnetic iron oxides as a novel strategy for the removal of microcystin-LR from water. The International Conference on Chemistry and the Environment (ICCE 2013)Satellite Event on Cyanobacteria and Cyanotoxins in Aquatic Environments. Barcelona, Spain, June 25, 2013. 